\title{
'NATURAL' HAZARDS, THE STATE AND INSURANCE: \\ RISK, RESPONSIBILITY AND PROMISES OF (IN)SECURITY
}

Eric J. Oh, B.Arts Sc.

\author{
A thesis submitted to \\ The Faculty of Graduate Studies and Research \\ in partial fulfillment of the requirements for the degree of \\ Master of Arts \\ Department of Geography
}
Carleton University
Ottawa, Ontario
August, 2007

(C) 2007, Eric J. Oh 


$\begin{array}{ll}\begin{array}{l}\text { Library and } \\ \text { Archives Canada }\end{array} & \begin{array}{l}\text { Bibliothèque et } \\ \text { Archives Canada }\end{array} \\ \begin{array}{l}\text { Published Heritage } \\ \text { Branch }\end{array} & \begin{array}{l}\text { Direction du } \\ \text { Patrimoine de l'édition }\end{array} \\ \begin{array}{l}\text { 395 Wellington Street } \\ \text { Ottawa ON K1A ON4 }\end{array} & \begin{array}{l}\text { 395, rue Wellington } \\ \text { Ottawa ON K1A ON4 } \\ \text { Canada }\end{array}\end{array}$

Your file Votre référence ISBN: 978-0-494-33757-8 Our file Notre référence ISBN: 978-0-494-33757-8

NOTICE:

The author has granted a nonexclusive license allowing Library and Archives Canada to reproduce, publish, archive, preserve, conserve, communicate to the public by telecommunication or on the Internet, loan, distribute and sell theses worldwide, for commercial or noncommercial purposes, in microform, paper, electronic and/or any other formats.

The author retains copyright ownership and moral rights in this thesis. Neither the thesis nor substantial extracts from it may be printed or otherwise reproduced without the author's permission.
AVIS:

L'auteur a accordé une licence non exclusive permettant à la Bibliothèque et Archives Canada de reproduire, publier, archiver, sauvegarder, conserver, transmettre au public par télécommunication ou par l'Internet, prêter, distribuer et vendre des thèses partout dans le monde, à des fins commerciales ou autres, sur support microforme, papier, électronique et/ou autres formats.

L'auteur conserve la propriété du droit d'auteur et des droits moraux qui protège cette thèse. $\mathrm{Ni}$ la thèse ni des extraits substantiels de celle-ci ne doivent être imprimés ou autrement reproduits sans son autorisation.
In compliance with the Canadian

Privacy Act some supporting forms may have been removed from this thesis.

While these forms may be included in the document page count, their removal does not represent any loss of content from the thesis.
Conformément à la loi canadienne sur la protection de la vie privée, quelques formulaires secondaires ont été enlevés de cette thèse.

Bien que ces formulaires aient inclus dans la pagination, il n'y aura aucun contenu manquant.

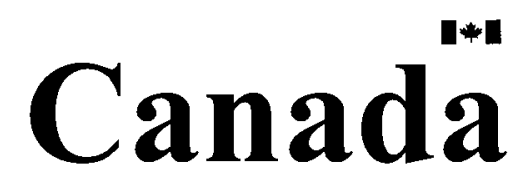




\begin{abstract}
Cold War security-era logics have been poorly translated to natural hazards where military and technological strategies are still unproblematically applied to these global dangers. That states alone have been charged with the task of securing communities from natural hazards is not surprising given that they have privileged themselves in these matters. Although states have been successful in some regards, their continued belief in traditional methods has limited their ability to provide a lasting and flexible security regime. Insurance, a business that sells security, offers reason for pause when considering current approaches to natural hazards and disasters. A three-year industry review demonstrates that major insurers and reinsurers remained profitable despite two uncharacteristically severe Atlantic hurricane seasons. Insurance provides much-needed spatial, temporal and financial flexibility and capacity. While insurance alone is not the answer, it raises new issues and challenges the state's exclusive right to provide security.
\end{abstract}




\section{Acknowledgements}

This research was made possible through the support and efforts of many people. First and foremost, I would like to thank my supervisor Simon Dalby and advisor Iain Wallace for their encouragement, guidance and comments throughout this process. Despite having many other duties and commitments, both Simon and Iain found the time to accommodate my unusual schedule, listen to my many ideas, read over unruly drafts and provide useful feedback. Their assistance is much appreciated.

I would also like to thank Hazel Anderson and Natalie Pressburger for their diligent work behind the scenes. All graduate students in the Department of Geography and Environmental Studies are, I am sure, aware of the Office's tireless efforts to make sure our research runs as smoothly as possible. Without their understanding, patience and diligent attention to detail, completion of this project would not have been possible.

This research owes a great deal to the many formal and informal discussions that I had with my fellow graduate students. In particular, I wish to thank Tristan Sturm for his enthusiasm, willingness to discuss my ideas at all hours of the day (and night) and careful editing skills. I wish him all the best in his future studies.

Of course, I owe a great deal of gratitude to my partner, Heather Finn, who kept me focussed and showed endless patience for my sometimes odd work habits.

Finally, funding for this research was generously provided by the Department of Geography and Environmental Studies and Graduate Studies at Carleton University, the Ontario Graduate Scholarship Program and the Social Sciences and Humanities Research Council of Canada. Without this support, this research would not have been possible. 


\section{Table of Contents}

Abstract

Acknowledgements

Table of Contents

List of Acronyms

Epigraph

CHAPTER 1: INTRODUCTION 1

Definitions and Research Limitations 4

Theoretical Approach $\quad 8$

\begin{tabular}{lr} 
Why Insurance? & 12 \\
\hline
\end{tabular}

$\begin{array}{lc}\text { Overview } & 18\end{array}$

CHAPTER 2: UNDERSTANDING 'NATURE' 24

$\begin{array}{lr}\text { The Social Construction of 'Nature' } & 25\end{array}$

Mutually Assured Destruction $\quad 31$

$\begin{array}{ll}\text { Understanding Hazards } & 38\end{array}$

CHAPTER 3: HAZARDS AND DISASTERS SECURITY AND THE 40

STATE

Global Dangers: New Threats, Old Responses 41

Environmental Security and the State $\quad 45$

Constructing Vulnerability: 'Enlightened' Science 51

$\begin{array}{ll}\text { A Geographical Mismatch } & 61\end{array}$

$\begin{array}{lc}\text { The Natural Disaster Syndrome } & 66\end{array}$

$\begin{array}{ll}\text { Conclusions } & 68\end{array}$

CHAPTER 4: INSURING FUTURES THROUGH RISK AND 73

RESPONSIBILITY

$\begin{array}{ll}\text { The 'Postmodern Local' } & 74\end{array}$

$\begin{array}{ll}\text { Insurance: Overcoming Scale } & 77\end{array}$

Towards a 'Responsibilizing' Culture $\quad 84$

$\begin{array}{ll}\text { Conclusions } & 91\end{array}$

CHAPTER 5: REDUCE RISKS, INCREASE PROFITS 95

Crying Poor: The 2004 and 2005 Aftermath 98

$\begin{array}{ll}\text { Bad as It Seems? } & 105\end{array}$

$\begin{array}{ll}\text { Leading the Way on Climate Change } & 112\end{array}$

$\begin{array}{ll}\text { Conclusions } & 118\end{array}$

CHAPTER 5: CONCLUSIONS 121

$\begin{array}{lr}\text { A Role for the State? } & 130\end{array}$

$\begin{array}{lr}\text { Directions for Future Research } & 134\end{array}$

$\begin{array}{ll}\text { BIBLIOGRAPHY } & 139\end{array}$ 


\section{List of Abbreviations}

ART

Alternative Risk Transfer

DART

Disaster Assistance Response Team

FEMA

Federal Emergency Management Agency

GHG

Greenhouse Gas

IBHS

Institute for Business and Home Safety

IDNDR

International Decade for Natural Disaster Reduction

IER

International Environmental Regime

IGO

Intergovernmental Organization

IPCC

Intergovernmental Panel on Climate Change

ISDR

International Strategy for Disaster Reduction

MGI Modern Geopolitical Imagination

NFIP

National Flood Insurance Program

NGO

Non-Governmental Organization

OECD

Organization for Economic Co-operation and Development

UNFCCC

United Nations Framework Convention on Climate Change 
Unless we recognize that humanity and Nature are mutually constitutive of each other - indeed, are virtually one and the same - we cannot meaningfully speak of protecting or sustaining the earth's environment... To be sure, nature does not exist to serve mankind, but nature's continued well-being does depend on human actions. Similarly, human beings survive only by co-existing with nature... and not destroying it or transforming it out of all recognition.

Ronnie Lipschutz, Global Environmental Politics: Power, Perspectives, and Practice 


\section{Chapter 1: Introduction}

The 'environment' as a separate area of study is a relatively new development.

Over the last several decades, the environment has found its way into the public discourse and has, at times, gained superstar-like attention in the popular media. Nature has again taken centre stage as cultural images ranging from former Presidential candidate documentaries to celebrities driving hybrid vehicles have made terms like 'climate change,' 'Kyoto' and 'biodiversity' part of the vernacular. Also, it seems that the public is taking notice of what appears to be a rise in the frequency and severity of natural hazards, a trend which many attribute to global warming. Hurricanes Katrina and Andrew, the Indian Ocean tsunami, droughts and various other extreme weather-related events have captured the world's attention as the sheer force of these hazards and the threat of losing one's life, family and possessions seems like a frightening possibility for many in the growing coastal communities of the world.

Whether or not hazards themselves have increased in recent years is still up for debate. While future climate projections are still somewhat crude, there is increasing evidence to suggest that hazards will increase in both size and frequency in the coming decades. The Intergovernmental Panel on Climate Change (IPCC) expects "more frequent heat waves, less frequent cold spells (barring so-called singular events), greater intensity of heavy rainfall events, more frequent midcontinental summer drought, greater intensity of tropical cyclones, and more intense El Niño-Southern Oscillation (ENSO) events" Critics of these projections rightly claim that scientific proof that explicitly links climate change to an increase in natural hazards incidents has yet to be presented;

\footnotetext{
'Intergovernmental Panel on Climate Change, Climate Change 2001: Impacts, Adaptation and Vulnerability, (Cambridge: Cambridge University Press, 2001). Available from http:/www.grida.no/climate/ipcc_tar/wg2/index.htm.
} 
however, as Berz writes, "even if scientific proof of this link has still yet to be presented, there is no doubt about the plausibility and gravity of this suspicion."

Society usually copes well with smaller disasters, such as those that occur every hundred years or those that miss major urban centres. White and Etkin argue that preparing for natural hazards and disasters is similar to a game where certain rules and parameters remain in place that allow citizens and institutions to develop disaster mitigation and response strategies. Generally, governments have made preparations to deal with hazard events such as designating shelter sites, arranging for transportation outside of disaster zones and providing health care, strategies that have worked relatively well according to the current rules of the game. Private companies also play a role in disaster preparedness as insurance companies, for instance, provide financial security against losses due to disasters. But what happens when these rules change? And what if these new rules are not known and/or they change again? White and Etkin suggest that climate change may drastically alter the way that societies prepare for and react to natural hazards and may uncover new vulnerabilities in our current methods. ${ }^{3}$

This thesis asks three questions: why do human societies view natural hazards as sources of insecurity? How effective are states at providing security from natural hazards and disasters? And finally, what do insurance companies offer hazards and disasters security research? This chapter will provide an overview of the subsequent arguments that are presented in this thesis. It will also contextualize the research by providing

\footnotetext{
${ }^{2}$ G. Berz, "Catastrophes and Climate Change: Concerns and Possible Countermeasures of the Insurance Industry," Mitigation and Adaptation Strategies for Global Change, Vol. 4, (1999): 284.

${ }^{3}$ R. White and D. Etkin, "Climate Change, Extreme Events and the Canadian Insurance Industry," Natural Hazards, 16, (1997): 135-163.
} 
research limitations, working definitions and a brief discussion of the theoretical approaches presented in this study.

This thesis will argue that natural hazards have emerged as sources of insecurity arising from the ontological separation of the human and natural worlds. Although states have been charged with responding to insecurity, it will be argued here that they have struggled to adapt to the changing nature of such nascent threats. Given the difficulties that states have in responding to hazards and preventing disasters, this thesis explores what can be gained from examining the ways in which insurers and reinsurers address these events. Property and casualty insurance, an institution that sells security, offers another approach to hazards and disasters security that addresses some of the shortcomings of state methods, but also raises new problems that will need to be addressed. It will be argued here that insurance has the ability to operate in various scales and helps to create realistic understandings of risk and responsibility. A three-year literature review will reveal that insurers possess tremendous financial flexibility and can withstand major financial losses fairly well through their risk-spreading arrangements and ability to transfer risk to different parties. Insurers are also self-interested in that they have taken the lead on climate change science and policy as a means to guarantee future profits. The main shortcoming of such an approach, however, is that insurance ignores the socioeconomic realities that prevent a significant portion of the population from accessing such promises of security. This thesis does not argue for an end to state-led hazards and disasters security models; rather, it seeks to expand the terms of the debate by taking hazards and disasters research in a different direction. In the face of an 
uncertain future, it is important to explore alternative modes of thinking that challenge pre-existing approaches to environment and insecurity.

\section{DEFINITIONS AND RESEARCH LIMITATIONS}

Before proceeding, some clarification should be made regarding the figures and language used in this thesis. Unless otherwise indicated, all dollar figures are assumed to be in US dollars. Also, it should be noted that the primary goal of this thesis is to interrogate the presuppositions that dictate why and how societies respond to natural hazards and disasters in particular ways. This thesis is about raising questions and providing alternatives to dominant modes of thought. While policy directives and 'real world' solutions are certainly useful and necessary, they are simply not within the scope or goals of this work.

The terms 'environment' and 'nature' will be used synonymously. This thesis will accept Castree's definition of nature (or lack thereof) and operate from the premise that nature is socially defined, that it does not exist until somebody chooses to attach the name onto a group of real-word phenomena. While various definitions of nature exist including 'the non-human world,' 'the essence of something' and 'an inherent force' - it will be argued here that nature is a social construct that cannot be universally defined by a specific set of objects or spatial exclusions. As Castree argues in Nature, "there is no such thing as nature" since "knowledges of nature are constructed and contestable."4 Thus, this thesis will not define what nature ought to be; rather, it will interrogate what we choose to collectively call 'nature' and how this impacts current perceptions of

\footnotetext{
${ }^{4}$ N. Castree, Nature, (New York: Routledge, 2005): 35 and 246 respectively.
} 
hazards and disasters. Chapter 2 will delve into what is meant by 'nature' for the present purposes and will discuss the ontological foundations of the concept.

The geographical focus of this thesis is admittedly quite vague, as many references will be made to a homogenous 'West' or 'developed' countries. Admittedly, these terms lack geographical specificity and are derived from discursive practices that privilege a particular worldview. Having said that, discussions on what the 'West' constitutes is simply not within the scope of this thesis. This thesis is a theoretical exercise in deconstructing what is considered 'normal' practice in natural hazards and disasters security. For the purposes of the present study, the 'West' and 'developed' countries will refer to OECD member countries whose citizens have access to property and casualty insurance. Furthermore, most of the analysis will focus on American hazards issues due to the large availability of information in English and the importance that the country's coastal states have had for insurance companies in recent years.

An important distinction must be made between 'natural hazards' and 'natural disasters.' The former refers specifically to the geophysical and biological processes associated with extreme weather-related events - which include typhoons, earthquakes, tornadoes, landslides and so forth - while 'natural disasters' deal with the rapid, sustained socioeconomic impacts that these processes have upon human lives. Thus, a disaster can be defined by a combination of geophysical and biological processes as well as the number of deaths, economic value of damage, losses to infrastructure and stresses placed on the social system. ${ }^{5}$ Hazards occur when ocean currents move in certain ways, when the planet's plates shift suddenly or when cumulus clouds form over particular

\footnotetext{
${ }^{5}$ B. Wisner, P. Blaikie, T. Cannon and I. Davis, At Risk: Natural Hazards, People's Vulnerability and Disasters. 2nd ed., (New York: Routledge, 2004); D. Alexander, “The Study of Natural Disasters, $1977-$ 1997, Some Reflections on a Changing Field of Knowledge," Disasters, 21, 4, (1997): 284-384.
} 
topographic features. Disasters, on the other hand, occur when people build homes and businesses on flood plains or when farmers grow crops on steep hillsides. In other words, the conditions of a disaster are always present or embedded in the local-level society; a hazard simply provides the catalytic agent that produces an intense social crisis. ${ }^{6}$ Security considerations must therefore include both the physical hazards themselves and the socioeconomic conditions that enable disasters. Present society is in danger of replicating the faults of environmental determinism, that is, attributing simple causal power to natural environments in human affairs while disregarding the human inputs. As Wisner et al. argue, disasters are "the product of social, political and economic environments (as distinct from the natural environment), because of the way these structure the lives of different groups of people."?

This study will focus mainly on hazards that originate in the atmosphere, such as hurricanes, droughts, tornadoes and floods; forest fires and landslides can also be included in this list as these events are caused, in part, by excessive precipitation, or the lack thereof. These extreme weather-related events are characterized by winds, precipitation and temperature among other things. While terrestrial-born hazards, such as earthquakes and volcanoes, will be discussed in passing, they will not be the focus of this study for three reasons. First, there is little evidence to suggest that human inputs have changed the nature and frequency of these events. Second, of the $\$ 1$ billion claims made between 1987 and 1999, only two of the events did not originate in the atmosphere (the Kobe earthquake in 1995 and the California earthquake in 1994). ${ }^{8}$ Finally, the subtext of

\footnotetext{
${ }^{6}$ G. Bankoff, "Rendering the World Unsafe: 'Vulnerability' as Western Discourse," Disasters, 25,1, (2001): 19-35.

${ }^{7}$ B. Wisner et al., At Risk, 4.

${ }^{8}$ G. Berz, "Catastrophes and Climate Change," 284.
} 
this thesis is to add to existing research that examines the linkages between climate change and natural hazards; to examine earthquakes and volcanoes would rob this study of focus and clarity.

Security also figures prominently in this discussion and so some effort should be made to clarify its meaning and usage. According to Simon Dalby, "security is a derivative concept, one that already assumes that there is something else, outside of itself, that has to be secured." That "something else' is an issue that has caused a great deal of contention for over two decades. In the early-1990s, much of the debate concerning environmental security posed security as an exclusive problem for and of states. Scholars like Gareth Porter insisted that states were the only referent object of security. ${ }^{10}$ While (as will be discussed in Chapter 3) this approach remains dominant in the political realm, it is worth noting the recent shift in how environmental security scholarship has broadened its focus away from states and their militaristic focus. For instance, Jon Barnett maintains that since security is achieved when peace and justice are present and structural violence is absent in a society, security should be a human-centred project; human security, he argues, encompasses environmental security because societies require potable water, clean air and fertile soil. ${ }^{11}$ Still others have suggested that the Earth itself should be the referent object of security. Although these matters are certainly important, it is not within the scope of this research to discuss the relative merits of the various approaches to environmental security. Since the goal of this thesis is to better understand Western society's approach and response to natural hazards in terms of their disruption of daily

\footnotetext{
${ }^{9}$ S. Dalby, Environmental Security, (Minneapolis: University of Minnesota Press, 2002): xxi.

${ }^{10}$ See G. Porter, "Environmental Security as a National Security Issue," Current History, 94, no. 592, (May 1995).

" J. Barnett, The Meaning of Environmental Security, (New York: Zed Books, 2001).
} 
human life, it follows that Barnett's human-centric approach to environmental security is appropriate here.

In linking natural hazards and disasters with environmental security, it is useful to call upon Simon Dalby's conceptualization of security: "[s]ecurity is about the future or fears about the future... [i]t is about control, certainty, and predictability in an uncertain world." ${ }^{12}$ The sporadic timing and location of droughts, hurricanes and floods make hazards an obvious source of insecurity and engender feelings of lack of control, uncertainty and unpredictability in the communities that place themselves at risk. Similarly, if we take Barnett's definition of security as a situation where "everyone has their basic needs satisfied," it would seem that natural hazards and disasters undermine the maintenance of human security. ${ }^{13}$ Hazards disrupt critical infrastructure, homes, businesses, transportation, health delivery and so forth, compromising the ability of individuals to meet their basic needs. This type of insecurity is borne out in the massive international response that followed the 2004 Indian Ocean tsunami when dozens of planes full of drinking water, temporary shelters, food and medical supplies were dispatched to the region. Security is hence a project in maintaining control in the face of hazards and ensuring that individuals' basic needs are not compromised before, during and after extreme events.

\section{THEORETICAL APPROACH}

In Society Must Be Defended, Foucault insists that power is a process, that it does not reside in a particular place, being or institution. He refers to the existence of a

\footnotetext{
${ }^{12}$ S. Dalby, Environmental Security, 163.

${ }^{13}$ J. Barnett, The Meaning of Environmental Security, 4.
} 
"multiplicity of powers" insofar as powers are simply political manifestations of a multitude of capacities, possibilities and potentials. In understanding power, he states, "[o]ur object is not to analyze rule-governed and legitimate forms of power which have a single center... [o]ur object is, on the contrary, to understand power by looking at its extremities, at its outer limits at the point where it becomes capillary." Thus, power is a reflexive process that "constantly asks questions and questions us; it constantly investigates and records; it institutionalizes the search for the truth, professionalizes it, and rewards it." ${ }^{\prime 4}$ The present study therefore represents a poststructuralist challenge to the assumptions that inform much of the current security studies and natural hazards literatures. It seeks to deconstruct the state's exclusive right to power when dealing with hazards and disasters and to suggest that power also resides in insurance. A reaction to the modern era of "monological, totalizing theory," poststructuralist theories suggest that truth is represented by "heterological, multipolar grids of knowledge and practice."15 Poststructuralism is a process of "'queering' that which seems to be common sense in order to open up to scrutiny the possibilities foreclosed... [poststructuralism] emphasizes a world in flux, where meanings and identities, forces and relations are fixed in only a provisional sense."16

The purpose of this literature review is to uncover the power dynamics that dictate constructions of the 'environment' and Western responses to environmental 'threats.' This work will also interrogate the state's right to power when dealing with natural

\footnotetext{
${ }^{14}$ M. Foucault, Society Must Be Defended: Lectures at the Collège de France, 1975-1976, eds. M. Bertani and A. Fontana, (New York: Picador, 2003): 27, 25 and 43 respectively.

${ }_{15}$ J. Der Derian, "The Boundaries of Knowledge and Power in International Relations," in International/Intertextual Relations: Postmodern Readings of World Politics, eds. J. Der Derian and M. Shapiro, (Cambridge: Cambridge University Press, 1989): 6.

${ }^{16}$ B. Braun and J. Wainwright, "Nature, Poststructuralism, and Politics," in Social Nature: Theory, Practice, and Politics, eds. Noel Castree and Bruce Braun, (Oxford: Blackwell Publishers, 2001): 60.
} 
hazards and evaluate the usefulness in considering insurance as an alternative to state power. As Agnew argues, "the spatiality of power... need not be invariably reduced to state territoriality... [as] the state-territorial conception of power is not a transcendental feature of modern human history." ${ }^{17}$ The traditional definition of power is one that is commonly found in Political Science texts, that is power is the ability of one actor (A) to get another (B) to do something that they would otherwise not do; this form of power typically is achieved through the use of force, threats, bribery and/or persuasion. But this impoverished and limited definition of power ignores the various discourses that produce and undermine power in far more subtle ways. Simply put, power is not necessarily an action, but a set of conditions or phenomena that constitutes society itself. ${ }^{18}$

This research will invoke Foucault's "analytics of power" which purport power as an "open, more-or-less coordinated... cluster of relations," as opposed to a "context-free, ahistorical objective description." According to Foucault, "power... is the operation of the political technologies throughout the social body." 'Nature' has thus emerged through a historically specific set of discursive practices that reflect the interests and beliefs of the powerful. Similarly, 'the state' and its institutions have been the dominant power-brokers in security matters for several centuries. Foucault's theories on power and governmentality have inspired a body of research that investigates the knowledges and practices that operate in the space between the individual and the state. Thus, rather than

\footnotetext{
${ }^{17}$ J. Agnew, Geopolitics: Re-Visioning World Politics, 2nd Ed, (New York: Routledge, 2003): 129 and 132 respectively.

${ }_{18}^{18}$ R. Lipschutz, Global Environmental Politics: Power, Perspectives, and Practice, (Washington: CQ Press, 2004).

${ }^{19}$ H. Dreyfus and P. Rabinow, Michel Foucault: Beyond Structuralism and Hermeneutics, 2nd ed., (Chicago: University of Chicago Press, 1983): 184 and 185 respectively.
} 
accepting nature and the state as "stable categories of being," this thesis seeks to question the 'truthfulness' of these entities and evaluate whether or not power resides elsewhere. ${ }^{20}$

This thesis critiques the current dominant approach to hazards and disasters security. The process entails "showing [knowledges] to be social products arising in particular contexts... [to serve] specific social or ecological ends. ${ }^{21}$ Again, this thesis will invoke Foucault who argues that political technologies, which are manifestations of power, take what is effectively a political problem, remove it from the realm of political discourse, and finally recast it in the "neutral language of science." Paradigms create rules for societies that isolate anomalies and normalize them into the dominant discourse. For example, the belief that the environment is rational, and hence manageable, is challenged by the inability of engineers and geologists to accurately predict and control earthquakes; but such deficiencies in the scientific model are simply treated as glitches in an otherwise uniform and logical system. Thus, "the ideal of normal science is that all these anomalies will eventually be shown to be compatible with the theory."22

But as Foucault's analysis of genealogy demonstrates, such paradigms are "not a timeless and essential secret, but the secret that they have no essence or that their essence was fabricated in a piecemeal fashion from alien forms." Since power is "born from chance," then truth and the resulting domination are the result of accidents and a "host of errors and phantasms." ${ }^{23}$ Hence, paradigms and what is understood as 'normal,' can be challenged on the grounds that they are not objective nor rationally defined. While

\footnotetext{
${ }^{20}$ B. Braun and J. Wainwright, "Nature, Poststructuralism, and Politics," 50.

${ }^{21}$ N. Castree, "Socializing Nature: Theory, Practice, and Politics," in Social Nature: Theory, Practice, and Politics, eds. N. Castree and B. Braun, (Oxford: Blackwell Publishers, 2001): 13.

${ }^{22} \mathrm{H}$. Dreyfus and P. Rabinow, Michel Foucault, 196 and 197 respectively.

${ }^{23}$ M. Foucault, Language, Counter-Memory, Practice: Selected Essays and Interviews, ed. D. Bouchard, trans. D. Bouchard and S. Simon, (Ithaca: Cornell University Press, 1977): 142 and 155 respectively.
} 
recognizing that it is impossible to escape power and its various manifestations, this thesis seeks to expand the possibilities of what constitutes 'normal' in the realms of environment, security, natural hazards and the role of the state.

\section{WHY INSURANCE?}

Insurance companies are primarily in the business of selling security. Insurance provides a futures market in security, where millions of consumers purchase a good that they have little knowledge about. Consumers buy "trust in an abstract system, a peace of mind and taken-for-grantedness that if the worst happens there will at least be financial compensation. ${ }^{, 24}$ Insurance promotes itself as a social technology that helps to gain a measure of control over an uncertain world, one of the goals of hazards and disasters security. Control is achieved through the invention of the calculus of risk, which makes the incalculable calculable. Monetary values are assigned to goods; if these goods are lost or damaged, then insurance will provide financial compensation according to their assigned values. Beck argues that insurance, with its rules for compensation and precautions, "creates present security in the face of an open [and] uncertain future."25 Rather than being consumer-driven and marketed as a 'cool' product, insurance is sold by sales staff who promote insecurity. Insurance provides promises of 'protection for you and your family' and 'we're ready for anything' to bolster its public image as a producer and supplier of security. ${ }^{26}$ Thus, "because the primary benefit of insurance is a sense of security that, for most people, is never tested by a catastrophic loss, the value of

\footnotetext{
${ }^{24}$ R. Ericson et al., Insurance as Governance, (Toronto: University of Toronto Press, 2003 ): 4.

${ }^{25}$ U. Beck, "From Industrial Society to the Risk Society: Questions of Survival, Social Structure and Ecological Enlightenment," Theory, Culture \& Society, Vol. 9, (1992): 100.

${ }^{26}$ R. White and D. Etkin, "Climate Change."
} 
insurance rests, in an important sense, in the imagination." 27 As the AllState website suggests, insurance provides "security, protection, peace of mind.",28

Insurance contracts, which burden the individual with fees just as they relieve them from dramatic damage costs, are not new - early intercontinental navigation and trade, for example, had financial mechanisms that protected explorers against losses due to illness, accidents, fire, theft and so forth. However, with the growth of industrial capitalism, insurance has been continually perfected and expanded into nearly all problem areas of social action, from property to employment to health. The ideal type of insurance is one where premiums are paid in advance, there is guaranteed indemnity in the event of a covered loss and risk-based premiums are based on the best available information regarding the expected losses of the individuals insured. ${ }^{29}$ Profit is thus maximised when an area is threatened by a potentially devastating ubiquitous risk whose probability of occurring is very low. ${ }^{30}$

But the era of low-risk, low-probability events is once more threatened by the prospect of more frequent and severe natural hazards. Insurance and reinsurance companies represent one sector of the economy that is highly aware of major environmental hazards and has a vested interest in alleviating, or at least understanding, them. These companies do not profit from natural hazards; they profit from the imagined threat of hazards. The industry is dangerously overexposed by events like billion-dollar hurricanes; a category 5 hurricane in Miami, for instance, could dwarf losses incurred due

\footnotetext{
${ }^{27}$ T. Baker and J. Simon, "Embracing Risk," in Embracing Risk: The Changing Culture of Insurance and Responsibility, eds. Tom Baker and Jonathan Simon, (Chicago: University of Chicago Press, 2002): 9.

${ }^{28}$ AllState, "Insurance Products at Allstate Insurance," 2005. Accessed 4 February 2005. Available from http://www.allstate.com/Products/pagerender.asp?page=main.htm.

${ }^{29}$ T. Baker and J. Simon, "Embracing Risk," 10.

${ }^{30}$ R. White and D. Etkin, "Climate Change."
} 
to Hurricane Katrina. While, as it will be argued here, insurers presently possess the financial capacity and flexibility to pay for these catastrophic losses, demographic and socioeconomic trends indicate that these costs may in the future outstrip the industry's ability to respond to catastrophic losses as factors such as population growth, increased wealth and urbanization of coastal areas may push damages to unsustainable levels. Despite entrenched poverty in many parts of the world, global wealth continues to expand. Population densities in high-risk coastal areas, particularly along the Gulf and California coasts, continue to rise in North America and elsewhere. More people with more goods living in coastal cities does not bode well for insurance and reinsurance providers as these trends threaten the future of the industry. ${ }^{31}$

It is not surprising that the insurance and reinsurance industries have allied themselves with various environmental groups in recent years. White and Etkin write, "if, indeed, climate change will result in a greater number of weather disasters, then the insurance industry cannot afford to take a 'wait-and-see' position with regard to climate change." While the seriousness of climate change has not convinced the industry as a whole to advocate the mitigation of greenhouse gas emissions, still over 50 companies signed the declaration with the United Nations Environment Programme on "The Insurance Industry and the Environment (Table III)" which urges governments to reduce GHG emissions worldwide. ${ }^{32}$ The unknowns of climate change have recently made the industry politically, socially and economically more relevant. The role of the industry in climate change initiatives will be discussed further in Chapter 5.

\footnotetext{
31 Ibid.

${ }^{32}$ Ibid., 136 and 153 respectively.
} 
Finally, it is important to look to insurance in the context of the present study simply because these corporations wield great influence in natural hazards and disasters security. A growing body of research, particularly in political economy, has suggested that we are headed toward, or have already entered, an era of decreased power of nationstates where finance and the flows of capital will play an increasingly greater role in controlling global events. Richard J. Barnet and John Cavanagh write in Global Dreams: Imperial Corporations and the New World Order,

By acquiring earth-spanning technologies, by developing products that can be produced anywhere and sold everywhere, by spreading credit around the world, and by connecting global channels of communication that can penetrate any village or neighbourhood, these institutions we normally think of as economic rather than political, private rather than public, are becoming the world empires of the twenty-first century. The architects and managers of these space age businesses understand that the balance of power in world politics has shifted in recent years from territorially bound governments to companies that can roam the world. ${ }^{33}$

It appears then that power may reside amidst the massive transnational flows of capital, information and commodities that occur on a daily basis. Thus, crucial 'certainties' from as recently as 15 years ago - such as the existence of fixed and unquestioned political boundaries between states - have either disappeared or are seriously in question. Issues such as natural hazards, international trade and transnational terrorism have put the validity of such 'truths' into serious doubt and have raised important questions as to where power now resides. As Agnew writes, "understanding power as if it is attached singularly to state territories makes no sense." ${ }^{34}$ What does make sense, however, is an

\footnotetext{
${ }^{33}$ R. Barnet and J. Cavanagh, Global Dreams: Imperial Corporations and the New World Order, (New York: Simon \& Schuster, 1994): 14 in S. Dalby, "Globalisation or Global Apartheid? Boundaries and Knowledge in Postmodern Times," Geopolitics. Vol. 3, No. 1, (Summer 1998): 132.

${ }^{34}$ J. Agnew, Geopolitics, 65.
} 
interrogation as to whether or not insurance holds power to influence how societies secure themselves from natural hazards.

Within the governmentality literature, insurance is one of the many forms of knowledge and practice that operate in the space between the individual and the state. Insurance companies are supervised by national governments, who "ensure that insurance companies will be financially competent to discharge their obligations, that insurance contracts are fair and that business is being conducted for the general public good." 35 Insurance interacts with other powerful businesses and states to negotiate political economy at all levels of society. Its power lies in its ability to transfer and distribute risk among various state and non-state actors from the local to the global. The industry is also significant in that it accounts for an incredible amount of financial activity in the global economy. As the world's largest industry, insurance penetration has averaged 9 per cent of GDP in developed countries and 5 per cent of GDP in developing countries; furthermore, the industry is benefiting from massive growth rates in the developing world due to the rise of economies like China and India. ${ }^{36}$ In Canada, there are at least 213 property and casualty insurance providers that together employ nearly 100,000 people. In 2004 , the sector generated sales of CDN $\$ 33.6$ billion and controlled nearly $\$ 100$ billion in assets - to place these numbers in context, the Canadian GDP is approximately $\$ 1$ trillion. ${ }^{37}$ Whether or not it chooses to actively engage in political decisions, an industry this large has no choice but to wield a tremendous amount of power.

\footnotetext{
${ }^{35}$ Insurance Bureau of Canada, Facts of the General Insurance Industry in Canada, 3 Ist ed., (Toronto: Insurance Bureau of Canada, 2005): 6.

${ }^{36}$ E. Mills et al. "Insurance in a Climate of Change." Science. 309, (12 August 2005): 1040.

${ }^{37}$ Insurance Bureau of Canada, Facts of the General Insurance Industry in Canada, 2.
} 
While insurance companies are influential political actors by virtue of their economic clout, it is also worth noting the power dynamics within the industry itself. National insurance industries tend to be dominated by a relatively small group of financially powerful companies. In the United States, ten companies accounted for nearly fifty per cent of the premiums collected by the entire property and casualty insurance industry in 2004; to put this figure into context, there are approximately 3,000 insurance companies operating in the United States. ${ }^{38}$ Also, most 'local' insurance companies belong to international financial conglomerates; for example, ING Canada is part of the ING Groep N.V. in the Netherlands which, in addition to selling insurance, offers a full range of financial and investment services for millions of clients worldwide. Although the randomness of hazards allows insurance companies to generate profits and pay for insured claims, it can also undermine their capital reserves. Most large insurance companies are able to cover damages using their own reserves; but, in extreme cases, reinsurers and capital markets help to fund claims payouts, such as following Hurricane Katrina in 2005. Despite being a massive industry that controls literally hundreds of billions of dollars worldwide, reinsurance is relatively specific in terms of its geography and power distribution. Nearly three-quarters of the its global business is underwritten by companies in Germany, Switzerland and the United States, with only a handful of companies controlling the industry, notably Swiss Re, Munich Re and Berkshire Hathaway ${ }^{39}$ Like the primary insurance industry, power is concentrated among few companies in the reinsurance industry. Both industries are thus notably oligopolistic in

\footnotetext{
${ }^{38}$ Insurance Information Institute, International Insurance Fact Book, 2006-2007, 2006. Available from http://www.internationalinsurance.org/international/toc/.

${ }^{39}$ Insurance Information Institute, "Reinsurance," Insurance Information Institute, July 2006. Available from http://www.iii.org/media/hottopics/insurance/reinsurance/.
} 
that a relatively small group of companies account for the majority of the industry's business and hold great sway in industry issues.

Insurance is embedded in all aspects of daily life - from driving a car to receiving a paycheque to renting a house - yet it remains in the background: "it is something that people take for granted to meet exigencies that they would prefer not to think about." ${ }^{, 40}$ Simon and Baker argue that insurance is "the sleeping giant of power... [and] is one of the greatest sources of regulatory authority over private life. ${ }^{, 41}$ Similarly, Ericson et al. unequivocally state, "insurance is the institution of governance beyond the state." As Foucault suggests, we cannot always defer to the obvious when dealing with matters of governance and behaviour as power can reside in the most unexpected places. Insurance is an institution which relies on governing how individuals relate to their natural surroundings. It is important then to understand how governance is used and its potential for future use in helping to reduce harm and loss that is often associated with natural hazards.

\section{OVERVIEW}

The focus of this thesis is to evaluate whether or not societies and their institutions are prepared for significant changes in the 'natural hazards game.' States are finding it increasingly difficult to act as sole providers of security from hazards due to their rigid geographies and reliance on scientific and technological 'solutions.' State responses have a tendency to absolve individuals of responsibility for natural hazards and disasters. It will be argued here that insurance has the potential to ameliorate some of the

\footnotetext{
${ }^{40} \mathrm{R}$. Ericson et al., Insurance as Governance, 3.

${ }^{41}$ T. Baker, and J. Simon, "Embracing Risk," 12-13.

${ }^{42} \mathrm{R}$. Ericson et al., Insurance as Governance, 14.
} 
shortcomings of the current hazards and disasters security regime through its ability to overcome problems of scale, its financial flexibility and its ability to dictate how much responsibility should be born by the individual. The ability of insurers to adjust to severe hazards and transfer greater responsibility to individuals is borne out in a three-year analysis of industry movements and transactions. Insurance, therefore, provides a different theoretical context from which societies can modify their ways of securing themselves against natural hazards and disasters. While the ontological foundations of the human-environment relationship may prove impossible to change, a more responsible way of living can certainly be encouraged through a better understanding of risk and responsibility.

Chapter 2 interrogates the discursive practices and presuppositions that have shaped current understandings of natural hazards. It will be argued that the ontological separation of 'humans' and 'nature' has led to a characteristically combative view of human-nature interactions which has coloured natural hazards in a negative and dichotomous manner.

Chapter 3 evaluates how states have performed in responding to natural hazards and disasters. The chapter will argue that states have translated Cold War logics into the present period where all security threats and global dangers are defined in familiar dichotomous terms. States are thus programmed to respond to all security threats in the same manner, that is, through military institutions and massive infrastructure projects. While such methods have met with limited success, a brief case study analysis will demonstrate the limits of such strategies in mitigating the effects of hazards and disasters. 
In fact, New Orleans' experience with Hurricane Katrina demonstrates that state actions exacerbated disaster in the region.

Chapter 4 evaluates what ideas and approaches the insurance industry can contribute to current hazards and disasters security research. Here it will be proposed that while insurance should not be seen as a replacement for current hazards and disasters security regimes - mainly the state and its institutions - its risk reduction methods provide a useful way of looking at these security problems in a different light. Insurance's ability to operate within various scales and to dictate individual responsibility can encourage greater hazards awareness. But this approach is not without its shortcomings. Given the economic dimension of insurance and the fact that it can be costly, insurance does not protect a significant proportion of the population. Also, insurance gives a false sense of security when people assume that disastrous places can be liveable when all possessions can be translated into capital; it reduces all things, sentimental or otherwise, to a mere commodity. When these commodities become too expensive to insure or insurance is unavailable, then perhaps it will force a re-evaluation of how one lives.

Chapter 5 will provide some empirical support to the arguments put forth in Chapter 4. An analysis of secondary sources from four major business publications will examine how insurance and reinsurance companies responded to two active and costly Atlantic hurricane seasons followed by a relatively quiet season. Company statements, official interviews, financial reports, press releases and so forth will demonstrate that insurers and reinsurers have the institutional capacity and flexibility to adjust to catastrophic loss events. Their ability to spread risks allows them to remain profitable and 
shifts a greater degree of responsibility to their policyholders. It will also be argued here that the industry has taken a leading role in climate change discussions as a means to maintain their profitability in an uncertain future and improve their public image.

Chapter 6 provides a summary of this thesis and attempts to answer any remaining questions. This chapter also attempts to situate the research within the broader academic context and provide opportunities for further research. That natural hazards represent an increasingly difficult spatial and temporal problem for states will become evident. This thesis examines what Hewitt calls the "self-inflicted failures of modernity," where state actions, under the banner of security, have in fact exacerbated disasters. ${ }^{43}$ The rigidity of political borders, the privileging of science and the reliance on military institutions arise from an ontological assumption that nature is both separate and subservient to human needs. These types of responses also create a moral hazard, where individuals fail to take responsibility for their own hazards and disasters security. While not the answer to the West's hazards woes, the insurance industry has found a way to work around some of the failings of state responses. The ability of insurers to govern homeowner behaviours through financial incentives and annual reviews in theory forces homeowners to realize and bear some of their own risks. Also, the industry possesses a built-in resiliency through its risk-spreading arrangements and large capital base that allows it to effectively approach and respond to catastrophic loss events like Hurricane Katrina. But the failings of insurance, mainly related to its financial focus and its own responsibility to shareholders, suggest that there remains a vital role for the state in these matters. The state is not dead; it merely needs to reinvent itself in the face of a changing

\footnotetext{
${ }^{43}$ K. Hewitt, Regions of Risk: A Geographical Introduction to Disasters, (Essex: Addison Wesley Longman Limited, 1997): 3.
} 
planet. While insurance alone is certainly not the answer, its success in rethinking hazards and disasters security forces a re-evaluation of the status quo. Thus, in offering the promise of security from natural hazards, neither institution can make such guarantees. The point is not to offer solutions, but to ask more questions.

The study of disasters is important because as Geographers, "we must take account of the interrelationships and distinctive mix of conditions that define human settlements and regions." ${ }^{44}$ Geography emerged as an academic subject in the latenineteenth century in order to try to bring society and nature "under one conceptual umbrella." ${ }^{45}$ That geographers study human impacts upon nature and natural impacts on humans is the underlying theme in the discipline. Disasters are particularly interesting since they unravel associations of 'people and place' and 'land and life' just as they destabilize soils, forests and rivers. Castree therefore situates the study of natural hazards in the "middle ground" of geography, where geographers must "share the study of society-nature relationships with environmental science, earth science and environmental management." ${ }^{, 46}$ Like Hewitt, Wisner et al., and others, this thesis focuses on the social causes of disasters and the responses to them, rather than the physical aspects that determine where, when and how extreme weather-related events strike. It also refuses to accept traditional geographical categorizations concerning how the world should be divided up, and searches instead for different ways to approach hazards' unique spatial

\footnotetext{
${ }^{44}$ K. Hewitt, Regions of Risk, 12.

${ }^{45}$ D. Livingstone, The Geographical Tradition: Episodes in the History of a Contested Enterprise, (Oxford: Blackwell Publishing Ltd., 1992): 177 in N. Castree, Nature, 10.

${ }^{46}$ N. Castree, Nature 10.
} 
and temporal considerations. An alternative vision as to how hazards and disasters security can be better understood is presented here. 


\section{Chapter 2 - Understanding 'Nature'}

As discussed in the opening chapter, this thesis' theoretical aim is to denaturalize the assumptions that define human responses to natural hazards in present (post)modern society. In order to properly consider Western approaches to landslides, hurricanes, 'wild' fires and so forth, it is necessary to challenge the presuppositions that inform humans' understanding of their place in the world order. Hierarchical perceptions of human-nature interactions will produce a distinctly different interpretation of the issues between these spheres than, for instance, a rendering of the cosmos in circular terms, where all things on the Earth are viewed as equals. Such ontological assumptions in turn influence the discourses that explain the cause and effect of degradation and catastrophe. Thus, our awareness of, responsibility for and reaction to natural hazards is fundamentally influenced by our relationship with 'nature.'

I argue here, as do others, that 'nature' is not a thing that is self-evident or objective, nor does it exist independently of the domains of power and politics; instead, 'nature' is explicitly an effect of power. ' Castree argues that there is "no objective, nondiscursive way of comprehending nature;" nature's discourses (for example, 'the natural sciences') do not "reveal or hide the truths of nature but, rather, create their own truths" (original italics). ${ }^{2}$ Thus, claims about 'nature' can serve as instruments of power and domination; the creation of 'wildlife parks,' for example, has displaced thousands of people in the African continent. The current vision of 'nature,' therefore, simply reflects

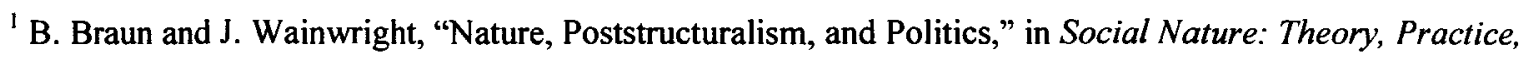
and Politics, eds. Noel Castree and Bruce Braun, (Oxford: Blackwell Publishers, 2001): 41-63.

${ }^{2}$ N. Castree, "Socializing Nature: Theory, Practice, and Politics," in Social Nature: Theory, Practice, and Politics, eds. N. Castree and B. Braun, (Oxford: Blackwell Publishers, 2001): 12.
} 
the priorities and visions of the powerful - observation, control, rationality, stewardship, predictability and so forth.

This chapter seeks to problematize what we in the West call 'nature' or 'environment.' Western societies have constructed this community of trees, animals, oceans, soil and insects as a backdrop for human progress such that science represents the only form of legitimate knowledge and control and domination governs our relationship with the natural world. Yet over the last hundred or so years, the seemingly peaceful relationship between these two distinct actors has devolved into one of mutual threats where humans and 'the environment' are seen as warring parties.

\section{THE SOCIAL CONSTRUCTION OF 'NATURE'}

The term 'nature,' or 'the environment,' rolls off the tongue so easily that we tend to forget what it really means. Western societies have long held that 'nature,' under its various formulations and definitions, sits opposed to the 'social' world, that is, the realm of human existence. The very idea of 'the environment' is something that is inherently non-social, as the term itself both linguistically and conceptually separates the land, air and nutrients that ensure our survival from the human species itself. The concept illustrates that the human and non-human worlds are mutually exclusive. Thus, there is also a spatial dimension at play, as Lipschutz writes, "our use of the term [nature] often seems to imply that we, as human beings, are external to the 'environment,' that we are 'in here,' within society, while nature is somewhere 'out there."'3 Castree points to the language used to describe human interactions with the environment; societies 'impact

\footnotetext{
${ }^{3}$ R. Lipschutz, Global Environmental Politics: Power, Perspectives, and Practice, (Washington: CQ Press, 2004): 2.
} 
on,' 'interfere with' or 'destroy' nature as if it were an outside actor. ${ }^{4}$ As Simon Dalby similarly writes, "[t]he environment in which we live was for a long time assumed to be separate, or at least in an important sense external to the lives of civilized people who live in cities, distant from nature." 5

Perhaps more than simply "a long time," the separation of the "natural" and 'human' worlds extends far deeper than temporal considerations. Various scholars have argued that there is a decidedly ontological foundation that shapes how humans perceive their place on and in the planet. Bourdeau, Lipschutz and others suggest that this ontological, and perhaps even cosmological, separation of 'humans' and 'nature' is rooted in Judeo-Christian traditions. ${ }^{6}$ According to these claims, Adam and Eve represented the culmination of God's great creation, following the creation of the Earth and its non-human living things. Moreover, God's apparent species-favouritism is so great that he explicitly grants the human species dominion over the non-human (i.e. the 'natural') world in the famous opening chapter of Genesis. ${ }^{7}$ This perceived right and/or duty to dominate nature is present even in non-religious tropes. As Dalby notes, "Mother Nature" is rendered feminine, thereby granting humans "the phallocentric prerogatives to power and control;" while Mother Nature may occasionally exert her power to punish

\footnotetext{
${ }^{4} \mathrm{~N}$. Castree, "Socializing Nature," 13.

5 S. Dalby, "Introduction to Part Four: The Geopolitics of Global Dangers," in The Geopolitics Reader, eds. S. Dalby and G. Ó Tuathail, 2nd ed., (New York: Routledge, 2006): 178.

${ }^{6} \mathrm{Ph}$. Bourdeau, "The Man-Nature Relationship and Environmental Ethics," Journal of Environmental Radioactivity, 72 (2004): 9-15; R. Lipschutz, Global Environmental Politics.

${ }^{7}$ While not crucial to the discussion at hand, it is important to recognize that such claims concerning JudeoChristian environmental ethics have been critiqued by various scholars. Some argue that Bourdeau, Lipschutz and others present the early chapters of Genesis as the sole basis of the Judeo-Christian environmental worldview, failing to recognize the more nuanced character that is presented in other biblical texts. For instance, God did not simply grant humans unchecked dominion over nature. Important concepts like 'stewardship' seek to guide the God-Society-Nature relationships in a responsible manner. See M. Northcott, Environment and Christian ethics, (Cambridge: Cambridge University Press, 1996) and P. Santmire, The Travail of Nature: the Ambiguous Ecological Promise of Christian Theology, (Philadelphia: Fortress Press, 1985).
} 
bad behaviour, she is ultimately a female and is therefore subservient and demure. ${ }^{8}$ It follows then that, in both religious and non-religious contexts, nature is reduced to "the single dimension of an object that can be appropriated."

Until recently, the belief that 'the environment' existed solely to serve the human species went unproblematized; such views were normalized and were simply accepted as fixed universal truths. However, recent scholarship suggests that the notion of a separate and subservient nature is in fact a social construction that exists predominantly in the West, representing only one possible way to engage in the natural world. North American aboriginal cosmologies, for instance, have recently been cited in various critical works that question the dominance of hierarchical Western cosmologies. Lakota and Iroquoian understandings of existence, for instance, provide an approach to environmental issues that is far removed from Western perceptions. Lakota cosmology is seen in circular rather than linear terms, whereby all things in the universe exist in a fixed balance of perfect equality and thus, hierarchical power relations do not, or rather cannot, exist. As a result, the notion of separating nature (let alone exploiting it for gain or profit) from human life would be antithetical to the deeply-held values that believe in the "ontological oneness of all creation." 10 This idea is best illustrated by the language that the Lakota use to refer to the natural world: "Humans share their world with Wakan and non-human persons, including human persons, stone persons, four-legged persons, winged-persons, crawling persons, standing persons (plants and trees), fish-persons, among others." ${ }^{11}$ Unlike in

\footnotetext{
${ }^{8}$ S. Dalby, "Ecological Metaphors of Security: World Politics in the Biosphere," Alternatives, 23, (1998): 296.

${ }^{9} \mathrm{Ph}$. Bourdeau, "The Man-Nature Relationship," 11.

${ }^{10}$ F. Detwiler, "“All My Relatives:' Persons in Oglala Religion," Religion, Vol. 22, no. 3, (July 1992): 238 in M. Beier, "Beyond Hegemonic State(ments) of Nature," in Power, Postcolonialism and International Relations, eds. G. Chowdhry and S. Nair, (London: Routledge Ltd., 2002): 104.

"F. Detwiler, “'All My Relatives,” 239 in M. Beier, "Beyond Hegemonic State(ments) of Nature," 104.
} 
Western models where values are assigned in relational terms, in circular cosmologies literally every living and non-living entity on the planet has intrinsic value and exists on its own terms. Although the concept of 'nature' as a separate entity would be completely irrelevant to indigenous groups such as the Lakota and the Iroquois, such understandings help to challenge the hegemony of the dichotomies prevalent in Western thinking. By considering differing cosmologies it is possible to fundamentally comprehend discursive practices that normalize unequal power relationships that ultimately lead to environmental degradation. ${ }^{12}$

Neil Smith writes that "external nature is pristine, God-given... it is the raw material from which society is built." ${ }^{" 13}$ European societies, and their many colonies, built their societies based on the belief that 'nature' was theirs to exploit. It follows then that modern, industrial capitalism literally produced nature to serve the narrow interests of profitability. European colonialism and the conquest of the Earth, for example, were inspired by the search for human and natural resources to fuel European power and wealth. ${ }^{14}$ Cooper similarly writes, "the constituents of nature, too, are originally experienced or encountered as 'equipment,' ready-made equipment, as it were - the wood, for example, as a forest of timber, and the south wind in relation to activities like farming."15 'Nature' thus becomes an 'event,' 'gift' or 'source' for humans to experience and/or utilize; it possesses a "certain direction" relative and relevant to human projects. ${ }^{16}$ In other words, 'nature' is defined, delimited and physically reconstituted by societies according to its utility to help facilitate the meeting of their goals. The philosophical

\footnotetext{
${ }^{12}$ M. Beier, "Beyond Hegemonic State(ments) of Nature."

${ }^{13}$ N. Smith, Uneven Development, (Oxford: Blackwell, 1984): 2 in N. Castree, "Socializing Nature," 6

${ }^{14}$ S. Dalby, "Introduction to Part Four: The Geopolitics of Global Dangers."

${ }^{15}$ D. Cooper, "Heidegger on Nature," Environmental Values, 14 (2005): 342.

${ }^{16}$ Ibid., 342.
} 
question is no longer, 'if a tree falls in the woods does it make a sound if no one is there to hear it?' Instead, the new dilemma is, 'if a tree cannot be harvested for pulp or lumber, does it have value?' The result is a 'nature' that is appreciated solely for its utility as a raw materials provider and waste disposal site, a construction that is made possible by the externalization of, and dominion over, the natural world.

The social construction of nature owes much of its being to the rise of 'modern' science. Just as the age of modernity inspired intrepid explorers to conquer foreign "wild lands,' early-modern scientists sought to uncover the secrets of the mysterious 'environment.' Derek Gregory argues that the modern age came to be represented as a triumph of 'culture' over 'nature' and that "modern cultures were supposed to have dissected nature so deeply and to have imposed themselves upon nature so forcefully that they were no longer at its mercy." ${ }^{17}$ Francis Bacon believed that humanity sat at the centre of the world and the purpose of science was to allow humans to dominate nature; Descartes, similarly felt that science would enable humans to become the 'masters and possessors of nature. ${ }^{, 18}$

European scientists constructed 'nature' as an external domain that lay outside the historical trajectories of 'culture;' it was as Heidegger suggests, "the conquest of the world as picture."19 Like a painting, drawing or map, 'nature' could be understood as a static entity that could be poked, prodded and analysed independently of human action; its processes could be observed directly and tested empirically, which contributed to a

\footnotetext{
${ }^{17}$ D. Gregory, "(Post)Colonialism and the Production of Nature," in Social Nature: Theory, Practice, and Politics, eds. N. Castree and B. Braun, (Oxford: Blackwell Publishers, 2001): 88.

${ }^{18} \mathrm{Ph}$. Bourdeau, "The Man-Nature Relationship," 11.

${ }^{19}$ D. Gregory, "(Post)Colonialism," 92.
} 
scientific body of 'truth. ${ }^{, 20}$ Such views of nature marked an epistemological turn, where knowledge in the 'spectator sense' was privileged above all other forms of knowledge, such as that gained through intuition or experience. Nature simply 'reported back' its numbers and figures to scientists who would use this information to develop "a uniquely true account of what nature is, independently of human nature."21 To understand nature, therefore, was to gain theoretical knowledge of an objective, material realm standing under and against human spectators.

This privileging of selective knowledge allowed modern scientists to imbue 'nature' with certain characteristics. Descartes 'viewed' nature as, "a complex of material entities behaving in accordance with 'laws of nature' or, at any rate, reliable statistical regularities." ${ }^{22}$ Similarly, Sir Charles Lyell believed that the Earth was a conservative, steady state system. His principle of "uniformitarianism" conflated the constancy of natural laws with Newtonian uniformities of rate and state. ${ }^{23}$ Like 'rational man [sic.],' the "modern production of nature codified an imaginary that defined European nature as temperate nature: a nature that was moderate, constant, and continent, without extremes or excesses. ${ }^{.24}$

Present-day discourses still retain many of science's assumptions about 'nature.' The centralized command and control mechanisms of 'environmental management' and 'sustainable development' have been touted as the solution to the planet's many problems. Even the "dressed up" language of "environmental security' fails to hide the

\footnotetext{
${ }^{20}$ D. Demeritt, "Being Constructive About Nature," in Social Nature: Theory, Practice, and Politics, eds. N. Castree and B. Braun, (Oxford: Blackwell Publishers, 2001).

${ }^{21}$ D. Cooper, "Heidegger on Nature," 341 and 344 respectively.

22 Ibid., 341.

${ }^{23}$ M. Davis, Ecology of Fear, (Toronto: Random House Inc., 1998): 15.

${ }^{24}$ D. Gregory, "(Post)Colonialism and the Production of Nature," 89.
} 
role and power of the dominant human species. ${ }^{25}$ Critics of Rachel Carson's text Silent Spring argued that "modern scientists know that it is man's [sic.] destiny to control nature. ${ }^{26}$ Moreover, contemporary societies have created what David Demeritt calls “'artefactual natures,' ones that are purposefully engineered;" examples include venues where 'nature' has become something that can be consumed through tourism and natural resource trade and protected through conservation projects (e.g. through the creation of botanical gardens, zoos, game reserves). ${ }^{27}$ The common thread over the last few centuries, since the enlightenment period in Europe, is that "'nature' was not only dominated; it was also domesticated" (original italics). ${ }^{28}$

\section{MUTUALLY ASSURED DESTRUCTION}

It is glaringly obvious that the domestication of nature has not gone exactly as planned, as the Western imagination of temperate, rational nature has began to unravel before our very eyes. The seemingly facile collection of 'average precipitation' data, for example, assumes that the 'average' makes sense, that climate is a rational, natural lawabiding system; but in Los Angeles, over a recorded period of 127 years, the annual precipitation came within 25 per cent of the 'average' only 17 per cent of the time, suggesting that the Southern California climate was anything but linear. ${ }^{29}$ Even our domesticated animals seem to have had enough, as 'mad cow disease' (which conjures

\footnotetext{
${ }^{25}$ S. Dalby, "Ecological Metaphors of Security," 313.

${ }^{26} \mathrm{G}$. MacDonald, "Environment: Evolution of a Concept," Journal of Environment and Development, 12, 2, (June 2003): 155.

${ }^{27}$ D. Demeritt, "Science, Social Constructivism and Nature," in Remaking Reality, eds. B. Braun and N. Castree, (London: Routledge, 1998): 173-192 in N. Castree, "Socializing Nature," 15; S. Dalby, "Ecological Politics, Violence, and the Theme of Empire," Global Environmental Politics, 4, 2, (May 2004): $1-11$.

${ }^{28}$ D. Gregory, "(Post)Colonialism and the Production of Nature," 89.

${ }^{29}$ M. Davis, Ecology of Fear, 16;
} 
analogies to the evil machinations of the 'mad scientist') and avian influenza continue to plague agriculture in the developed world. Again, it is worth noting that Carson's Silent Spring introduced the radical notion (at the time) that the environment was broken and sick, no longer able to play the role of docile servant to its human masters, but certainly capable of 'biting back., 30

Natural hazards are perhaps the most obvious and exciting reminder of how nature refuses to be entirely domesticated by science and technology. Despite impressive advances in engineering, geophysical sciences and technological capacities, the social and economic impacts of natural hazards have actually increased in recent decades. As Burton et al. write, "in a time of extraordinary human effort to control the natural world, the global toll from extreme events is increasing."31 A cursory analysis of recorded disasters (defined by a minimum of 1,000 deaths or $\$ 1$ billion in overall losses) between 1977 and 1997 showed that the impacts of earthquakes, storms, floods, volcanic activity, 'wild' fires and droughts showed no noticeable improvement. For example, in 1991, 145,000 people were killed in Bangladesh after a devastating tropical cyclone hit the region, and the 1995 Kobe earthquake cost the Japanese economy over $\$ 130$ billion. ${ }^{32}$ More recently, the 2004 tsunami in South East Asia killed nearly 300,000 people in several countries and the 2005 hurricane season - dramatically punctuated by Katrina, Wilma and Rita - caused over $\$ 80$ billion in damages. ${ }^{33}$ It would seem then that the planet is not falling in-step with scientific progress as natural events continue to taunt

\footnotetext{
${ }^{30}$ R. Carson, Silent Spring, (New York: Haughton Mifflin Company, 1962).

${ }^{31}$ I. Burton, R. Kates and G. White, The Environment as Hazard, (New York: Oxford University Press, 1978): 1 .

${ }^{32}$ D. Alexander, "The Study of Natural Disasters, 1977-1997, Some Reflections on a Changing Field of Knowledge," Disasters, 21, 4, (1997): 286-287.

${ }^{33}$ H. Lambourne, “Tsunami: Anatomy of a Disaster," $B B C$ News, 27 March 2005. Available from http://news.bbc.co.uk/1/hi/sci/tech/4381395.stm; A. Felsted et al., “An Ill Wind: Why the Rising Cost of Cover for Natural Disasters Will Alter an Industry," The Financial Times, 20 December 2005: 13.
} 
early-warning detection systems, retaining walls, levees, "earthquake-proof" structures and so forth.

Such human and economic costs seem to support the belief that the environment is in fact becoming more hazardous (to answer Burton et al.'s introductory question to their 1978 book, Environment as Hazard).${ }^{34}$ As Charles Darwin wrote in his later years, "a bad earthquake at once destroys our oldest associations: the earth, the very emblem of solidity, has moved beneath our feet like a thin crust over a fluid—one second of time has created in the mind a strange idea of insecurity, which hours of reflection would not have produced" (italics added for emphasis). ${ }^{35}$ By the turn of the twentieth century at least, the Earth had become a source of insecurity, no longer a stable and predictable provider of food, housing and economic livelihood. 'Nature,' it was believed, had turned against its ruler and was increasingly becoming a threat to humanity.

Based on such formulations of a rebellious environment, natural hazards can be seen as representing external attacks on 'helpless' human societies. In one of their earlier texts, Burton and Kates defined natural hazards as "those elements of the physical environment harmful to man [sic.] and caused by forces extraneous to him [sic.]," suggesting that blame can be apportioned to "the violent forces of nature" or "nature on the rampage. ${ }^{.36}$ Following the March 28, 2005 earthquake off the Indonesian coast, one BBC News correspondent wrote the following concerning a coastal community's fears:

\footnotetext{
${ }^{34}$ I. Burton et al., The Environment as Hazard, 1.

${ }^{35}$ K. Hewitt, Regions of Risk: A Geographical Introduction to Disasters, (Essex: Addison Wesley Longman Limited, 1997): 48.

${ }^{36}$ I. Burton and R. Kates, "The Perception of Natural Hazards in Resource Management," Natural Resources Journal, Vol. 3, (1964): 412-441 in M. Pelling, "Natural Disasters?" in Social Nature: Theory, Practice, and Politics, eds. N. Castree and B. Braun, (Oxford: Blackwell Publishers, 2001): 174; B. Wisner, P. Blaikie, T. Cannon and I. Davis, At Risk: Natural Hazards, People's Vulnerability and Disasters. 2nd ed., (New York: Routledge, 2004): 10.
} 
"despite their determination to rebuild, many of them still live in fear that the sea will once again turn against them." ${ }^{37}$

Still, others believe that it is not a natural actor that continues to threaten communities, but the invisible hand that directs the storms, slides and tremors-in other words, God. Burton et al. write that "an overwhelming majority of the people asked about hazard and disaster in their own localities view the occurrence as either unaccountable or as an act of nature or of God (or gods) or some other supernatural force. Rarely is it viewed as an act of people" (italics added for emphasis). ${ }^{38}$ Following a two-week long storm that flooded most of Los Angeles, one Los Angeles Times columnist joked, "there's no question that [we are] caught in the middle of something strange... maybe God, as the biblical sorts preach, is mad at us for making all those dirty movies. ${ }^{39}$ Also, the 2004 Indian Ocean tsunami inspired an outpouring of religious interpretations of the disaster, leading one writer to facetiously remark, "send a message to God: He has gone too far this time. ${ }^{.40}$ The point is that when it comes to natural disasters, human societies have tended to blame outside forces, whether it be 'nature' or some higher power, for the devastation wreaked on homes, public infrastructure, lands and human lives.

While 'nature' seems to have made its own statements against the human regime, human beings have done irrevocable violence to the planet. The litany of human-caused environmental ills is well-known to even the casual observer. Global warming, holes in the ozone layer, desertification, deforestation, loss of biodiversity, species extinctions,

\footnotetext{
${ }^{37}$ K. McGeown, "Tsunami-Hit Thais Live in Fear," BBC News, 29 March 2005. Available from http://news.bbc.co.uk/2/hi/asia-pacific/4389721.stm.

${ }^{38}$ I. Burton et al., The Environment as Hazard, 212.

${ }^{39}$ P. King, "The Latest 100-Year Disaster," The Los Angeles Times, 15 March 1995 in M. Davis, Ecology of Fear, 6.

${ }^{40}$ H. MacDonald, "Send a Message to God: He has Gone Too Far this Time," Slate Magazine, 10 January 2005. Available from http://www.slate.com.
} 
water pollution, air pollution, toxic waste and so forth are just a few of the many ways that 'advancing' human societies have disturbed the Earth and its processes. While admittedly most of these environmental problems were not deliberately caused by human beings, the evidence of their actions is unmistakable. According to the Worldwatch Institute, two-thirds of Caribbean coral reefs are currently threatened by over-fishing and pollution; up to 90 per cent of the water in the two rivers destined for the already shrinking Aral Sea is diverted for hydropower, irrigation and other human uses; toxic metals from discarded cellular phones threaten groundwater in large parts of India and Pakistan, two of the world's most densely populated countries; tropical rainforests continue to shrink at an alarming rate; and between 1990 and 2000, global carbon dioxide emissions rose by over 10 per cent. ${ }^{41}$ There is no question that the human species is wreaking havoc on the Earth's vital systems.

Although industrial practices began nearly two centuries ago, awareness of human-caused environmental degradation only became a widespread concern for the West in the post-World War II period. It was during this time that the negative sideeffects of economic development were finally felt in places like Los Angeles, where thick, yellow clouds took up permanent residence in the San Fernando Valley. Rachel Carson has been credited with being one of the first scientists to openly and successfully challenge the belief that chemicals were harmless and posed no long-term threat to life on Earth. ${ }^{42}$ But the evidence became increasingly undeniable given the increasing frequency

\footnotetext{
${ }^{41}$ L. Brown, "State of the World: A Year in Review," in State of the World 2005: A Worldwatch Institute Report on Progress Toward a Sustainable Society, ed. L. Starke, (New York: W.W. Norton and Company, 2005): xxiii-xxvii; World Resources Institute, International Energy Agency, United Nations Framework Convention on Climate Change, Climate and Atmosphere. 2005. Available from http://earthtrends.wri.org/pdf_library/data_tables/cli1_2005.pdf.

${ }^{42} \mathrm{G}$. MacDonald, "Environment."
} 
and severity of incidents like Love Canal and Bhopal, and soon the threatened 'environment' permanently entered Western political discourses. Furthermore, recent international conferences on climate change (Kyoto 1997), the environment and development (Rio 1992) and the ozone layer (Montreal 1987) have granted environmental problems a certain legitimacy in international politics.

The incredible speed and severity at which human beings have affected the planet has led some academics to suggest that we are living in a new geological era - the Anthropocene. According to the International Geosphere Biosphere Program, "humans now have the capacity to alter the Earth System in ways that threaten the very processes and components, both biotic and abiotic, upon which humans depend. ${ }^{, 43}$ While shrinking glaciers, artificial nitrogen "fixing," major river diversions and desertification would likely not have occurred without concerted inputs by the human species, what is more striking is that entire ecosystems and natural processes have been irrevocably changed by the human species. Human activities and technologies have grown such that their effects are felt at the planetary level. It is argued that such scales of analysis force us to consider that the Holocene period - the period between the end of the last ice age and the emergence of industrial society - has ended; we now live in the 'Anthropocene,' a term used to "denote the arrival of a new geological period when a dramatic new series of forces has been unleashed on the planetary biosphere, changing the atmosphere as well as

\footnotetext{
${ }^{43}$ International Geosphere Biosphere Program, "Global Change and the Earth System: A Planet Under Pressure," IGBP Science, No. 4 (2001) in S. Dalby, “Anthropocene Ethics: Rethinking 'the Political' after Environment," Conference Paper, Montreal: International Studies Association, March 2004.
} 
geomorphic processes and most natural cycles that involve a biomass of any substantial size." ${ }^{44}$

The notion of the Anthropocene is supported by arguments that humans are a leading cause of hazards and disasters. Due to the sheer scale, both in terms of energy and geography, and the number of factors that affect most hazards, assigning indisputable causality is still rarely possible; nevertheless, well-informed inferences can be made. Landslides and flooding for example have been known to be caused, or at least exacerbated, by massive deforestation and land-use changes. The annual flooding in Manila, Philippines has progressively worsened since the 1950s as upstream logging continues to deposit tonnes of silt into the area's riverbeds, hindering the river ecosystem's naturally ability to cope with rising water levels. ${ }^{45}$ Similarly, widespread mangrove deforestation, primarily for aquaculture and fuel, in South Asia hindered the coasts' natural ability to withstand the 2005 Indian Ocean tsunami's formidable waves mangroves provide a strong physical barrier and can efficiently absorb and divert incredible volumes of water. ${ }^{46}$ Assigning human causality to hurricanes, tornados and other atmospheric hazards, on the other hand, becomes more difficult given the incredible complexity of global climate systems that must account for wind, sea and air temperatures, ocean currents and so forth. Most climate experts agree that climate change is in part due to human activities and that this may lead to an increase in the frequency of extreme weather events. The uncertainty lies in to what extent these atmospheric changes

\footnotetext{
${ }^{44}$ S. Dalby, "Environmental Security: Ecology or International Relations?" in International Ecopolitical Theory: Critical Approaches, eds. P. Stoett and E. Laferrière, (Vancouver: University of British Columbia Press, 2006): 21.

${ }^{45}$ G. Bankoff, "Constructing Vulnerability: The Historical, Natural and Social Generation of Flooding in Metropolitan Manila," Disasters, 27, 3, (2003): 224-238.

${ }^{46}$ J. Kremmer, "A Natural Low-Tech Solution to Tsunamis: Mangroves," The Christian Science Monitor, 10 January 2005. Available from http://www.csmonitor.com/2005/01 10/p07s01-wosc.html.
} 
are human-induced and/or attributed to the Earth's natural cycles and to what extent natural hazards are in fact linked to global warming. ${ }^{47}$ What is certain is that humans are not entirely blameless regarding the causes of natural hazards.

\section{UNDERSTANDING HAZARDS}

The relationship between humans and 'nature,' particularly natural hazards, has undergone a significant change in the last century. The ontological separation of the human and non-human worlds has allowed societies to develop convenient conceptualizations of 'environment' that are based on specific historical contexts. For example, the European continent enjoyed relatively stable environmental conditions for much of the sixteenth through nineteenth centuries, which likely nurtured the belief that 'nature' was rational and could therefore be understood and controlled in its entirety. It was accepted that the natural world would offer up its bounty in order to provide for human socioeconomic security. Similarly, from nature's standpoint, humans were one of many species that relied on its flora, fauna, land and water to survive. The arrangement worked from both directions.

But as the scale of activity grew beyond Europe and North America and as the Earth's population and technological capacity ballooned in the twentieth century, a different formulation of 'nature' emerged. The natural world is no longer viewed simply as a milieu in which humans operate; rather, 'environment' has been recast as an actor with its own intentions and actions. Much of the early hazards literature and popular media reports have constructed a vengeful and dangerous environment that seeks to

\footnotetext{
${ }^{47}$ R. White, D. Etkin. "Climate Change, Extreme Events and the Canadian Insurance Industry," Natural Hazards, 16, (1997): 135-163.
} 
punish and arbitrarily disrupt human societies, while some environmental security analysts have posed the environment as a cause of violent conflict. ${ }^{48}$ The Earth's natural systems have thus been redefined as a threat to homes, businesses, political stability and social systems. In other words, 'nature' has become a source of insecurity. Likewise, the Earth has suffered greatly at the hands of industrialization and economic development; the human species has left its mark on virtually every ecosystem on the planet, altering the biological and geological processes that have remained constant for thousands of years.

Since hazards are a problem 'out there,' interactions with hazards, particularly the act of securing against them, often requires an accompanying institution that controls, or at least supervises, how communities react to hazards. The goal of the following chapters is to interrogate the ways in which human societies have responded to natural hazards through two major institutions.

${ }^{48}$ See M. Klare, Resource Wars: The New Landscape of Global Conflict, (Metropolitan Books: New York, 2001). 


\section{Chapter 3-Hazards and disasters security and the State}

Taken in its broadest context, 'security' has long been a central goal for human societies, that is (to borrow Barnett's definition) the maintenance of peace and justice. But as Simon Dalby writes, security is "frequently a violent practice." ${ }^{1}$ For example, the current American-led 'War on Terror' has used military invasions in Afghanistan and Iraq as a supposed means to reduce the harm posed by the asymmetric threats of global terrorism on citizens in the West. Security thus assumes that the world, to varying extents, is an unpredictable and uncertain place that, in the Western context at least, requires organizations and strategies whose goal is to regain and/or maintain control, usually by force. As discussed in the previous chapter, natural hazards represent docile nature's dark side which threatens to destabilize innocent human societies. Therefore, natural hazards are defined as a security threat precisely because they are synonymous with a lack of control, uncertainty and unpredictability in what should be a certain world.

This chapter will analyse and evaluate the role that states play in providing security against natural hazards. States remain the default guarantors of security, a position that has not been adequately problematized in modern practice. Despite facing new 'global dangers,' states continue to rely on Cold War approaches to insecurity where responses to natural hazards and disasters tend to be highly dichotomous, structured and militaristic in nature. A brief analysis of New Orleans' experience in the summer of 2005 will demonstrate how state actions before and after Hurricane Katrina actually exacerbated disaster in the city. The case study will also suggest that engineeringintensive solutions to hazards, while technologically impressive and effective at absorbing some hazards, are not always capable of preventing 'worst-case-scenario'

\footnotetext{
'S. Dalby, Environmental Security, (Minneapolis: University of Minnesota Press, 2002): 163.
} 
disasters, nor do they move beyond an untenable ontology that pits humans versus nature. A short section discussing the 'natural disaster syndrome' will briefly examine the role that state-funded disaster relief programs have in reducing an individual's incentive to take loss-prevention measures. Finally, this chapter will argue that a geographical mismatch exists between natural hazards and state institutions. Although natural hazards have vague geographies that do not adhere to geopolitical boundaries, we continue to turn to the rigid parameters that define state politics to provide security against such imprecise threats. The goals of this chapter are thus to challenge why states are seen as the default guarantors of security against a new age of global dangers and to evaluate the effectiveness of state actions in preventing and/or mitigating the effects of natural hazards and disasters.

\section{GLOBAL DANGERS: NEW THREATS, OLD RESPONSES}

The Realist definition of 'security' was popularized during the Cold War, in both scholarship and practice, and shaped current institutional responses to what were, and still are, deemed by those in power to be threats. The decades-long conflict between the United States and the Soviet Union provided a convenient backdrop against which scholars and politicians could mould a new geopolitical framework for the international order. The war was defined by two distinct powers with their own political, economic, social and religious systems that competed for dominance in a world that was rebuilding from two devastating wars. Moreover, previously formidable nations - notably England, Germany, France and Japan - were in no position to contest these rising superpowers. Security was thus measured in military terms, as seen by the arms and space races that 
the Soviet Union and the United States engaged in for much of the Cold War. By 1985, the United States and the Soviet Union had just over 20,000 nuclear warheads combined, an astonishing figure in its own right but especially frightening given that each superpower required only 200 to 300 in order to completely annihilate the other. ${ }^{2}$ It would seem that the reason for such excess was based on the belief that one nation's level of security was directly proportional to military might.

In addition to being violent, Cold War discourses used spatial metaphors to define security. Dalby argues that throughout the Cold War "security was a matter of "keeping the bad guys out" by the threat of the use of force."3 Security was, and still is, understood through a demarcation of safe 'insides' and dangerous 'outsides.' David Campbell writes that, "the ability to represent things as alien, subversive, dirty or sick has been pivotal to the articulation of danger in the [Western] experience." ${ }^{44}$ Security relies on the production of such an external danger which threatens an internal victim; the act of securing, therefore, requires protecting the 'good' inside against the danger posed by the 'bad' outside. ${ }^{5}$ In the case of the Cold War, security was achieved through arms production and sabre rattling. With thousands of nuclear missiles literally pointed at each other, it is thus not surprising that security was defined in such spatially dichotomous and violent terms.

\footnotetext{
${ }^{2}$ W. McWilliams and H. Piotrowski, The World Since 1945: A History of International Relations, (Boulder: Lynne Rienner Publishers, 1997): 569.

${ }^{3}$ S. Dalby, Environmental Security, 5.

${ }^{4}$ D. Campbell, Writing Security: United Sates Foreign Policy and the Politics of Identity, 2nd Ed, (Minneapolis: University of Minnesota Press, 1998): 3.

5 It is important to recognize that this brief discussion only presents one particular viewpoint of how security is defined and what the act of securing entails - discussions of collective security and democratic peace theory, for example, do not always assume such dichotomous conceptual frameworks nor do they take for granted that security is violent. However, when considering what 'mainstream' security studies experts and politicians believed and practiced for much of the $20^{\text {th }}$ century, it is impossible to ignore this particular view of security. The Realist approach to international politics irrevocably shaped government institutions and their responses to what were understood as security dilemmas. Interrogating the validity of the dominant approach to security is simply not within the scope of this thesis.
} 
The end of the Cold War, however, failed to challenge the modern imagination of security and how it was, and still is, to be achieved. The power of this violent and dichotomous discourse extends well beyond mere policies, political rhetoric and scholarship, as entire economies and systems of governance have been built around the production of enemies and forceful responses. Many of the world's largest corporations IBM, General Motors, Boeing, Exxon-Mobil - owe much of their great wealth to wars and still dedicate a good portion of their production capacity and research and development for military purposes; furthermore, it is no secret that such businesses benefit greatly from military operations as combat increases demand for weapons, technology and transportation. The 'insecurity' caused by the September 11, 2001 attacks led to a 41 per cent increase in US military spending from 2001 to 2005, suggesting that military force still represents the best way to combat terrorism. ${ }^{6}$ Even a cursory look at the naming of major government institutions - such as Homeland Security in the United States and National Defence in Canada - points to the continued relevance of the Realist conception of security in national politics. Finally, political rhetoric has changed little since the end of the Cold War. Recent 'wars' waged on drugs, terrorism and even obesity point to the greater legitimacy that is afforded to a problem when it is posed as an organized military confrontation, suggesting that perhaps climate change needs a 'war on greenhouse gases.' President Bush's famous "with us or against us" speech in November 2001, for example, framed international terrorism in Cold War terms as he stated, "[Osama Bin Laden] is an evil man that we're dealing with, and I wouldn't put it past him

\footnotetext{
${ }^{6}$ Office of the Assistant Secretary of Defense (Public Affairs), "Fiscal 2006 Department of Defense Budget is Released," U.S. Department of Defense. 7 February 2005. Available from http://www.defenselink.mil/releases/2005/nr20050207-2066.html.
} 
to develop evil weapons to try to harm civilization as we know it. And that's why we must prevail, and that's why we must win."7

While admittedly this brief discussion provides only a sampling of the types of responses and institutions that continue to adhere to Realist thinking, the point is that the identification of an external, evil enemy and the privileging of a military, state-organized response to that threat still remains paramount in the articulation of danger and security in the current Western context. Despite its having ended nearly 20 years ago, little has changed since the Cold War with regard to the institutions and discourses that are charged with responding to insecurity.

While Cold War security discourses remain dominant even today, it is obvious that the geography of the enemy to which all this energy, time and expertise is dedicated has dramatically changed. The threats posed by 'rogue' nations such as Iraq, Iran and North Korea in the last decade are simply not on the same scale as those by the former Soviet Union: not since 1989 has the United States had a clearly identifiable state enemy whose military and economic powers threaten to destabilize Western (and what are typically Realist) notions of security. Climate change, ozone holes, global terrorism, the international drug trade and ethnic nationalism all represent a new kind of threat that Cold War security frameworks continue to grapple with.

What is common here is that these 'global dangers' possess blurred geographies: they are in almost all cases not state-sanctioned; they originate in various places around the world; they are asymmetric in that they destabilize security through unorganized and

\footnotetext{
${ }^{7}$ CNN, "You are Either With Us or Against Us," CNN.com. 6 November 2001. Available from http://archives.cnn.com/2001/US/11/06/gen.attack.on.terror/.
} 
imprecise means; and they are often caused by a multitude of factors. ${ }^{8}$ Unlike during the Cold War, where the enemy was clearly demarcated by political boundaries and followed the 'rules' of international combat (for example, the Geneva Conventions), these postmodern 'deterritorialized threats' are "only sometimes mapped, but are always understood as threats out there somewhere that threaten our well being in the supposed safe domestic spaces of our lives and communities." ${ }^{\prime 9}$ The point is that while the discursive framing of threat remains unchanged from Cold War logics, the geography of the enemy and the origin of security threats are no longer clearly identifiable. In other words, it is the specific geography of the threat, or the lack thereof, that makes global dangers dangerous.

\section{ENVIRONMENTAL SECURITY AND THE STATE}

As already discussed in the previous chapter, natural hazards represent a source of insecurity for human societies; they are one of many global dangers that threaten national security in the post-Cold War world. Not surprisingly, national security discourses have adopted natural hazards, and more generally the environment, as a source of insecurity in the last decade and a half. Such inquiries have led to the growth of an area of study that is more generally known as 'environmental security.' For most of the 1990s, the environment acted as a convenient threat to which Cold War analytics and responses could be unproblematically applied; the Soviet Empire was replaced by natural hazards and resource shortages. Robert Kaplan's 1994 article, "The Coming Anarchy," poses "the environment as a hostile power" and unequivocally states that the new global threat is

\footnotetext{
${ }^{8}$ S. Dalby, "Introduction to Part Four: The Geopolitics of Global Dangers," in The Geopolitics Reader, eds. G. Ó Tuathail, S. Dalby and P. Routledge, 2nd ed., (New York: Routledge, 2006): 177-187.

${ }^{9}$ Ibid., 183.
} 
"nature unchecked." Kaplan ominously refers to 'the environment' as "the national security issue of the early twenty-first century." ${ }^{, 10}$ While Kaplan's doomsday claims have been discredited by numerous studies, such as those led by Thomas Homer-Dixon, it is important to credit Kaplan for transplanting environmental issues into the 'high politics' of security studies in the 1990s. Other academics, analysts and political figures including Gareth Porter, Michael Klare and Jessica Tuchman Matthews - joined a growing group of voices who believed that the world was being threatened by environmental degradation and resource scarcities and that states needed to mobilize to protect their citizens against future insecurity. ${ }^{11}$

The idea that states provide security against external threats is not new. In fact, the history of this concept extends as far back as 1648 , when the Treaty of Westphalia set in place a system that divided the world into the spatial blocs that we call states. John Agnew refers to the post-Westphalian world as the Modern Geopolitical Imagination (MGI), which is "a system of visualizing the world" based on the European-American experience. ${ }^{12} \mathrm{O}$ Tuathail argues that the MGI is "a powerful discourse of power that seeks to interpret world politics within territorial, nation-state and strategic categories."13 The MGI is a way of viewing the world which 'sacralizes' the nation-state as the ultimate spatial-political organization. ${ }^{14}$ In the case of security, the state functions as "the

\footnotetext{
${ }^{10}$ R. Kaplan, "The Coming Anarchy," Atlantic Monthly, 273, 2, (1994): 54 and 58 respectively.

${ }^{11}$ See G. Porter, "Environmental Security as a National Security Issue," Current History, 94, no. 592, (May 1995); M. Klare, Resource Wars: The New Landscape of Global Conflict, (Metropolitan Books: New York, 2001); J.T. Matthews, "The Environment and International Security," in World Security: Challenges for a New Century, eds. M.T. Klare and D.C. Thomas, (New York: St. Martin's Press, 1994): 274-289.

${ }^{12}$ J. Agnew, Geopolitics: Re-Visioning World Politics, 2nd Ed., (New York: Routledge, 2003): 2.

${ }^{13}$ G. Ó Tuathail, "De-Territorialised Threats and Global Dangers: Geopolitics and Risk Society," Geopolitics, Vol. 3, No. 1, (Summer 1998): 18.

${ }^{14} \mathrm{~J}$. Agnew, Geopolitics.
} 
inevitable and sole provider[s] of security arrangements for humanity." 15 Just as the state was responsible for responding to the threats posed by Nazi Germany, the Soviet Union and Iraq, current governments are seen as the default guarantors for security threats posed by global dangers.

Since natural hazards have been established as national security threats, then according to the dominant geopolitical discourse, only states may respond to eliminating, or at least reducing, the threat. In the United States, institutions such as the Federal Emergency Management Agency (FEMA), which operates under the authority of the Department of Homeland Security, and the National Flood Insurance Program (NFIP) have been established to supposedly present a unified and integrated front against natural hazards and disasters. Also, governments have funded massive infrastructure projects to help reduce disruptions to and destruction of infrastructure. These institutions have been largely responsible for reducing the threats to citizens posed by extreme weather events and other hazards. The success of these institutions and projects is debatable and will be discussed later in the chapter. What is important here is to recognize the geographical scale of the responses to natural hazards. It is the state that is ultimately responsible for offering security against tornadoes, drought, flooding, landslides and so forth.

In addition to deciding who is entitled and has the capacity to respond to security threats, Cold War logics have dictated how states react to natural hazards and other global dangers. During the Cold War, it was believed that problems could be controlled by established institutions with the application of instrumental rationality. ${ }^{16}$ State responses to environmental problems have been quite similar as nation-states insist on

\footnotetext{
${ }^{15}$ Simon Dalby, "Security, Modernity, Ecology: The Dilemmas of Post-Cold War Security Discourse." Alternatives 17, (1992): 102.

${ }^{16}$ G. Ó Tuathail, "De-Territorialised Threats," 28.
} 
'taming' nature through river diversions and massive irrigation projects. Most disaster mitigation strategies involve highly sophisticated (and expensive) early-warning detection and monitoring systems through satellites and web-based communications. ${ }^{17}$ Following the 2004 Boxing Day Tsunami, Kofi Annan declared that, "prevention and early warning systems must become a priority." In addition, the Indian government unveiled plans to invest nearly $\$ 30$ million in a highly sophisticated tsunami monitoring system. ${ }^{18}$ In other instances, public and private funds in addition to human resources have gone into administrative bodies, large-scale construction projects, observation centres and so forth, responses that are not entirely dissimilar to the United States' troubled 'War on Terror.'

Hazards are predominantly seen as specialized problems for scientists and engineers, which in effect quarantines disasters in both thought and practice. ${ }^{19}$ Burton et al. write, "the prevailing public approach [to disasters] has been to offer immediate relief and then to turn to the technological approach." ${ }^{20}$ Such responses show a preference for technological solutions, a preference that is evident in various international agreements. A 1972 UN Stockholm Conference report stated that "it is believed that not only do the causes of such disasters fall within the province of science and technology, but also, in some cases their prevention, as well as the organizational arrangements made for forecasting them and reducing their impact when they occur." At the same conference, the UN Advisory Committee on the Application of Science and Technology to Development recommended that "technological research be undertaken or fostered to

\footnotetext{
${ }^{17}$ D. Alexander, "The Study of Natural Disasters, 1977-1997, Some Reflections on a Changing Field of Knowledge," Disasters, 21, 4, (1997): 286-287.

${ }^{18}$ D. Adam, "Leaders Say Warning System is Priority," The Guardian, 7 January 2005.

${ }^{19}$ G. Bankoff, "Rendering the World Unsafe."

${ }^{20}$ I. Burton et al., The Environment as Hazard, 213.
} 
ensure a better protection against the effects of natural disaster." ${ }^{21}$ More recently, the agenda for the 1990s International Decade of Natural Disaster Reduction (IDNDR) was committed primarily to sharing existing knowledge in developed countries and deploying advanced sciences, training and technology transfer for other nations. ${ }^{22}$ Such views have changed little as it would seem that the international community continues to believe that science and technology are the panaceas for natural disasters prevention.

Security against natural hazards and disasters is best understood as being achieved through improving scientific prediction, engineering preparedness and administrative management. Such an approach is consistent with the previous chapter's discussion concerning the social construction of 'nature' as an entity that operates independently of human actions. Like a series of gears, pulleys and levers, it is believed that natural hazards follow scientific rules and can therefore be studied and analysed through observation and hypothesis-testing. By unproblematically applying the tenets of the scientific method to the environment, it is assumed that hazards behave both logically and predictably. And so, "attributing disasters to natural forces, representing them as a departure from a state of normalcy to which a society returns to on recovery, denies the wider historical and social dimensions of hazard and focuses attention largely on technocratic solutions."23

Such modes of thinking provide a false sense of security that suggests that societies can ameliorate or avoid disasters through appropriate technologies, which often neglects more fundamental issues, such as why certain groups are more vulnerable to

\footnotetext{
21 Ibid., 213.

${ }^{22}$ K. Hewitt, Regions of Risk: A Geographical Introduction to Disasters, (Essex: Addison Wesley Longman Limited, 1997).

${ }^{23}$ G. Bankoff, "Rendering the World Unsafe," 24.
} 
natural hazards than others. Furthermore, similar to traditional militaristic notions of security, the techno-centric approach to hazards poses the act of securing as being a reactionary, defensive measure where technology offers security against an external threat. What is also forgotten is that science constantly improves upon past conclusions as new theories refute previous claims to 'truth.' New knowledge can turn what are seemingly innocuous activities into hazards overnight, such as smoking cigarettes or burning hydrocarbons for fuel. Technology and science do not have a defined endpoint; progress demands that conclusions undergo frequent questioning. In cases where populations rely on 'expert' opinions, it is important to remember that "no one is an expert - particularly not the experts." 24

The act of securing assumes that "internal secure spaces [can be] kept separate from external threats by surveillance and technological acumen." ${ }^{, 25}$ Just as nation A invests vast sums of money and expertise into surveillance, research and weaponry in order to protect itself against nation $\mathrm{B}$, the overriding response to natural hazards has been to invest human, institutional and financial capital into technological 'solutions.' In the latter case, the environment is seen as a source of insecurity, which necessitates the purchase and development of technologies that protect good 'insides' from evil 'outsides.' It seems then that the dichotomous and militaristic Cold War security logics have reinvented themselves within the natural hazards debates.

\footnotetext{
${ }^{24}$ U. Beck, "From Industrial Society to the Risk Society: Questions of Survival, Social Structure and Ecological Enlightenment," Theory, Culture \& Society, Vol. 9, (1992): 106.

${ }^{25}$ S. Dalby, Environmental Security, 163-4.
} 


\section{CONSTRUCTING VULNERABILITY: 'ENLIGHTENED' SCIENCE}

Ulrich Beck's view of 'Risk Society' maintains that industrial society's successes (e.g. its institutions, knowledges, technologies and productive processes) have created the present era's risks on a massive scale (e.g. global warming, nuclear catastrophe and natural disasters). ${ }^{26}$ In the pre-industrial period, hazards were seen as 'strokes of fate,' attributable to a mystic 'other' - gods, demons or Nature. But in the present risk society, hazards and insecurities seem to have a normalized birth in the centres of rationality with the blessings of the guarantors of law and order. ${ }^{27}$ Echoing arguments made by Wisner et al., Beck argues that disasters differ from hazards in that disasters are caused by the social, political and economic environments of a society; there is no 'other' to which blame can be assigned to as disasters are decidedly an inside job. Hurricane Katrina demonstrated that the disaster was, in many ways, a state-sanctioned event where concerted decisions related to poverty and urban planning allowed the events to unfold as they did.

On August 29, 2005, Hurricane Katrina made landfall just east of New Orleans, Louisiana enabling what Karen Bakker calls, "the largest 'natural disaster' to ever occur in the continental United States. ${ }^{\not 28}$ Just hours before, Katrina had reached category 5 status, punctuating what was already an unusually busy hurricane season that affected no fewer than four countries. The aftermath of Hurricane Katrina saw thousands displaced, dead and homeless in the New Orleans area alone. What is striking about Katrina was not the severity of the storm itself; instead, it was the government's complete lack of action

\footnotetext{
${ }^{26}$ R. Ericson et al., Insurance as Governance, Toronto: University of Toronto Press, 2003.

${ }^{27}$ U. Beck, "From Industrial Society to the Risk Society," 98.

${ }^{28}$ K. Bakker, "Katrina: the Public Transcript of 'Disaster," Environment and Planning D: Society and Space, 23, (2005), 795.
} 
and political will to mitigate the 'disasterness' of the hurricane. Rain, winds and waves did not directly cause the majority of the destruction and death that continues to afflict New Orleans years later. Echoing arguments made by Wisner et al. over a decade ago, Karen Bakker, Bruce Braun and others have suggested that the city's vulnerability and susceptibility to natural hazards was built into the human-made environment; a disaster like Katrina was simply a matter of time. To understand why the events unfolded as they did after August 29,2005, it is necessary to look at the history and geography of the region. It is clear that the state failed to secure its citizens against the hurricane both before and after the event.

New Orleans sits at the mouth of the Mississippi River along the Gulf of Mexico. Located in what was once a coastal wetland, much of New Orleans sits in a bowl below sea level, surrounded by the Mississippi River and lakes Pontchartrain, Borgne, Cataouatche and Salvador. ${ }^{29}$ Amazingly, it is one of the few cities in the world where one must look up in order to see bodies of water. Due to its position in a natural delta and its proximity to warm currents in the Atlantic Ocean, the region is prone to seasonal flooding and tropical storms. Common sense would normally dissuade people from settling in the area, but economic opportunities ultimately won out when the French founded New Orleans in 1718 . The city provides access to the Gulf of Mexico and the Mississippi River basin, which provides access to nearly 40 per cent of the continental United States. New Orleans' ports are vital to the American oil and gas industry and agriculture. In spite of the potentially disastrous topography, hydrology and climate of the region, approximately one million people insist (or did so in 2005) on calling New

\footnotetext{
${ }^{29}$ G. Brouwer, "The Creeping Storm," Civil Engineering, Vol. 73, No. 6, (June 2003): 46-88.
} 
Orleans home. As historian Ari Kelman writes, "the city is a misguided urban project, a fool's errand, a disaster waiting to happen."30

New Orleans' leaders have long turned to technology to impose order on its environs. The city's reliance on massive engineering projects led one observer to remark, "New Orleans is utterly dependent for its survival on engineered landscapes and the wilful suspension of disbelief that technology has allowed its citizens to sustain." Massive pumping stations and levees have been constructed in the city since its founding to allow settlement below sea level. The irony of course is that the higher the levees are built, the greater the severity and catastrophic power of flooding when they eventually overtop the barriers, which also puts greater strain on the city's pumping stations. To make matters worse, the city has been sinking for decades: the draining of wetlands for urban sprawl has exposed the area's alluvial soils which have a tendency to compact. ${ }^{32}$ Normally silt flowing down the Mississippi River would accumulate in the Delta and keep New Orleans from sinking; however, since the early 1900s, lawmakers have approved projects to straighten the river in order to ease levee construction and to provide easier passage for ships. Instead of shoring up a sinking city, the silt is then carried straight out to sea. ${ }^{33}$

New Orleans' problems have also been accelerated by the disappearance of coastal wetlands, which act as a natural buffer between human settlements and storms, helping to absorb severe wind, rain and waves from tropical storms. Coastal wetlands in

\footnotetext{
${ }^{30}$ A. Kelman, "City of Nature: New Orleans' blessing; New Orleans' curse," Slate Magazine. 31 August 2006. Available from http://www.slate.com/id/2125346/.

31 Ibid.

${ }^{32}$ Bakker, "Katrina."

${ }^{33}$ J. Eilpern, "Shrinking Louisiana Coastline Contributes to Flooding," The Washington Post, 30 August 2005, A07.
} 
Louisiana have been disappearing at a rate of approximately $100 \mathrm{~km}^{2}$ of land per year. Since the 1930s, the state has seen its coastal wetlands shrink by one million acres. The combination of a straighter Mississippi River and disappearing wetlands has "opened up what some term as a 'hurricane highway' into the city, through which storm surges can be channelled and amplified." ${ }^{34}$ What is of note is that the destruction of wetlands and reengineering of the Mississippi were all sanctioned by the federal government through the US Army Corps of Engineers. ${ }^{35}$ While the projects were conceived and undertaken with the region's best interests in mind, the consequences have been far from benign. Moreover, these projects revealed the ontological underpinnings of the human-nature relationship that guided state actions, mainly that nature could be brought under human control. It seems that the reliance on science and technology, while effective for a few decades, was ultimately unable to provide security against a natural disaster.

In the aftermath of Katrina it was discovered that much of what happened in New Orleans had been predicted years before with a high degree of precision. Despite possessing this information, the municipal, state and federal governments did little to prevent the disaster, instead relying on luck, decades-old technology and human ingenuity to address the city's problems. A June 2003 article in Civil Engineering, for example, notes that the levees and pumping stations in New Orleans can only withstand a fast-moving category 3 hurricane; improving the infrastructure to handle a category 4 or 5 storm would take 30 years to complete. ${ }^{36}$ Unfortunately, most of these warnings went unnoticed as more pressing issues - such as tax cuts and the 'War on Terror' - trumped investment in flood control measures.

\footnotetext{
${ }^{34}$ K. Bakker, "Katrina," 796.

${ }^{35}$ G. Brouwer, "The Creeping Storm."

${ }^{36} \mathrm{Ibid}, 47$ and 52 respectively.
} 
What Katrina ultimately revealed was how ill-prepared governments, at all levels, were at providing security against the hurricane and, most importantly, its after-effects. The media images and reports were frightening: thousands of poor, black people huddled in the New Orleans Convention Centre and the ironically-named 'Superdome' without adequate food, water or medical supplies. Predictably, the government responded by deploying teams of engineers and the National Guard to the region, while soldiers patrolled the flooded streets charged with the task of protecting infrastructure, rather than people, on 'shoot-to-kill' orders. With the majority of able-bodied soldiers fighting terrorism in Iraq, the government was also forced to hire private security agents armed with M-16s from Blackwater, "a professional military, law enforcement, security, peacekeeping and stability operations firm who provides turnkey solutions. ${ }^{, 37}$ In another striking image, US military helicopters dropped dozens of massive sandbags into breeches along the levees, hoping to shore up the compromised barriers; however, television coverage showed the futility of the efforts as these giant sandbags literally disappeared into the floodwaters. It seemed then that in a time of great insecurity caused by a natural hazard, the state reverted to an automatic response - deploy the military which did little to improve security in New Orleans.

Much of the political rhetoric following Hurricane Katrina focussed on fingerpointing and scapegoating as different levels of government refused to take responsibility for what was ultimate a systemic failure of governance and common sense. Mayor Ray Nagin, Louisiana Governor Kathleen Blanco, FEMA director Mike Brown, Secretary of the Department of Homeland Security Michael Chertoff and the Bush Administration all,

\footnotetext{
${ }^{37}$ B. Braun, "Hurricane Katrina and Abandoned Being," Environment and Planning D: Society and Space, 23, (2005), 803; Blackwater USA, “About Us," 2005. Accessed 12 August 2006. Available from http://www.blackwaterusa.com/about/.
} 
at various times, blamed a different level of government for the failure to initiate an effective emergency response. Media reports were also very critical of the various leaders. Commentators from the religious right blamed everybody from the Bush Administration to the city's citizens suggesting that Katrina was "God's judgement for sins as diverse as the US government's sanction of Gaza's evacuation and New Orleans' 'decadent night life." ${ }^{38}$ But as Bakker argues, "much of this 'blame game' has been focussed on the red herring of individual incompetence, distracting debate from a more fundamental set of questions about the role of the state, and of markets, in producing 'natural disasters." 39

Hurricane Katrina unveiled broader questions concerning hazards and disasters security in North America. Some academics, for instance, have attributed Katrina's unusual strength - and the unusually active 2005 hurricane season in general - to global climate change; if true, this theory "is a tragically ironic example of Louisiana's oil economy coming full political ecological circle" and puts into question the wider effects of energy intensive economies in the West. Bakker argues that "few of the debates over responses to Katrina have questioned the appropriateness of the engineering-intensive solutions by the US Army Corps of Engineers and the wider project of converting rivers into damned, diked and diverted drainpipes. ${ }^{\circ 40}$ Finally, Hurricane Katrina revealed that the state had abandoned an entire segment of its population. The government abandoned many poor, black citizens through inaction, by not providing an effective emergency response plan that provided food, water and shelter for those displaced by the flooding. In addition, concerted state action pushed displaced citizens even further to the outskirts of

\footnotetext{
${ }^{38}$ K. Bakker, "Katrina," 798.

${ }^{39}$ Ibid., 798.

${ }^{40}$ Ibid., 796 and 799 respectively.
} 
society as the eventual response was highly militaristic and violent in nature, more concerned with protecting businesses than helping people. Perhaps recognizing the inability of the government's organizations to effectively deliver aid to the region, President Bush urged people to donate money and supplies to "the armies of compassion," including the Red Cross, the Salvation Army and the Catholic Charities. ${ }^{41}$ Thus, "the failure of the state, and of much of society, to successfully undertake such a project in New Orleans is precisely what was laid bare by Katrina., ${ }^{, 42}$

The point of this brief case study is to demonstrate the many deficiencies of the techno-centric and militaristic state approach to natural hazards and disasters. First of all, the environment does not always behave 'rationally' and does not necessarily follow given patterns - hurricanes, for example, do not follow pre-ordained yearly schedules. State strategies tend to be rigid and thus require a high degree of warning and planning, things that are not always available. Secondly, technological approaches are often costly and require a great deal of long-term expenditures on maintenance and staff, financial resources that only a handful of governments and organizations worldwide possess. Furthermore, technologies cannot always prevent hazards from becoming disasters and often exacerbate the conditions that lead to disaster. Writing in the early 1990s, Ulrich Beck warned against the problems that would certainly arise in such manufactured landscapes as New Orleans; he writes, "this monopoly of scientists and engineers in the diagnosis of hazards, however, is simultaneously being called into question by the 'reality crisis' of the natural and engineering sciences in their dealings with the hazards they

\footnotetext{
${ }^{41}$ M. Rothschild, "Katrina Compounded," The Progressive, 2 September 2005. Available from http://www.commondreams.org/cgi-bin/print.cgi?file=/views05/0902-26.htm.

${ }^{42}$ B. Braun, "Hurricane Katrina," 805.
} 
produce... [S]afety and probable safety, seemingly so close, are worlds apart." ${ }^{\text {"43 }}$ Third, New Orleans' experience demonstrated the predictability of state behaviour when dealing with security threats; states will attempt to engineer their way through hazards threats and, when that fails, they will respond to hazards and disasters with their military institutions. Finally, current methods fail to address the complex social contexts that enable hazards to become disasters - poverty and private property rights are just two examples. Separating 'natural' disasters from the social frameworks that influence how hazards affect people places too much attention on the 'natural' on not enough on the social environment. ${ }^{44}$

The flooding in New Orleans pointed out a glaring contradiction: even in the world's wealthiest nation, which possesses sophisticated technical capabilities and is blessed with a relatively stable climate and robust economic system, disasters still occur. But it is important to remember that New Orleans was, and still is, an anomalous event. These types of disasters do not occur on a regular basis in the developed world; such catastrophic infrastructural failures and state incompetence are the exception rather than the rule. Moreover, it is important to remember that the death toll in New Orleans was just over 1,000 , which is serious but unremarkable in disaster terms, especially when considering casualty numbers in Third World disasters - the 2004 Tsunami, for instance, claimed nearly 300,000 lives. $^{45}$

To some extent, New Orleans averted what could have been a potentially worse natural disaster. If a similar disaster had occurred in Dhaka, Bangladesh - a city with

\footnotetext{
${ }^{43}$ U. Beck, "From Industrial Society to the Risk Society," 107.

${ }^{44}$ B. Wisner et al. At Risk.

${ }^{45}$ D. Crossley, "10 'Worst' Natural Disasters," Department of Earth and Atmospheric Sciences, St. Louis University. 18 October 2005. Available from http://www.eas.slu.edu/hazards.html.
} 
poor infrastructure and emergency response services - casualties would have likely numbered in the tens of thousands. On the other hand, if New Orleans was in Japan, it is possible that the dikes would have been built to withstand a category 5 hurricane leading to a much smaller death toll. Despite very high population densities, strict building code regulations and access to skilled labourers and high-quality building materials in Japan have kept casualties to a minimum in disaster situations. In Hokkaido, only one person died in a massive 8.0 magnitude earthquake on 25 September 2003, whereas nearly 20,000 people lost their lives in a 7.4 magnitude earthquake in Kocaeli-Gölcük, Turkey four years prior. ${ }^{46}$ Closer to home, the Red River Floodway in Manitoba, which was built in the 1950 s, has secured savings 20 -fold greater than the initial investment of CDN $\$ 60$ million and has generally done its part to protect Winnipeg against almost annual flooding. ${ }^{47}$ States therefore have the capacity and power to influence the "disasterness" of disasters through their ability to control building regulations, infrastructure projects and emergency response measures. The only problem is that states do not always possess the funds or the political foresight to implement such changes.

These cases certainly raise the question of just how unique New Orleans actually is, especially when considering the unique circumstances and geography of the region. While New Orleans' experience was certainly rare, it is not a stretch to suggest that these types of incidents will in fact become more common in the future. Many cities in the developing world for instance are plagued by numerous factors that increase the amount of damage caused by hazards: uncontrolled urbanization, the expansion of slums or

\footnotetext{
${ }^{46}$ B. Sengezer and E. Koç, "A Critical Analysis of Earthquakes and Urban Planning in Turkey," Disasters, 2005, 29(2): 188 .

${ }^{47}$ Insurance Bureau of Canada, A National Mitigation Strategy: Protecting Canadians from Severe Weather and Earthquakes, (Toronto: Insurance Bureau of Canada, April 1999): 5.
} 
ghettos, poor design and building techniques, lack of enforcement of land use regulations and construction processes, lack of qualified technical personnel, corruption and financial constraints that limit the capacity to upgrade existing infrastructure. For example, ninetytwo per cent of Turkey's landmass faces the threat of an earthquake, which encompasses the nation's largest and most industrialized cities: Bursa, Istanbul and Izmir. The high economic and human losses suffered in Kocaeli-Gölcük in 2003 were due largely to the poor quality of buildings. The inability of many to afford proper building materials, a shortage of skilled labourers, a rise in the number of illegal buildings and the lack of adequate inspections during the construction process are common problems in Turkey, where both private and publicly-funded building projects prove to be equally vuinerable to earthquake damage. ${ }^{48}$

Although many of these problems are not as severe in the developed world, evidence suggests that New Orleans-type disasters are not entirely unique in the West. Hurricane Andrew caused, what was at the time, unprecedented damages in the Miami area in 1992 and the possibility of a sequel is high as, like New Orleans, Miami has adopted a style of urbanization that predisposes the area to disasters. The area's population and wealth have exploded in recent years as massive developments have claimed coastal lands and Florida's signature ecosystem: the everglades. ${ }^{49}$ On the other side of the continent, Mike Davis calls Los Angeles a "Book of Apocalypse theme park" where disasters, or at least their threat, have become part of daily life. From 1992 to 1995 , the city experienced three storms and floods, one firestorm and two earthquakes with cumulative damages of over $\$ 40$ billion and just over one hundred deaths.

\footnotetext{
${ }^{48}$ B. Sengezer and E. Koç, "A Critical Analysis of Earthquakes and Urban Planning in Turkey."

${ }^{49} \mathrm{~S}$. Changnon and D. Changnon, "Record-High Losses for Weather Disasters in the United States During the 1990s: How Excessive and Why?" Natural Hazards, 18, (1999): 287-300.
} 
According to Davis, the majority of these disasters were self-imposed as both the geography of the region and urban development projects have increased hazards risks. He writes,

Historic wildfire corridors have been turned into view-lot suburbs, wetland liquefaction zones into marinas, and floodplains into industrial districts and housing tracts. Monolithic public works have been substituted for regional planning and responsible land ethic. As a result, Southern California has reaped flood, fire, and earthquake tragedies that were as avoidable, as unnatural, as the beating of Rodney King and the ensuing explosion in the streets.

Cities in the Northern Hemisphere are committing 'environmental suicide' where business-as-usual modes of thinking persist at the expense of environmental common sense. Davis believes that Los Angeles represents the direction in which our cities are headed and even if the frequency of natural hazards around the world remains relatively constant, the number of deaths and economic losses will likely rise as citizens continue to flock to coastal urban centres. The geography, government incompetence and poverty of New Orleans seem to indicate that Katrina was an unusual event, but mounting evidence suggests that such disasters may become more common, certainly in the developing world, and quite possibly in the developed world. This uncertain future puts into question the belief that communities can engineer and literally fight their way out of disaster situations and demonstrates that hazards and disasters security remains a moving target. ${ }^{50}$

\section{A GEOGRAPHICAL MISMATCH}

While reliance on engineering-intensive and militaristic solutions certainly poses problems for disaster mitigation strategies, a more fundamental concern has yet to be discussed: geography. Statehood and our modern international system are fundamentally

\footnotetext{
${ }^{50}$ M. Davis, Ecology of Fear, (Toronto: Random House Inc., 1998): 7, 10 and 318 respectively.
} 
based on the principle of inviolable borders. States are therefore seen as "autonomous permanent entities" where "the space occupied by states is seen as fixed, as if for all time." The normalizing of state politics is due to what Agnew calls the 'territorial trap,' which is based on three principles: first, that states have exclusive power within their territories (i.e. sovereignty); second, that 'domestic' and 'foreign' affairs are separate realms each with their own set of rules; third, that states determine and influence the social order within their boundaries. ${ }^{52}$ But natural hazards seem to pose a dilemma for these reified states. As Lipschutz writes, "a serious mismatch exists between those institutions assigned the task of dealing with environmental damage, no matter what the scale, and the sources and nature of those problems." 53 State borders are understood to be inviolable, yet air, water and earth all travel freely across these supposedly sacred divisions and natural hazards detection, reduction and response strategies tend to require international cooperation.

It is evident that natural hazards, due to their variable size and effect, put into question the efficacy of addressing these problems on simply state terms. When trying to understand and predict hazards, climate scientists consistently encounter familiar problems concerning geographical and temporal scales. In a report for the IPCC, Albritton et al. write, "trends in severe weather events are notoriously difficult to detect because of their relatively rare occurrence and large spatial variability." ${ }^{, 54}$ For example, hurricanes originate in the Atlantic Ocean and sweep through the Caribbean Sea before

\footnotetext{
${ }^{51}$ S. Dalby, Environmental Security, 67; J. Agnew, Geopolitics, 51.

52 J. Agnew, Geopolitics, 2.

${ }^{53}$ R. Lipschutz, Global Environmental Politics: Power, Perspectives, and Practice, (Washington: CQ Press, 2004): 21.

${ }^{54}$ D.L. Albritton et al., "Technical Summary of the Working Group I Report," in Climate Change 2001:

The Scientific Basis, eds. J.T. Houghton et al., (New York: Cambridge University Press, 2001): 33.
} 
dissipating over North America; along the way, they can wreak havoc on dozens of countries. The 2004 Boxing Day Tsunami also affected numerous nations in the Indian Ocean region.

These types of natural hazards require a concerted effort by states to prepare for and respond to these events - through information and knowledge sharing and foreign aid - which according to some academics violates the tenets of sovereignty. International interactions are made even more difficult if fault is considered; for instance, if it is true that higher concentrations of GHG emissions are indeed responsible for an increase in the number of extreme weather events, then wealthy countries in the North should be held accountable for their high emission levels. On the opposite end, highly localized hazards, such as landslides require mobilization and assistance on a much smaller scale which may or may not cross political boundaries; in such cases, state institutions may be too large and cumbersome to effectively deal with a local situation. Ultimately though, the world-as-states model remains unquestioned and is automatically charged with addressing these problems.

Since the 1972 signing of the Stockholm Declaration, dozens of international environmental agreements - covering issues ranging from endangered species, greenhouse gas emissions to ozone holes - have been signed and ratified by numerous nations. For many state leaders, the ratification of the Kyoto Protocol - and the larger United Nations Framework Convention on Climate Change (UNFCCC) - represented the pinnacle of international cooperation and decision-making. On February 16, 2005, then Canadian Environment Minister Stephane Dion proudly remarked, "in Kyoto, in 1997, the world agreed on the first step to start addressing global climate change. Today marks 
a significant milestone in international cooperation as the Kyoto Protocol enters into force. ${ }^{, 55}$ Part of the impetus for the treaty was to reduce the frequency and severity of natural hazards which were, and still are, believed to be in some measure caused by global warming. ${ }^{56}$ Certainly, the Kyoto Protocol demonstrated that states were willing to address a transnational environmental issue in a productive manner. But many critics have been quick to point out the impotence of the agreement on several counts including the lack of involvement of China and the United States and the lack of an enforcement mechanism among others. What is most troubling about the Kyoto Protocol, is that like other international environmental regimes (IERs), these agreements further entrench the belief that national goals matter most and that nations represent the only meaningful players in international institutions. The Kyoto Protocol, for instance, was only debated, signed and ratified by states; businesses, NGOs and other groups only participated as observers. ${ }^{57}$

Despite the transboundary nature of hazards, states have yet to make a formal international effort on natural disasters reduction. The IDNDR combined the work of various UN agencies, international scientific and humanitarian organizations, national committees, NGOs and citizen groups. Similarly, the IDNDR spawned the International Strategy for Disaster Reduction (ISDR), which too is a loose affiliation of state and nonstate groups. Wisner argues that given the current international climate and the ability of states to mobilize moral will, the ISDR has been rendered powerless by state inaction. It

\footnotetext{
${ }^{55}$ S. Dion, "Minister Dion's Statement for the Japanese Webcast on the Entry into Force of the Kyoto Protocol," 18 February 2005. Available from http://www.climatechange.gc.ca/english/newsroom/2005/kyoto_feb16statement.asp.

${ }^{56}$ United Nations Framework Convention on Climate Change, "Essential Background," 24 May 2004.

Available from http://unfccc.int/essential_background/items/2877.php.

${ }^{57}$ R. Lipschutz, Global Environmental Politics.
} 
seems that states do not want to get involved or do not believe that an international treaty for disasters reduction is warranted. ${ }^{58}$

As already discussed, the reified state "acts as the container of modern society... [it] is seen as the guarantor of social order in modern societies." ${ }^{, 59}$ Thus, the international community has decided that natural disasters can be best addressed through the state system and its existing power structures: "transboundary problems come to be defined in ways that fit existing institutional structures, rather than in other ways that would, among other things, clarify who is responsible for problems, who holds power over whom, and to what ends power is being directed by those who hold it." In theory, IERs should reduce state power as they restrict state conduct in international affairs. However, in practice, they only provide the illusion that states have relinquished power for the greater good when in actual fact they have further entrenched states' right to speak and act. Hence, even institutions which are designed to deal with specific environmental matters remain deeply rooted in already-existing institutions and practices that serve more to reinforce the status quo than to address the problem in more innovative ways. As Lipschutz argues, "in place of devising institutional responses appropriate to the nature of contemporary environmental problems, we have resorted to framing the problems in terms of the institutions and practices already in hand." $" 60$

\footnotetext{
${ }^{58}$ B. Wisner, "Disaster: What the United Nations Can Do," UN Chronicle. Vol. 39, No. 4, (December 2000/February 2001). Available from http://www.un.org/Pubs/chronicle/2000/issue4/0400p6p.htm. 59 J. Agnew, Geopolitics, 53.

${ }^{60}$ R. Lipschutz, Global Environmental Politics, 23 and 21 respectively.
} 


\section{THE NATURAL DISASTER SYNDROME}

Kunreuther defines the 'natural disaster syndrome' as the following: "prior to a disaster, individuals in hazard-prone regions do not voluntarily adopt cost-effective loss reduction measures. ${ }^{961} \mathrm{He}$ blames this syndrome partly on human nature's tendency to underestimate risks or take an 'it will never happen to me' approach and on the supposed protection that government programs offer before and after a catastrophic event. While measures such as using stronger shingles and glass, sealing foundations and/or elevating homes do not make homes impervious to wind and water, they certainly reduce the damages caused by severe storms. Yet in the presence of government bail-out programs and public insurance schemes, Kunreuther argues that preventive measures are less likely to be undertaken, thereby worsening the natural disaster syndrome. ${ }^{62}$

In the case of flooding damage, a 2006 study found that government projects, such as the building of levees, give residents a false sense of security, when in fact they are targets for catastrophe should the levee be breached or overtopped. The problem is worsened when local public officials do not enforce building codes or allow development in high-risk areas as homeowners are rarely involved in these processes. For instance, insurance experts have estimated that 25 per cent of the insured losses from Hurricane Andrew could have been prevented through better building code compliance and enforcement; in Dade Country, the area struck by Hurricane Andrew, there were only 60 building inspectors for an area that saw on average 20,000 new buildings per year. In another case, after Hurricane Camille destroyed an apartment complex in Past Christian, Mississippi in 1969, a shopping centre was built in the same location. Hurricane Katrina

\footnotetext{
${ }^{61}$ H. Kunreuther, "Disaster Mitigation and Insurance: Learning from Katrina" Annals of the American Academy of Political and Social Science. Vol. 604, (March 2006): 208.

${ }^{62}$ Ibid.
} 
has since levelled the shopping center, and developers already have plans to build condominiums on the same site with no opposition from local authorities. ${ }^{63}$

Government insurance programs also reduce the incentive for individuals to take responsibility for high-risk living arrangements. Established in 1968 in response to both the withdrawal of many primary insurers and to encourage individuals to purchase flood insurance in hazard-prone areas, the NFIP was seen as a means to alleviate the need for disaster assistance. However, few individuals voluntarily bought this coverage - less than 40 per cent of the victims of Hurricane Katrina in Mississippi and Louisiana had flood insurance - which Kunreuther attributes to the myopic view that individuals take in thinking in short time horizons, minimizing risks and assuming that government assistance will bail them out. ${ }^{64}$ In addition, as critics of the NFIP have pointed out, statefunded programs are not designed to be self-sufficient - the NFIP was buoyed by a $\$ 1.5$ billion line of credit with the United States Treasury. Even though many insurers abandoned providing flood insurance decades ago citing untenable risk, the NFIP continues to provide affordable premiums to citizens who would otherwise be left without insurance. The premiums charged to policyholders under this program are not based on actuarial calculations, but on public opinion. Thus, the availability and affordability of such government programs ignores actual risk, thereby facilitating homeowners' decisions to continually live in risky situations. ${ }^{65}$

\footnotetext{
${ }^{63}$ Ibid., 220-221.

${ }^{64}$ Ibid.

${ }^{65}$ D. Jaffee and T. Russell, "Should Governments Provide Catastrophe Insurance?" The Economists' Voice, Vol. 3, No. 5, (April 2005). Available from http://www.bepress.com/ev/vol3/iss5/art6.
} 


\section{CONCLUSIONS}

In trying to secure human populations against the threats posed by natural hazards and disasters (both in terms of reducing future uncertainty and ensuring that everyone's daily needs are met) it seems that states alone are not prepared to provide such guarantees. In the current MGI, states possess exclusive rights to provide security against all threats. But state discourses and practices continue to exhibit Cold War era thinking where threats are seen as being spatially separated and inherently opposing the good state. Furthermore, the act of securing is understood to be a highly technical and violent practice that is akin to war. Even in an age where populations must contend with a litany of global dangers, states continue to act as the default guarantor of security, applying the same strategies and mobilizing the same institutions to contend with the post-modern age's increasingly varied and complex threats.

Natural hazards are one of the many global dangers that states must protect their citizens from. When dealing with the threats posed by hurricanes, 'wild' fires, landslides, floods and so forth, states insist on relying on familiar engineering-intensive solutions and military institutions. River diversions, levees, retaining walls and break walls are all familiar sights in many North American cities; they are often massive state-funded engineering projects whose aims are to reduce the threat that natural hazards pose on an increasingly urban population. The United States government's handling of New Orleans before and after Katrina was a lesson in what not to do when dealing with natural hazards and disasters. The re-engineering of the Mississippi River and the Louisiana coastline, the war on Iraq, the reliance on serendipity and the abandonment of poor citizens all served to exacerbate the hurricane's effects. Furthermore, when it was clear that the city required 
assistance, the US government reverted to a familiar response: they called in the National Guard. While New Orleans was able to survive the hurricane itself, it was unable to withstand the self-imposed blow administered by poor urban planning. That the city was built in an artificial bowl surrounded by levees and poorly maintained pumping stations was the true cause of disaster. Thus, for the state, natural hazards and disasters security "degenerates into mere technical safety" as these events are seen as systematic events that require general political regulation. ${ }^{66}$

The variability of natural hazards geography also poses a problem for the state. Small-scale hazards such as tornadoes and landslides require immediate and highly localized responses which large states are incapable of effectively providing. On the transnational level, states must coordinate efforts to detect, minimize and respond to large-scale storms and earthquakes. The only formal international disasters initiative, the ISDR, has been led by non-state actors. Even in cases where it seems that states have cooperated on an international level, a detailed analysis of the terms of debate and the actors involved demonstrates that coordinated partnerships and IERs are merely a façade for the status quo. The Kyoto Protocol, for example, serves to further entrench state interests rather than forcing states to relinquish some of their power for the greater good. Simply put, natural hazards pose a geographical dilemma for states.

Finally, while largely benevolent in intent, government programs have a tendency to minimize risks, thereby reducing the incentive for individuals to take loss-prevention measures. Poor enforcement of building codes and short-sighted land-use decisions serve to offer false protection and minimize the true nature of risks, thereby encouraging individuals to believe that a catastrophic event will not happen to them. Similarly, state-

${ }^{66}$ U. Beck, "From Industrial Society to the Risk Society," 103. 
funded insurance programs set prices according to public sentiments rather than through rigorous actuarial processes.

It seems that states are, on their own, an ineffective means of providing security against the threats posed by natural hazards and disasters. States certainly have the capacity to mitigate the effects of some events: the cases of Hokkaido and the Red River Floodway lend credence to the belief that state actions can provide a great deal of security against natural hazards and should be replicated in other regions. But such measures do not address the underlying problems of the dominant hazards and disasters security approach. Certainly, improvements in these areas will help to alleviate disasters, particularly human losses, in hazards-prone regions; yet there are questions as to whether or not such approaches are sustainable in the long-term. Also, relying solely on improvements to infrastructure maintains a status quo which insists that human societies can engineer their way through environmental problems. The theoretical framework of this thesis necessitates the questioning of such normalized activities and beliefs no matter how entrenched they may be.

If we accept that hazards and disasters security requires some measure of control over the feature and the satisfaction of basic needs, then an alternative approach to security is required, one that looks beyond end-of-pipe solutions to what are incredibly complex problems. Our continued reliance on centuries-old geographical categories and the belief that science and technology offers the ultimate solution is short-sighted and precludes many other approaches, techniques and strategies. Infrastructure-centred responses are costly, inflexible and they do not always address the root causes of hazards and disasters, such as socioeconomic disparities, short-sighted environmental 
management, poor environmental awareness and so forth. Moreover, they absolve individuals of responsibility for hazards, as preparation and mitigation becomes 'someone else's problem.' States only provide passive solutions to what are often dynamic problems; they are better-suited to react against problems as opposed to finding the root causes of them and trying to prevent them from occurring in the future. ${ }^{67} \mathrm{New}$ Orleans' experience demonstrated that in an era of more frequent and unpredictable weather-related extreme events, such projects are approaching their limit.

In an era of global dangers, states represent an increasingly inappropriate institution to which society's hopes of security should be exclusively pinned. The recent proliferation of organizations "without borders" is a simple, yet pointed, reminder that states lack the institutional flexibility to deal with an increasingly varied and complex list of global problems. Also, the significant scale of non-governmental organization (NGO) activity following the Boxing Day Tsunami in 2004 demonstrated how these stateless groups could respond quickly and effectively to disasters. While state institutions, like Canada's Disaster Assistance Response Team (DART) team, took several days to mobilize, various NGOs were on the ground within hours of the tsunami. ${ }^{68}$ As already mentioned, the IDNDR and the ISDR have largely been NGO-led initiatives.

Dalby writes that the "lines of demarcation around precisely defined sovereign states are an increasingly unconvincing description of contemporary political life and an unconvincing answer as to how politics ought to be thought and practiced." ${ }^{\text {"S9 }}$ Similarly, Ó Tuathail argues that we are currently in a "crisis of security," where "the power and

\footnotetext{
${ }^{67}$ R. Lipschutz, Global Environmental Politics.

${ }^{68}$ CBC News, "Canada Sending DART to Help in Sri Lanka," cbc.ca. 4 January 2005. Available from http://www.cbc.ca/story/canada/national/2005/01/03/dart-050103.html.

${ }^{69}$ S. Dalby, "Globalisation or Global Apartheid? Boundaries and Knowledge in Postmodern Times,"

Geopolitics, Vol. 3, No. 1, (Summer 1998): 134.
} 
legitimacy of aging industrial society institutions of security and order is likely to be exposed and challenged." ${ }^{, 70}$ The crucial point is that the idea that only states provide security in the present era is no longer tenable. States have become the default spokespersons for understanding natural hazards and administering security. While many wealthy governments have successfully reduced the incidents of disasters in certain regions, these moves have done little to change or at least challenge the existing ontological separation of humans and nature as they continue to use technology and combative strategies to control this relationship. What is needed is a rethinking of how humans relate to natural hazards and to develop a more proactive course of action. It is time that we looked to different institutions, discourses and actors to find ways to secure human societies against the threats posed by natural hazards and disasters.

\footnotetext{
${ }^{70}$ G. Ó Tuathail, "De-Territorialised Threats and Global Dangers," 29.
} 


\section{Chapter 4-Insuring Futures through Risk and Responsibility}

States have difficulty securing against natural hazards for several reasons. First, the varying and often contradictory scales of natural hazards are problematic for the rigid geographies of state politics. Second, with the uncertainty concerning technical end of pipe 'solutions' and continued social vulnerability to natural hazards, states can no longer claim to take full responsibility for protecting their citizens from disaster. Third, political imperatives prevent states from fostering realistic understandings of risk among their citizens and so programs designed to help homeowners serve to minimize the actual risks involved in a particular locality. Finally, state responses reinforce an ontology that pits humans and nature in such a way that the former repeatedly reverts to using science and technology to control the latter, an approach that provides only limited security.

While some top-down projects have certainly proven successful, it is still useful to examine an approach to hazards that provides a different way to address the social determinants of disasters and challenges the ontological separation of the 'human' and 'natural' worlds. There is a lack of reflexivity when it comes to understanding the world in which individuals act upon on a daily basis. That some of its methods work relatively well does not shield the state from criticism and research into alternatives. Under the current approach, hazards are separated in both spatial ('somebody else's problem') and temporal ('wait and see what happens') terms. For example, media coverage of the annual Atlantic hurricane season often displays images of homes situated precariously close to cliffs or on slivers of land that jut out into the ocean with angry owners pleading for government assistance. The belief that state laws and human engineering will secure these property owners from hazards is hopeful at best. 
It seems that the current hazards and disasters security arrangement needs to be challenged and alternatives examined. Although technological expertise is still useful, it is also worth exploring an approach to hazards and disasters security that accounts for varying scales and one that instils a greater sense of individual responsibility over the human-environment relationship. This chapter will discuss the merits of viewing insurance as a securing agent for natural hazards. Insurance companies are in the business of selling security and are thus an appropriate institution to interrogate on how well they handle hazards and disasters security. As discussed in the opening chapter, transnational flows of capital, information and commodities have emerged as a genuine force in global politics that challenges state claims to exclusive power. Because insurance has the ability to link the local with the global and back to the local again through a network of risksharing arrangements, it has the capacity to overcome the problems of scale that are associated with natural hazards. By shifting responsibility onto the individual, insurance creates a more direct and responsible relationship between 'humans' and 'nature.' While insurance is not posed as a replacement for state-led responses to hazards and disasters, it is a useful theoretical tool in that it represents an alternative source of power and can thus be used to re-examine hazards and disasters security in a different light.

\section{THE 'POSTMODERN LOCAL'}

As discussed in the previous chapter, transnational global environmental impacts cannot always be addressed through state actions and cooperative international regimes. In the context of modern day natural hazards and disasters, the local and global are inextricably bound to one another and the line between where the local ends and the 
global begins proves elusive. Thus, in an age of global dangers, "thinking about global security seriously is precisely a matter of thinking through these connections and understanding the consequences of actions in one place on people elsewhere."1

Natural hazards pose a unique problem for societies primarily because the scales of their cause and effect are so amorphous. On one hand, extreme weather-related events such as hurricanes operate on massive scales, effortlessly moving across oceans and continents. They are also influenced by planetary variations in wind, humidity, ocean currents, land formations and so forth. Even the world's best atmospheric prediction models can only reach resolutions of approximately $250 \mathrm{~km}^{2}$ as the planet's highly integrated systems have proven to be very difficult to replicate with great confidence and precision. ${ }^{2}$ However, large-scale hazards also have local implications, as weather-related hazards tend to affect particular regions repeatedly, such as the Gulf Coast in the United States. It is no surprise then that states have difficulty dealing with these events; hazards simultaneously originate and travel on enormous scales and speeds, while at the same time they have decidedly local consequences.

The human side of hazards poses similar problems for grasping scale and assigning responsibility. The transition from hazard to disaster is often based on individual decisions, such as choosing (or being forced) to settle in hazard-prone areas or using sub-standard building materials. As discussed in the opening chapter, the conditions of a disaster are always present or embedded in the local-level society; a hazard simply provides the catalytic agent that produces an intense social crisis.

\footnotetext{
' S. Dalby, "Introduction to Part Four: The Geopolitics of Global Dangers," in The Geopolitics Reader, eds. G. Ó Tuathail, S. Dalby and P. Routledge, 2nd ed., (New York: Routledge, 2006): 185.

${ }^{2}$ D.L. Albritton et al., "Technical Summary of the Working Group I Report," in Climate Change 2001: The Scientific Basis, eds. J.T. Houghton et al., (New York: Cambridge University Press, 2001): 48.
} 
Questions of scale and responsibility become even more problematic when considering the causes of more complex phenomena, such as global warming which will likely lead to an increase in natural hazards. Inputs to greenhouse gas levels, for instance, are produced largely in the developed economies of North America, Europe and East Asia, but the effects of these inputs are felt asymmetrically around the world. Tuvalu's proposed case against the United States and Australia for causing rising sea levels is an appropriate yet odd example of the variable effects of global warming. Similarly, while activities such as air conditioning a 10,000 square-foot home every day of the year appears to be locally and spatially limited, such actions can have implications on a much wider level where certain regions of the world will experience varying effects of climate change in the coming decades. Responding, or at least attempting, to secure against natural hazards thus becomes increasingly difficult as global climate events can affect localities in severe ways just as local activities can contribute to damages elsewhere.

As discussed in the previous chapter, the 'modern' state is poorly equipped to address the amorphous geographies of natural hazards both in terms of the physical events themselves and the ways in which they are affected by, and in turn affect, humans. The MGI is associated with the Westphalian system, which dates back to seventeenth century Europe, hardly an era where global dangers, technological developments, the proliferation of the human species and the lack of reflexivity towards the humanenvironment relationship posed a great threat to societies. It is in the postmodern world where "states are no longer as sovereign as they once were, where transnational actors and forces are problematising domestic/foreign borders."3 The "postmodern local' is thus

\footnotetext{
${ }^{3}$ G. Ó Tuathail, "De-Territorialised Threats and Global Dangers: Geopolitics and Risk Society," Geopolitics. Vol. 3, No. 1, (Summer 1998): 17.
} 
a geographical space that is not bounded by traditional boundaries or 'rules' as to how the world ought to be divided up; it is a way of envisioning the world that "takes place seriously as the settings for human life and tries to understand the world in terms of its impacts on the material welfare and identities of people in different places."4

\section{INSURANCE: OVERCOMING SCALE}

For insurance companies, providing widespread coverage, even in the most hazards-prone areas, has proven profitable for two reasons: first, hazards are spatially imprecise and second, they occur relatively infrequently. Rodney White and David Etkin write, "the insurance industry is based on the randomness of events in both time and space" and so profits can be generated when claims payments are the exception, rather than the rule. ${ }^{5}$ Prior to the 2005 hurricane season, industry models suggested that the worst-case loss event would cost approximately $\$ 80$ billion, which is more than the 2001 terrorist attacks and Hurricane Andrew combined, both of which did not cause significant changes in the industry's modus operandi: "more insurance for more people." But as the 2005 Atlantic hurricane season's costs continued to mount in the Gulf region insurance and reinsurance providers considered raising the cost of a worst-case scenario anywhere from $\$ 120$ billion to $\$ 200$ billion, as greater wealth in coastal regions and the probability of more frequent and violent storms increased the threat of financial exposure for virtually all of the major insurance and reinsurance providers in the world. The frightening fact was that Hurricane Katrina was only a category 4 storm whose epicentre

\footnotetext{
${ }^{4}$ J. Agnew, Geopolitics: Re-Visioning World Politics, 2nd Ed., (New York: Routledge, 2003): 128-9.

${ }^{5}$ R. White and D. Etkin, "Climate Change, Extreme Events and the Canadian Insurance Industry," Natural Hazards, 16, (1997): 159.

${ }^{6}$ T. Baker and J. Simon, "Embracing Risk," in Embracing Risk: The Changing Culture of Insurance and Responsibility, eds. Tom Baker and Jonathan Simon, (Chicago: University of Chicago Press, 2002): 3.
} 
missed New Orleans. Compared to states like Florida and Texas, Louisiana and Mississippi do not have the same population density or wealth. ${ }^{7}$

Despite the prospect of exorbitant claims due to extreme weather-related events, the insurance industry demonstrated its continued ability to adapt to such threats to its bottom line. As discussed in the previous chapter, states tend to be hamstrung by their rigid geographies; they are cumbersome at the local level and powerless at the global level. The insurance industry, on the other hand, seems to possess the institutional flexibility that is required to deal with the changing spatial and financial demands posed by natural hazards.

Brokers and agents often market themselves as being caring members of the community and provide coverage options that cater to an area's needs. In North America, many brokers work independently, selling insurance products from a variety of companies, most of which are based in the United States and Western Europe. The basic premise of an insurance agreement is that insurers collect premiums from many policyholders in order to compensate the unfortunate few who suffer an insured loss; insurance companies therefore assume part of the inherent risk in running a business, driving a car or owning a home. But having insurance through a primary insurance company, like ING Direct or State Farm, is often not enough, as nearly all insurers search for greater financial protection.

Traditionally, insurance tends to rely on the "law of large numbers" where households are insured against independent risks that are unpredictable at the individual level, but become more predictable at the aggregate level of many households. For such

\footnotetext{
${ }^{7}$ A. Felsted et al., "An Ill Wind: Why the Rising Cost of Cover for Natural Disasters Will Alter an Industry," Financial Times, 20 December 2005: 13.
} 
losses, insurers can predict their average losses for any given year with a good deal of accuracy and reserve a portion of capital to pay for these losses. However, catastrophic losses present a different problem where the number and severity of natural disasters is unpredictable and thus requires a large amount of capital at hand for claims payments. Because of this unusual loss-distribution pattern and the associated capital requirements, primary insurers often transfer a significant portion of this financial risk to reinsurers. Primary insurance companies (e.g. those that operate at the local level) pay premiums to reinsurers in exchange for an agreement to have a proportion of their claims paid for them, particularly in the event of a major loss, which mirrors the homeowner-primary insurer relationship. Reinsurance thus serves to diversify the risks that individual companies cannot offset internally. ${ }^{8}$

Insurers and reinsurers have historically responded to increased loss events and rising claims by raising the premiums that they charge to customers and reducing their exposure to natural hazards risks. But a more recent phenomenon has emerged in the last decade as firms have sought out more novel methods of increasing capacity and protecting their businesses from catastrophic losses. As the name suggests, Alternative Risk Transfers (ARTs) spread risks through global securities markets, rather than through reinsurers' own capital bases. The risks associated with a certain insurer's policies are shared among a pool of international investors who, in essence, gamble on whether or not the insurer will have to pay for a high-loss event - typically a US hurricane or earthquake. Like insurance and reinsurance, the arrangement offers another level of

\footnotetext{
${ }^{8}$ D. Hofman and P. Brukoff, "Insuring Public Finances Against Natural Disasters: A Survey of Options and Recent Initiatives," International Monetary Fund Working Paper. August 2006. Available from http://www.imf.org/external/pubs/ft/wp/2006/wp06199.pdf.
} 
financial protection and remains geographically flexible since an American insurer's policies are supported by global securities markets. ${ }^{9}$

ARTs emerged in the late 1990s in response to declining profits and increasing costs of catastrophic losses. They are typically used by reinsurers who are unable to bear the risks of a "once in a century" type of event. ${ }^{10}$ Catastrophe bonds are the most commonly issued type of ART and have seen the greatest growth in recent years. They work by transferring a specified set of risks from an insurance company (e.g. policies issued to homeowners in Texas) to a group of international investors. A set of trigger conditions are tied to the issuing of the bond (e.g. dollar amount in damages or maximum wind speed). If the conditions are met, then the investors lose all or part of their principal; however, if by a certain date the conditions have not been met, then investors receive a massive payout. The benefits for the industry are that catastrophe bonds offer greater financial capacity, funds can be released more quickly and bonds can be locked down for several years, rather than face renewal on an annual basis. In addition, catastrophe bonds serve to reduce the price of reinsurance since financial risk is shared among a large pool of investors. " For investors, the potential windfall offsets the risks of losing a significant amount of money; returns of 8 to 10 per cent on a short-term investment are not uncommon. ${ }^{12}$ One such windfall was seen at the end of 2006 , when an abnormally inactive Atlantic hurricane season saw investors earn huge returns in spite of forecasts of significant hazards damages. ${ }^{13}$

\footnotetext{
${ }^{9}$ A. Smolka, "Natural Disasters and the Challenge of Extreme Events: Risk Management from an Insurance Perspective," Philosophical Transactions of The Royal Society A. 364, (2006): 2147-2165.

${ }^{10}$ J. De Mey, "Insurance and Capital Markets," The Geneva Papers. Vol. 32, (2007): 37.

"D. Hofman and P. Brukoff, "Insuring Public Finances Against Natural Disasters."

${ }^{12}$ A. Colter, "Catastrophe-Bond Supply Builds Up," The Wall Street Journal, 27 September 2006.

${ }^{13}$ The Economist. "Balmy in Bermuda - Catastrophe insurance." The Economist. 14 October 2006.
} 
With the rising costs of natural disasters and growing concerns about a "once in a century" event, ARTs have seen unprecedented growth in the last decade. Since 1997, some 69 cat bonds have been issued and by the end of 2005 , ARTs were worth $\$ 10$ billion. ${ }^{14}$ While this amount appears relatively insignificant when compared to the size of the industry as a whole, it is worth noting that the number of new bonds issued grew nearly 400 per cent between 2004 and 2006. As well, the majority of the world's biggest insurers have joined the potentially lucrative catastrophe bond market, with Munich Re, Hannover Re, PXRe and Swiss Re all issuing bonds in $2005 .{ }^{15}$

The vast majority of catastrophe bonds issued have been linked to American hurricanes and earthquakes, although the investors and issuing firms are globally dispersed. Hurricane Katrina frightened many insurers and reinsurers, since it was only a category 4 storm that just missed a major city. If such an event could cause $\$ 40$ billion in damages, those within the industry wondered what would happen to reinsurance rates if a category 5 storm landed directly in Miami or Houston, causing damages in the $\$ 80$ to 90 billion range. To date, just one catastrophe bond has been triggered, a $\$ 190$ million security tied to policies written by Zurich Financial Services in the Gulf states. The bond was issued in August 2005 by Swiss Re and triggered by Katrina one month later. The initial conditions on the bond were that investors would lose their principal if Zurich Financial Services had to pay more than $\$ 1$ billion in claims from any hurricane or earthquake in the United States before August 2010. ${ }^{16}$

\footnotetext{
${ }^{14}$ D. Hofman and P. Brukoff, "Insuring Public Finances Against Natural Disasters;" A. Felsted, "Hurricane losses start to bite: Insurance Rates," The Financial Times, 25 April 2006.

${ }^{15}$ A. Colter, "Catastrophe-Bond Supply Builds Up."

${ }^{16}$ C. Fleming, "Katrina Claims Could Leave Holders of a 'Cat Bond' With Major Losses," The Wall Street Journal, 6 October 2005.
} 
More recently issued bonds are worth substantially more than $\$ 190$ million and trigger conditions are significantly higher. While currently it seems that catastrophe bonds are serving their intended purpose, that is, increasing the industry's capacity, there is still a great deal of uncertainty concerning the long-term viability of these arrangements. There is general agreement among insurers and reinsurers alike that ARTs do not have the built-in financial resiliency of reinsurance since investors tend to be fickle. Also, as with anything experiencing massive short-term growth and 'too good to be true' outcomes, caution must be exercised. Some question how high trigger conditions will go and what the repercussions on the global economy will be if investors are faced with massive losses from an $\$ 80$ to 90 billion event. Of course, ARTs are still in their nascent period, time will be the best judge of their ability to spread risk. ${ }^{17}$

The emergence of ARTs and the industry's own risk-sharing arrangements suggest that insurers have the ability to effectively share risks among a large pool of stakeholders; it remains the paradigmatic risk-spreading institution. Insurance is understood as the "science and art of spreading risks over populations... it was a veritable genie from a bottle." ${ }^{n 18}$ Insurance depends on the participation of many to share the burden of those few with a qualifying need; for example, premiums paid in Ottawa may help to cover the costs of hurricane damage in Halifax or Orlando. The act of purchasing insurance admits the individual into a collective whose common interests are to minimize loss and to compensate those who have suffered loss. Thus, more customers create larger risk pools which increases the promise of financial security from natural hazards.

\footnotetext{
${ }^{17}$ lbid.

${ }^{18}$ T. Baker and J. Simon, "Embracing Risk," 2-3.
} 
Consumers are therefore part of the product: the product consists of funds collected from all members of the risk pool that the insurance company packages and sells. ${ }^{19}$

An individual's decision to purchase property insurance from a local agent unveils the industry's unique spatial considerations. On one hand, purchasing insurance is geographically specific, as the location has attributes which enter into the insurer's calculation of what is the appropriate premium. On the other hand, the transaction and resulting contract links the individual to a network of global corporations and financiers, a relationship that ensures that his/her wealth remains secured. Insurance uses a series of independent, bilateral contracts to link these agreements to a vast network of financial flows. Like natural hazards, the insurance industry operates in imprecise geographies that are neither local nor global.

Insurance is a highly adaptable collective security regime that is able to use its amorphous structure to provide financial security from a whole litany of risks. It is an institution that is neither 'here' nor 'there;' there is no locus from which the industry roots itself. With sales offices in thousands of communities and policies extending from bilateral contracts to multi-billion dollar reinsurance policies, the industry connects individuals to a global network of finance and risk-sharing pools. The insurance industry is a postmodern institution that is both local and global at the same time. When considering the problematic geography of natural hazards, it seems that insurers are wellsuited to deal with these transnational events.

\footnotetext{
${ }^{19}$ R. Ericson et al., Insurance as Governance, Toronto: University of Toronto Press, 2003.
} 


\section{TOWARDS A 'RESPONSIBILIZING' CULTURE}

Much of this thesis has focussed on the environmental risks posed by natural hazards. While risk refers to the potential to cause harm, responsibility refers to the potential to reduce risks. In the present context, responsibility considers those who bear the various costs associated with a risk. Without risk, responsibility would not exist; in other words, "risk creates responsibility." ${ }^{20}$ When governments absorb hazards risks, there is an implicit assumption that this type of disaster is the responsibility of all residents in a country as the government transfers risks to each citizen through the power of taxation - for example, the NFIP in the United States is subsidized by tax dollars. ${ }^{21}$ As discussed in Chapter 3, government programs generally treat all disaster victims identically without regard for need or ability to pay; typically, disaster assistance is a function of location rather than whether or not the claimant behaved in an irresponsible manner: "the fact that the claimant made a deliberate decision to expose himself to damage by consciously living in a high risk zone does not impact his ability to receive assistance after the disaster." ${ }^{22}$ Furthermore, such irresponsible decisions are often condoned by the government on several fronts: first, zoning an area fit for development provides consent to inhabit high-risk areas; second, government-funded infrastructure projects provide a false sense of security from hazards risks and finally; premiums under government insurance programs do not reflect actual risk. According to Kunreuther, such forms of state involvement create a type of "Samaritan's dilemma: providing assistance

\footnotetext{
${ }^{20}$ T. Baker, "Risk, Insurance, and the Social Construction of Responsibility," in Embracing Risk: The Changing Culture of Insurance and Responsibility, eds. Tom Baker and Jonathan Simon, (Chicago: University of Chicago Press, 2002): 33.

${ }^{21}$ R. Ericson et al., Insurance as Governance.

${ }^{22}$ P. Freeman and H. Kunreuther, "Managing Environmental Risk Through Insurance," in International Yearbook of Environmental and Resource Economics, H. Folmer and T. Tietenberg, eds., London: Edward Elgar Publishing Ltd., 2003. Available from http://grace.wharton.upenn.edu/risk/downloads/02-15-HK.pdf.
} 
ex post (after hardship) reduces parties' incentives to manage risks ex ante (before hardship occurs). ${ }^{.23}$ This wait-and-see approach provides few opportunities to encourage a human-nature relationship that recognizes hazards risks in a more realistic and environmentally responsible manner.

The welfare state model calls for a strong central government to create a large and undifferentiated risk pool that fosters social responsibility first, and environmental responsibility second. But with the decline of the welfare state, governments have shifted responsibility for securing against such risks to 'professional risk bearers' and the individual citizen. Insurance providers and, by extension, individuals are now more responsible for self-governance. ${ }^{24}$

While security cannot be guaranteed, insurance providers argue that the financial risks associated with hazards can be calculated and objectified into relative degrees of harm. Insurance technology makes everything it objectifies calculable and therefore subject to pricing; objective risks, such as the potential for flooding in New Orleans, are turned into probability classifications which are assigned corresponding monetary values. The insurance industry is a self-contained system as it possesses its own institutional knowledge and technological and productive capacities that, when combined, claim to provide safety and security. Recognizing that not every chance can be tamed or controlled, insurers can use their products to modify behaviour and regulate choices to reduce the harms caused by hazards risks. ${ }^{25}$

\footnotetext{
${ }^{23}$ H. Kunreuther "Disaster Mitigation and Insurance: Learning from Katrina," Annals of the American Academy of Political and Social Science, Vol. 604, (March 2006): 214.

${ }^{24} \mathrm{R}$. Ericson et al., Insurance as Governance.

${ }^{25}$ Ibid.
} 
New Orleans' experience in the fall of 2005 demonstrated a pressing need to reevaluate the ways in which human communities understand and relate to their natural environment. With states as the default moderators between communities and hazards, we have come to rely on the opinions and strategies of 'experts.' This division of knowledge and action privileges the views of scientists and government officials over the common sense observations of citizens and it exonerates individuals from making poor decisions. Ulrich Beck asks, "are we dependent in all the details of life and death issues on the judgement of experts, even dissenting experts, or will we win back the competence to make our own judgement through a culturally created perceptibility of the hazards?"26 Experts believed that straightening the Mississippi River and developing over coastal wetlands would benefit New Orleans. In theory, these projects served their intended purpose - they increased financial activity in the region - but security was sacrificed as the massive changes to both land and sea demonstrated the growing disconnection between human needs and natural limits. Given the state's inability to provide comprehensive security against natural hazards, it is important for individuals to assume greater responsibility for their own risks.

In the present context, responsibility means taking personal ownership of hazards and disasters security by seeking to understand and embrace the environmental risks posed by hazards through a re-evaluation of the human-nature relationship. This type of thinking not only puts risks into perspective, but it helps to unite the varied scales of natural hazards by recognizing the connections that link individual decisions and actions 'here,' to repercussions 'here' and 'there.' While reaching out to insurance companies for

\footnotetext{
${ }^{26}$ U. Beck, "From Industrial Society to the Risk Society: Questions of Survival, Social Structure and Ecological Enlightenment," Theory, Culture \& Society, Vol. 9, (1992): 120.
} 
financial protection in many ways cedes responsibility to them, insurance institutions can use their technologies to influence how much responsibility they will inherit. Insurance providers can dictate how much responsibility is assumed by the individual by changing coverage options, requirements and premiums. Thus, insurance not only distributes risk, it also distributes responsibility. ${ }^{27}$

Insurance is a social technology that raises questions about moral citizenship and responsibility and regulates behaviours related to natural hazards. "If insurance simply responded to risks that are objective, in the sense that they are unrelated contingencies beyond individual control, then there would be no need to address individual responsibility for them." ${ }^{28}$ But many of the current risks that relate to natural hazards such as the social causes of disasters - have an element of human control within them and so insurance companies must manage the 'moral hazards' involved with providing coverage. Kunreuther and Pauly argue that "a system of risk-based premiums also provides economic incentives to homeowners to invest in cost-effective loss prevention measures. ${ }^{29}$ If risk is not properly managed - for instance, in state programs - insurance can reduce the incentive to be careful to avoid a loss. But it also works in reverse: insurance can encourage responsible behaviour through education campaigns, refused coverage, high premiums and deductibles and/or attaching conditions to a policy. ${ }^{30}$ Insurance underwrites the ability to play with danger; it is designed to protect against fallible institutions, people, knowledge and technological capacity. Its purpose is to protect against accidents that are beyond one's control rather than bankroll ill-

\footnotetext{
${ }^{27}$ T. Baker, "Risk, Insurance, and the Social Construction of Responsibility."

${ }^{28}$ R. Ericson et al., Insurance as Governance, 12.

${ }^{29}$ H. Kunreuther and M. Pauly, "Rules Rather than Discretion: Lessons from Hurricane Katrina," Journal of Risk and Uncertainty. Vol. 33, (2006): 111.

${ }^{30}$ T. Baker and J. Simon, "Embracing Risk," 15.
} 
conceived projects and decisions. Thus, when insurance companies manage moral hazards, they regulate behaviour in addition to spreading risk by 'responsibilizing' those on every level: the insured, company officials and agents, claims service providers and industry coalitions. ${ }^{31}$ For instance, insurance companies manage moral hazards by forcing policyholders to undertake specific loss reduction activities (such as installing sump pumps in homes) before receiving coverage or offering premium reductions as a reward for responsible behaviours.

That insurance possesses some institutional power to govern grants insurance the capacity and flexibility to make individuals more responsible for securing themselves against natural hazards. Its flexibility is in large part due to the fact that it is a selffunding business where collected premiums are held in reserve to pay future claims; in order for the business to survive, it must ensure that its inputs (premiums and investments) match or exceed its outputs (claims payments and operating expenses). ${ }^{32}$ While government projects and legislation generally require years, if not decades, to complete, insurance policies run on an annual or semi-annual basis which allows providers to fine-tune the balance between payouts, premiums and profits on a much more focussed temporal scale. Also, as private businesses, insurance providers do not have a social obligation to provide widespread, affordable coverage to all persons. If they deem an area too risky to insure, they can withdraw coverage or charge higher premiums. As danger grows, protection via insurance decreases or becomes increasingly costly, forcing property owners to bear a greater share of risk and responsibility.

\footnotetext{
${ }^{31}$ R. Ericson et al., Insurance as Governance, 11.

${ }^{32}$ P. Freeman and H. Kunreuther, "Managing Environmental Risk Through Insurance."
} 
A reduction in insurance coverage, or the application of more conditions on the insured, not only shifts responsibility onto the individual, but it also has the potential to introduce an environmental ethic into the human-nature relationship. A recognition of the true risks associated with living in floodplains, coastal areas, hillsides and so forth is often masked by the availability of coverage, either through the state or through private insurance. But with many insurance providers re-evaluating their business models in an age of more frequent and severe extreme weather-related events, the responsibility for taking risky choices may shift increasingly onto property owners. Following a catastrophic event like Hurricane Katrina, residents have three options: move out of harm's way, self-protect by building structures that are less vulnerable to damage and/or purchase more insurance. ${ }^{33}$ Given the socioeconomic position of the city's citizens and their experiences during and after Hurricane Katrina, it is not surprising that many of New Orleans' displaced residents decided not to return:

Forty-four per cent of those surveyed in Houston shelters in September 2005 said that they plan to relocate permanently, with the overwhelming majority saying that they plan to remain in Houston or elsewhere in Texas. While plans may change, it is likely that many will not return to their hometowns in Louisiana and Mississippi. ${ }^{34}$

This population shift will likely reduce the region's population and, therefore, the potential for future disasters in the region. Those who choose to return, or have already done so, are predominantly members of the upper-class and have access to funds through successful claims and other means. But insurers have already pressured these homeowners with higher premiums, reduced coverage and/or an increase in education campaigns to self-protect through home improvement measures. Such actions by

\footnotetext{
${ }^{33}$ V. Smith et al., "Adjusting to Natural Disasters," Journal of Risk and Uncertainty, 33, (2006): 37-54. ${ }^{34}$ W. Waugh Jr., "The Political Costs of Failure in the Katrina and Rita Disasters," The Annals of the American Academy of Political and Social Science. 604, (March 2006): 19.
} 
insurance providers may force individuals in the area to reassess their understanding of the environment around them by taking on a greater share of risk or relocating to areas of lower risk.

In addition to shifting greater responsibility for risks onto policyholders through financial means, insurance providers often use education campaigns to 'responsibilize' their customer base. Insurance companies do not want to make claims payments, and premium-based incentives to reduce risks can only go so far. In response, insurers will often participate in broad education campaigns aimed at transforming the insured into better "agents of prevention," with the goal of socializing the insured into acting as their own inspectorate. Lessons in prevention are incorporated into marketing campaigns and sales processes; for instance, insurance websites and offices are heavily decorated with information pamphlets such as 'Protect Your Home,' 'Safety Conduct,' 'Family Safety Guide,' 'Hurricanes and You' and so forth. In Canada, the Insurance Bureau of Canada distributes materials to teachers on fire drills, earthquake drills and hazard recognition among others. The goal of these education campaigns is to reduce insured losses by promoting a culture of risk reflexivity that is embedded in the routines of everyday life. ${ }^{35}$

Ericson et al. write, "the insurance system requires each insured to govern her own risk environment and secure it against loss. Ideally, if each insured is reflexive about risks and makes rational choices to minimize them, there will be security for all." ${ }^{36}$ The goal for insurance companies should be to find a workable risk and responsibility balance that insulates property owners against catastrophic loss while also requiring that owners recognize the realities of living in certain areas. According to Baker and Simon, people in

\footnotetext{
${ }^{35} \mathrm{R}$. Ericson et al., Insurance as Governance, 267.

${ }^{36}$ Ibid., 267.
} 
the West have been programmed to take risks because of the safety nets provided by the welfare state and insurance; but, in the coming years, rather than simply spreading risks among populations, we must learn to embrace risk by being more intelligent about what the risks truly are. ${ }^{37}$

\section{CONCLUSIONS}

While insurance should not be seen as a replacement for the state, it is certainly worthwhile to consider what it offers to hazards and disasters security research in the present context. Insurance seeks to secure property owners against natural hazards and disasters by making individuals more responsible for their own security and in the process reducing some future uncertainty. As argued in the previous chapter, states are on their own unable to address such concerns as they are restricted by borders and remain focussed on engineered landscapes. States also insist on supporting age-old techniques, despite the fact that security threats have dramatically changed in recent years. While massive infrastructure projects can sometimes avoid or at least mitigate disasters, states run into problems of rigid scales, poor institutional flexibility and the lack of reflexivity in these approaches.

Insurance, on the other hand, is a fluid institution that is able to easily cross boundaries using financial channels to link individual policyholders to massive financial networks abroad. Customers buy policies through community-based brokers and agents who sell insurance products from dozens of multinational insurance companies who, in turn, purchase reinsurance policies with even larger corporations. More recently, these policies have been plugged into securities markets as ARTs further spread local hazards

\footnotetext{
${ }^{37}$ T. Baker and J. Simon, "Embracing Risk."
} 
risks to a global pool of investors. Insurance thus creates a collective that unites millions of individuals and corporations under the banner of hazards and disasters security. It is a social technology that, due to its amorphous structure, is able to adapt to the postmodern geographies that, in part, define global dangers. As Mills et al write, "insurance is part of a broader public-private patchwork for spreading risks across time, over large geographical areas, and among diverse social and commercial communities."38

While insurance certainly offers potentially helpful concepts for hazards and disasters security research, its shortcomings must also be considered. First of all, although insurance serves to link the world through risk-sharing arrangements, the primary goal of insurance companies is to generate profits for shareholders. Contrary to the discourses in their marketing campaigns and materials, insurers are not altruistic corporate entities that seek to protect individuals against the harms caused by themselves and/or by hazards. The profitability imperative forces companies to alienate potential customers through high premiums and/or conditional coverage. Even in areas of very high risk - such as the Los Angeles area - competition for profits makes it difficult for a company to simply withdraw coverage. As one commercial underwriter for a multinational insurance company states, "it's pretty much that competitive right now where somebody will always take everything out there. If it's that bad a risk, there's probably some decent [premium] money in it." 39 Thus, while insurance providers may try to 'responsibilize' their clients, they themselves may behave irresponsibly if there is a dollar to be made.

\footnotetext{
${ }^{38}$ E. Mills et al. "Insurance in a Climate of Change." Science. 309, (12 August 2005): 1040.

${ }^{39}$ R. Ericson et al., Insurance as Governance, 294.
} 
Second, because insurance provides economic security by translating all losses into dollar terms, it is not very good at providing non-economic forms of security. One of insurance's defining features is its actuarial science, which claims the ability to assess risks with reasonable accuracy in order to commodify and distribute them. ${ }^{40}$ Assigning values to certain goods works well as long as they have prices attached to them: cars, household items, buildings and so forth are relatively straightforward. However, insurance cannot cover the loss of non-economic 'goods' such as community sentiments and culture. Certainly the industry has a long history of insuring against losses of life and employment, but these forms of insurance only provide financial recompense; they cannot replace that which was lost. When considering the loss of community and culture in New Orleans for instance, it is quite clear that money alone cannot replace these features that help to define the city. Even if some insurance company had sold some form of 'cultural insurance' to New Orleans, it is unlikely that dollars alone would have been able to restore the city's Cajun cuisine, jazz music and Mardi Gras festival. These are largely social losses, whereas insurance only covers economic ones.

Rather than offering a rigid solution to hazards and disasters security problems, this chapter is about providing critiques that may help to improve the status quo. It is also about understanding the connections and flows that link humans to risk and responsibility. Insurance is a highly flexible institution, both in terms of its scale and ability to modify policyholder behaviour. Education campaigns and advertising are often used to create a culture of prevention among policyholders. Also, providers can use premiums, conditions and coverage options to regulate how much risk, and thus responsibility, is born by the individual policyholder. It is this flexibility that positions

${ }^{40}$ Ibid. 
insurance as a potential means to help secure communities against natural hazards and prevent them from becoming disasters. More importantly, these considerations can assist states in improving their approaches to extreme weather-related events. Perhaps placing greater risk and responsibility with individuals in high-risk areas will encourage a more environmentally sound way of building and living. Responsibility for natural hazards and disasters security requires individuals to be reflexive as to how their actions relate to their surroundings and to the global community. Security thus requires a fundamental move away from 'business-as-usual' approaches to environment, a shift that can be administered through rethinking property insurance and the role of the state. 


\section{Chapter 5: Reduce Risks, Increase Profits}

The previous chapter considered the theoretical aspects of how insurance fits into current iterations of natural hazards and disasters security. Certainly, its risk-spreading arrangements are not perfect, nor should it be seen as a replacement for state initiatives, but insurance offers an alternative framework from which new ideas and strategies may emerge. It has been argued here that insurance is beneficial in three ways: first, as a geographically-flexible risk-spreading institution, it has the ability to seamlessly operate at and between community, national and global levels; second, its temporal flexibility and annual modelling analyses allow for rapid adjustments and force insurance and reinsurance providers to re-evaluate the cost of ever-changing risks; and finally, the industry can use pricing and coverage options to dictate how much responsibility a customer (whether it be a homeowner or a primary insurer) should bear for damages.

The purpose of this chapter is to take this theoretical discussion a step further and assess how the industry approached and responded to natural hazards from 2004 to 2006 . This period is particularly important since it was during this time that extreme weatherrelated events particularly in the United States once more replaced terrorism as the main concern for the insurance industry. Furthermore, the especially active and costly 2004 and 2005 Atlantic hurricane seasons forced insurers and reinsurers into the spotlight as record damages and claims payments caused many within the industry to question the long-term viability of their business model. Interestingly, 2006 proved to be a record year as well, but for the opposite reason: insured losses fell to their lowest level in years. This comparison, therefore, contrasts how the industry responds to two costly years versus a relatively inexpensive year. In addition, this three-year period saw the emergence of a 
new voice in the power dynamics of the present age as the industry took a leading role in climate change discussions.

This chapter, therefore, seeks to understand the discourses that have emerged from the insurance industry in the wake of two of the most expensive years (followed by one of the least expensive) in history in terms of insured losses. Since insurers and reinsurers are private businesses that rely heavily on maintaining good public relations, these firms remain relatively clandestine in their private agendas. There are few sources that are readily available to the public which outline the industry's intentions and views when dealing with natural hazards and disasters. Industry-specific publications like Insurance Journal and Reinsurance tend to be highly technical, difficult for the public to access, of poor quality, or they simply do not engage in the substantive issues that are being addressed in this thesis. As a result, secondary sources must be called upon to serve as proxies for the insurance industry's discourses.

The discourses in this context take the form of financial data, company moves and transactions, press releases and interviews; it is from these public sources that it is hoped a private discourse will emerge. This chapter analyses over 60 pieces from four major business publications: The Economist, The New York Times, The Financial Times and The Wall Street Journal. Articles were selected from these journals using specific search criteria. The time period was restricted to articles published from January 1, 2004 to December 31, 2006 for the reasons state above. Also, each publication was searched for references to the following key terms: Katrina, natural hazards, natural disasters, hurricane, flood, climate change, global warming, insurance/insurer and reinsurance/reinsurer. While certainly a pertinent and timely issue, articles pertaining to 
terrorism and biohazard insurance were ignored due to the limited scope of the present research.

Several considerations were made in selecting these particular journals: first, these journals are some of the most widely circulated and recognized English language business papers in the world; second, with head offices in Washington, New York and London, these journals cover the world's largest financial markets where insurers are regular participants; third, the fact that none of these journals saw a significant shift in editorial policy or a change in corporate ownership from 2004 to 2006 suggests that the coverage of events in this period remained fairly consistent; finally, as far as mainline business publications are concerned, these four journals serve as reasonably reliable and reputable sources for financial data and business news.

The present analysis will interrogate how the industry has responded to such highloss events as Katrina and assess whether or not there has been a shift in the power dynamics within and without the industry. As the 'sleeping giant of power,' insurers and reinsurers have historically preferred to operate quietly in the background or through conduits, wielding their influence through financial markets and their policyholders. Since their businesses rely heavily on building trust and goodwill, there is often a disconnect between what is said publicly and what is meant privately. It is here where Foucault's approach proves to be particularly useful as he insists that discourses must be deconstructed and challenged; often, as is the case here, there is an underlying message and power dynamic at play. The financial data reveal that while, on one hand, many insurers and reinsurers warned of record losses in the 2004 to 2006 period, the industry quietly maintained its strong financial performance, experiencing only a slight dip in 
profits due to above-normal hurricane activity in 2004 and 2005. It seemed that the industry had the built-in resiliency and flexibility to adapt to such catastrophic loss events and, in the process, shifted a greater degree of responsibility for hazards onto its customers. Nevertheless, the 2004 and 2005 hurricane seasons appeared to have scared the industry enough that, recognizing the inaction of governments on the issue, prominent reinsurers have continued to lead climate change discussions and develop action plans accordingly.

\section{CRYING POOR: THE 2004 AND 2005 AFTERMATH}

At a total cost of $\$ 49$ billion in insured losses, 2004 was the worst year in natural disaster losses in history - Hurricanes Charley, Frances, Ivan and Jeanne accounted for $\$ 28$ billion alone. ${ }^{41}$ For the first time since 1953, the official list of 21 names was not enough to cover the 27 severe tropical cyclones that formed in the Atlantic Ocean. ${ }^{42}$ The 2004 Atlantic hurricane season was the worst year on record for insurance payouts, eclipsing both the 1992 hurricane season and the September 11 terrorist attacks, which cost $\$ 22$ billion and $\$ 21$ billion respectively. But 2005 proved to be even more costly than 2004 at a total cost of $\$ 80$ billion, $\$ 70$ billion of which came from US markets Katrina alone cost the insurance industry $\$ 45$ billion in insured losses. ${ }^{43}$ The three major Atlantic storms in 2005 - Katrina, Rita and Wilma - struck 2 million homes, 40 oil rigs and 150 offshore oil platforms. ${ }^{44}$

\footnotetext{
${ }^{41}$ FT.com, "Lex: Insurance," FT.com, 10 August 2005; A. Felsted, "A Rapidly Shifting Landscape of Risk: The Process of Protecting Businesses Against Hazards is Subject to Unprecedented Change," The Financial Times, 18 April 2005.

${ }^{42}$ A. Felsted, "Natural Catastrophes: Nature's Toll increases," The Financial Times, 24 April 2006.

${ }^{43}$ A. Felsted, "Insurers Face Record \$80 Billion Bill for 2005," The Financial Times, 20 December 2005.

${ }^{44}$ A. Felsted et al., "Reinsurers Confront Question of Catastrophe," FT.com, 19 December 2006.
} 
In light of these two record years of losses, which were closely preceded by the costly September 11 attacks, insurance companies warned of significant profit shortcomings and vowed to make major adjustments to the way in which they conducted business. For instance, mere days after Hurricane Katrina, Munich Re and Hannover Re publicly warned investors of significant losses. ${ }^{45}$ Insurance follows a cyclical pattern in that insurers and reinsurers increase premiums following a rash of claims in order to build up capital; similarly, they will often reduce rates following years of few claims. A recent study of American insurance markets from 1984 to 2004 by Born and Viscusi confirmed this behaviour, finding that insurers nearly always raised premiums and/or reduced their exposure following high-loss years. Companies predictably raised premiums in order to improve, or at least return to, profitability and/or regenerate reserves. Interestingly though, the data demonstrated that, despite premium increases, total premiums declined after high-loss years. The study also found that catastrophes led to a reduction in the number of firms that are willing to write insurance in a particular state and in the number of customers willing to pay for higher premiums. ${ }^{46}$ The financial and organizational behaviour data since these years of record losses, not surprisingly, support the findings of the study.

Reinsurance premiums, for the most part, rose dramatically following the 2005 Atlantic hurricane season. The increases were particularly significant for those reinsurers with a large presence in American markets, notably Lloyd's of London, Munich Re and Swiss Re. Lloyd's of London seemed particularly spooked after experiencing their first

\footnotetext{
${ }^{45}$ The Wall Street Journal, "Munich Re: Reinsurers Say Their Exposure To Hurricane Will Hurt Profits," The Wall Street Journal, 6 September 2005.

${ }^{46}$ P. Born and W. Viscusi, "The Catastrophic Effects of Natural Disasters on Insurance Markets," Journal of Risk and Uncertainty, 33, (2006): 55-72.
} 
financial loss since the 2001 terrorist attacks. ${ }^{47}$ Primary insurers that operated in the Gulf states saw their reinsurance rates climb in 2006 by anywhere from 50 to 300 per cent, compared to 10 per cent increases elsewhere in the United States and as far as the United Kingdom and Asia; these higher premiums followed recent declines of, on average, 10 per cent per year. ${ }^{48}$ Only a few of the world's smaller firms chose to leave the region. Despite abnormally high claims payments, reinsurers maintained their presence in the United States, making premium hikes their only significant adjustment to their modus operandi in the Gulf states. Major providers like Swiss Re, Munich Re and PXRe continued to write policies for insurers in the Gulf states, arguing that the region was still profitable. $^{49}$

While the continued availability of reinsurance for US insurers remained a good sign for property owners and insurance providers in the Gulf states, the increased premiums placed a great deal of pressure on primary insurers' bottom lines. With reinsurance being a necessary precaution, both in the eyes of investors and state laws, insurers were faced with two options: raise their customers' premiums or pull out of costly markets.

Raising premiums following a high-loss year is probably the simplest and most obvious response to high reinsurance rates for primary insurers, but in order to do so, insurers must first apply for such increases to regulators in every state in which they want to raise premiums. Being international business entities with no set geographical and financial centres, reinsurers are not subject to the same forms of government regulations.

\footnotetext{
${ }^{47}$ A. Felsted, "Hurricanes Give Lloyd's a Lashing," The Financial Times. 4 April 2006.

${ }^{48}$ A. Felsted, "Hurricane Losses Start to Bite: Insurance Rates," The Financial Times, 25 April 2006; J. Treaster, "Storm and Crisis: The Coverage," The New York Times, 24 September 2005.

${ }^{49}$ A. Felsted, "Premiums Soar in Disaster Areas," The Financial Times,. 13 April 2006; A. Felsted et al., "Reinsurers confront question of catastrophe."
} 
Following the 2004 Atlantic hurricane season, insurance premiums for property and home owners in Florida rose by as much as 50 per cent after many of the state's insurance companies, including State Farm and Allstate, successfully applied for rate increases with regulators; insurers in Louisiana, Mississippi, Texas and Alabama also won similar increases. Companies cited projections of another busy hurricane season and climbing reinsurance rates as reasons for these rate hikes. But the rising cost of insurance was not limited to those living and conducting business in the Gulf states. Just as reinsurance rates climbed around the world, insurance premiums rose dramatically throughout the United States as insurers sought to offset the higher cost of reinsurance. After experiencing considerable exposure to the 2004 and 2005 hurricane seasons, Allstate applied for premium increases in nearly all Gulf and Atlantic coast states, citing unacceptable storm risks. For instance, the company successfully raised its rates in the northeast by 10 to 15 per cent, fearing a large Atlantic storm as far north as New York, Massachusetts and Maine. In a clear demonstration of the 'postmodern local,' insurance companies spread their losses throughout the United States, sparing those at the highestrisk from the full brunt of the increased cost. ${ }^{50}$

While increasing premiums helped to generate capital, spread risks and more accurately reflect the cost of coastal living (and elsewhere) in the United States, there was a mixed response from primary insurers insofar as deciding when the risks of operating in a particular region became too costly. The list of insurers who have pulled out of markets in the Gulf states is long, nearly all of whom have left due to high reinsurance costs and economically infeasible hurricane risks in the region. Brit Insurance, the United

\footnotetext{
${ }^{50}$ M. McQueen, "Homeowners Face Rising Insurance Rates: Reeling After Katrina, Insurers Drop Policies And Increase Premiums Far From Disaster Zones," The Wall Street Journal, 23 March 2006.
} 
Kingdom's largest insurer, began reducing its exposure in areas at high risk for natural catastrophes in $2006 .^{51}$ Beginning in 2005, Florida's largest insurers - Allstate, State Farm, Nationwide Mutual and Poe Financial Group - all refused to write any new policies in the state. Nationwide Mutual went a step further in 2006 and extended its new policy ban along the Gulf coast to Texas. ${ }^{52}$ Poe Financial, however, did not fare well, as Florida's fourth largest personal insurer went bankrupt in $2006 .{ }^{53}$ The state's largest insurer, Citizens' Property Insurance (a state-funded company), ran a $\$ 1.6$ billion deficit in 2005 as the company was forced to absorb many customers that were dropped by fleeing insurers. ${ }^{54}$ The exodus of primary insurers from these risky markets can largely be explained by the fact that, despite the aforementioned successful applications for rate increases, state regulators continued to maintain premiums caps that remained well below what insurance companies needed to charge based on their actuarial calculations leaving insurers little financial reason to offer coverage. ${ }^{55}$

As perhaps the most eager firm to cut its ties in the Gulf insurance market, Allstate, the second largest provider of homeowner's insurance in the United States, vowed to pull out of areas where home and property owners place themselves at too great a risk. Allstate lost $\$ 2$ billion in 2004 due to the storms in Florida, wiping out all of the company's profits that it had earned in the state since 1992; the insurer lost a further $\$ 4.7$ billion in 2005 even after it refused to write new policies in Florida in 2005. Fortunately, these losses were limited to the company's remaining property and casualty insurance

\footnotetext{
${ }^{51}$ A. Felsted et al., "Reinsurers Confront Question of Catastrophe."

${ }^{52}$ M. McQueen, "Homeowners Face Rising Insurance Rates."

${ }^{53}$ P. Born and W. Viscusi, "The Catastrophic Effects of Natural Disasters on Insurance Markets."

54 J. Gapper, "Earthquake Insurance Should Cost a Lot," The Financial Times, 3 April 2006.

${ }^{55}$ H. Kunreuther and M. Pauly, "Rules Rather than Discretion: Lessons from Hurricane Katrina," Journal of Risk and Uncertainty. Vol. 33, (2006): 101-116.
} 
business in Florida. ${ }^{56}$ Allstate went a step further and dropped over 200,000 existing customers in Florida in 2005 and 2006 - it is very rare for an insurance provider to drop existing customers. ${ }^{57}$ In addition to raising rates elsewhere in the United States, Allstate made the unusual move of pulling out of what were historically deemed less risky markets. For instance, as well as raising rates in states like Massachusetts, Rhode Island, Maine and New York, the insurer stopped writing new policies in the region and dropped 27,000 existing customers in the New York City area, citing that the north-east was "long overdue" for a massive storm. ${ }^{58}$ The company argued that the concentration of wealth and the increased population density in the region meant that even a smaller storm could have devastating impacts for insurers. ${ }^{59}$

Allstate, however, is not convinced that such traditional adjustments to risk exposure are enough to ensure the long-term viability of the industry. Arguing that the present insurance market in the United States is in disrepair, the company has taken the unusual step of publicly calling for insurers to scale back their activity in high-risk areas and to join the company in lobbying for a federally-funded national insurance plan. ${ }^{60}$ Like the situation in 1968 when many insurance companies refused to offer flood insurance in certain flood-prone areas (which led to the creation of the NFIP), Allstate hopes to spearhead a similar program for catastrophic losses due to, for instance, a terrorism attack or hurricane. The proposal for the program asks the government to

\footnotetext{
${ }^{56}$ T. Francis and M. Schroeder, "Hurricanes Push Insurers to Seek Government Aid," The Wall Street Journal, 26 September 2005; J. Mead, "Will Other Insurers Follow Allstate's Move?" The New York Times, 5 February 2006.

${ }^{57}$ L. Pleven, "Risk and Reward: Hurricane Losses Prompt Allstate to Pursue New Path - Cutting Coverage on Coasts, It Eyes Big Opportunity to Insure Boomers' Lives - Challenges of a Personal Pitch," The Wall Street Journal, 24 November 2006.

${ }_{58}^{58}$ Ibid.; M. McQueen, "Homeowners Face Rising Insurance Rates."

${ }^{59} \mathrm{~J}$. Mead, "Will Other Insurers Follow Allstate's Move?"

${ }^{60}$ A. Felsted, "Allstate Tries to Bring a Breath of Sanity," The Financial Times, 16 October 2006.
} 
contribute public funds after the industry has paid the first $\$ 4.5$ billion in damages under this plan, the federal government would have been responsible for over $\$ 40$ billion in damages due to Hurricane Katrina ${ }^{61}$ Allstate argues that, since insurers are scaling back at a time when risks are increasing, the government must share some of the burden of risk and offer some assistance to homeowners and the remaining insurers in the region. The company insists that its goal is to provide homeowners with affordable premiums in order to cover rising reinsurance costs. But such an arrangement can also be seen as a government subsidy for private insurers.

The sentiment coming out of Allstate is that the insurance industry is not designed to handle massive infrequent events; it is better suited for more frequent small-scale events. ${ }^{62}$ While it seems that many companies have heeded Allstate's call and reduced their hazards exposure, so far State Farm has been the only notable company to back Allstate's national insurance plan. This partnership, however, may prove to be difficult to ignore, as State Farm and Allstate provide nearly 35 per cent of all home insurance in the United States and, until recent years, the two companies were the largest insurers by market-share along the Gulf coast. ${ }^{63}$

It would appear then that a change to the modus operandi of the insurance business has started to emerge. In particular, both insurers and reinsurers are looking within their own industry and questioning if their pricing models reflect true risk and whether the US market remains financially viable. The impressive, but not surprising, rise in reinsurance rates for firms operating in the United States led Charlie Cantlay, the

\footnotetext{
${ }^{61}$ J. Treatser, "A Proposal for Federal Protection from Catastrophe Divides Insurers," The New York Times, 31 October 2006.

${ }^{62}$ A. Felsted, "Allstate Tries to Bring a Breath of Sanity."

${ }^{63}$ J. Treatser, "A Proposal for Federal Protection from Catastrophe Divides Insurers."
} 
deputy chairman of Aon Re UK, to remark that the global reinsurance market had become a "two tier market" between US hurricanes and non-US hurricanes. ${ }^{64}$ This, however, is not entirely a bad thing as American customers account for 75 per cent of the world's natural catastrophe claims, but only pay for 50 per cent of the world's premiums. ${ }^{65}$ In addition to having the effect of generating capital reserves and reducing risk, raising capital and pulling out of costly markets has also served to equilibrate what was until recently a very uneven international insurance market.

The 2004 and 2005 Atlantic hurricane seasons caused significant financial damage to the world's largest industry. The financial figures, interviews and press releases coming out of firms around the world suggest that two consecutive years of record claims payments are cause for adjustments to the 'insurance for more people' mentality of the business. Moreover, some in the industry have recognized that developed societies have reached a limit insofar as what is deemed to be an acceptable amount of risk. Former Allstate CEO, Edward M. Liddy, states, "there are too many people living in exposed areas, and the traditional insurance companies are scaling back at the time risk is increasing. That's not a good situation." 66

\section{BAD AS IT SEEMS?}

But not all insurers have been quick to follow Allstate and State Farm's lead. Many competitors have used the withdrawal of the larger insurers as an opportunity for growth, seeking a greater share of markets that were dominated by Allstate and State

\footnotetext{
${ }^{64}$ A. Felsted, "Premiums Soar in Disaster Areas."

${ }^{65}$ The Economist, "Assessing the Damage - Insurers and Hurricane Katrina," The Economist, 17 September 2005.

${ }^{66}$ T. Francis, "Boss Talk: CEO Says Allstate Adjusts Storm Plan," The Wall Street Journal, 6 September 2005 .
} 
Farm; caution and pause have not been embraced as guiding principles industry-wide. In fact, the Fireman's Fund Insurance Company (a subsidiary of German insurer Allianz AG), American Insurance Group and Chubb Group of Insurance Companies have all pushed forward into markets such as Florida, albeit at a higher cost to homeowners, offering coverage of up to $\$ 15$ million per policy. ${ }^{67}$ Furthermore, mere months after Katrina, Swiss Re purchased General Electric's fledging US-based reinsurance business and, in doing so, increased the company's exposure to US hurricane risks. ${ }^{68}$ Despite the increased risk of a catastrophic loss in these areas and the hit that ratings agencies, such as Standard and Poor, have levied on these companies, it seems that the sheer concentration of wealth along US coastlines is too enticing for some insurers to ignore.

Allstate and State Farm have also been confronted with a significant degree of opposition regarding their proposed national insurance plan, particularly from within the industry itself. The American Insurance Association - the national trade association for property and casualty insurance providers - argues that there is no need for government intervention, citing the already heavy-hand of state regulations and restrictions on current insurance practices in the United States. They maintain that the solution is not a state reinsurance policy; rather, regulations and subsidies need to be lifted so that insurers can charge premiums that reflect the actual risk of living in a particular area ${ }^{69}$ Presently, in order to meet state-imposed premium caps in high-risk areas, insurers must raise their rates in lower-risk states. This geographical averaging allows insurers to collect sufficient total premiums to cover anticipated losses for a given year. But as Kunreuther and Pauly

\footnotetext{
${ }^{67}$ M. McQueen, "Who Needs A Flood Policy? There's a Good Chance You Do: Feds Urge More Inlanders to Buy Insurance Before the Next Katrina," The Wall Street Journal, 6 May 2006.

${ }^{68}$ J. Treaster and C. Deutsch, "G.E. to Sell Insurance Business to Swiss Re," The New York Times, 19 November 2005.

${ }^{69}$ A. Felsted, "Allstate Tries to Bring a Breath of Sanity."
} 
write, "if one believes that those residing in hazard-prone areas should be responsible for bearing their own financial burden for losses from a natural disaster, then insurance rates should reflect the risk." ${ }^{70}$ State regulations, it is argued, behave like subsidies, in that the averaging of premiums between high and low-risk regions prevents insurers from setting rates that reflect actual risk. Moreover, Jaffee and Russell argue that given insurers' ability to use premium pricing to yield profits and the ability of companies to access capital, "there is no obvious reason why private insurance markets should not be able to provide [catastrophe insurance]." ${ }^{71}$ Similarly, Ted Kelly, CEO of the Liberty Mutual Group, states "there is plenty of capacity in the private sector to handle natural catastrophes."72

Officials at Munich Re disagree with the proposed federal reinsurance plan, insisting instead that there is a distinct role for the government outside of offering insurance. The state's main efforts should focus on risk management and reduction by designing and enforcing land use and building regulations, developing emergency plans and coordination of authorities and agencies involved in post-disaster response, regulating insurance company behaviour and so forth. As discussed in Chapter 3, one of the main problems with government insurance plans is that they add another dimension of control to industry practices and, more importantly, they tend to follow public sentiments rather than rigorous risk analyses, thereby pricing themselves into debt. For instance, it is more politically expedient for the government to hold premiums artificially low than it is to allow market forces and risk projections to push them upward. As

\footnotetext{
${ }^{70}$ H. Kunreuther and M. Pauly, "Rules Rather than Discretion," 111.

${ }^{71}$ D. Jaffee and T. Russell, "Should Governments Provide Catastrophe Insurance?" The Economists' Voice, Vol. 3, No. 5, (April 2005). Available from http://www.bepress.com/ev/vol3/iss5/art6.

${ }^{72}$ L. Pleven, "Risk and Reward."
} 
Anselm Smolka, Head of Munich Re's GeoRisks department, writes, "the state has to act as a reinsurer of last resort or for very rare, extraordinary losses and/or uninsurable risks that exceed the capacity of the private sector." 73

Yet the most telling rebuttal of the industry's supposed woes can be found in the business pages of any major publication. It seems that concerns coming from the industry through press releases, conferences and interviews should not be taken entirely at face value. In the immediate aftermath of Hurricane Katrina, Hannover Re, Munich Re and Swiss Re all released statements warning investors of serious profit target shortfalls. ${ }^{74}$ Certainly, 2004 and 2005 were destructive years and wreaked havoc on many political, social and economic concerns, but it would seem that insurers and reinsurers did not suffer in those years. While a significant amount of press was dedicated to the woes wrought by Charley, Ivan, Katrina, Rita, Wilma and others, many insurers and reinsurers quietly improved, or at the very least maintained, profitability.

Despite massive claims payouts in 2004 and 2005, these two years also happened to be some of the most profitable in the industry's history. Moreover, an unusually inactive 2006 Atlantic hurricane season further boosted earnings to unprecedented levels. In 2004, Brit Insurance achieved record profits, breaching the GBP 100 million mark for the first time in history; Munich Re, which was badly exposed to hurricanes in 2004, met its full year earnings forecast; French insurer Axa saw its 2004 profits grow an incredible 500 per cent over 2003; and Swiss Re recorded its second best results in its history despite record claims from US hurricanes and the Asian tsunami. What is even more

\footnotetext{
${ }^{73}$ A. Smolka, "Natural Disasters and the Challenge of Extreme Events: Risk Management from an Insurance Perspective," Philosophical Transactions of The Royal Society A. 364, (2006): 2153.

${ }^{74}$ U. Dauer, "In Katrina's Wake: Oil-Rig Insurers Expect Price Jumps - Premiums Could Rise 50\% Following Damages in Gulf to at Least 58 Installations," The Wall Street Journal, 8 September 2005.
} 
interesting is that many companies, notably Swiss Re, were profitable in virtually all of their business units, including property and casualty insurance. ${ }^{75}$

The industry predictably experienced mixed results in 2005 as Hurricane Katrina tested the industry's capacity to handle such large one-time losses. American insurers collected a record $\$ 1.1$ trillion in premiums in 2005 following their widely-publicized rate hikes. ${ }^{76}$ In spite of record payouts in 2005, Allianz increased its 3-year profit projections by 33 per cent and negotiated a merger with a large Italian insurance provider; Swiss Re, in addition to increasing its US hurricane exposure, raised $\$ 21$ billion in new capital after the 2005 Atlantic hurricane season; and Munich Re defied its own warnings and once again met its full year profit targets. ${ }^{77}$ As expected, some companies suffered. Lloyd's of London experienced its first financial loss since $2001{ }^{78} \mathrm{As}$ previously mentioned, many primary American insurers, including Allstate, St. Paul's Travellers and State Farm were over-exposed in 2005. Similarly, both Hannover Re and Swiss Re had to cut their 2005 profit goals following abnormally high claims due to Katrina. ${ }^{79}$ But these companies all adjusted accordingly, either by increasing premiums or pulling out of risky markets, and bounced back in 2006. Thus, overall, two consecutive years of costly and destructive natural hazards did little to the damage industry's bottom line or long-term outlook.

\footnotetext{
${ }^{75}$ P. Davies, "Brit Insurance Makes Record Profits," The Financial Times, 1 March 2005; The Wall Street Journal, "Munich Re AG: Profit Soared in Fourth Period on Cost Cuts, Lower Tax Rates," The Wall Street Journal, 16 March 2005; The Wall Street Journal, "Moving the Market: Catastrophe Losses Drop Sharply from 2005," The Wall Street Journal, 21 December 2006.

${ }^{76}$ The Economist, "Time for a Makeover - Insurance in America," The Economist, 12 August 2006.

${ }^{77}$ The Wall Street Journal, "Moving the Market;" J. Treaster and C. Deutsch, "G.E. to Sell Insurance Business to Swiss Re;" L. Adetunji, "Munich Re Promises 55\% Dividend Rise - Insurance," The Financial Times, 30 December 2005.

${ }_{79}^{78}$ A. Felsted, "Hurricanes Give Lloyd's a Lashing."

${ }^{79}$ J. Bayot, "Cost Estimates by Reinsurers are Climbing," The New York Times Abstracts, 13 September 2005.
} 
In fact, Hurricane Katrina only caused blips in earnings for most insurers and reinsurers. In the early weeks of September 2005, various insurance companies released statements warning of significant losses, bracing their investors and customers for serious consequences. Certainly, Katrina tested the capacity of the global reinsurance industry and its reserves, but virtually all major insurers and reinsurers emerged unscathed. Swiss Re's Chief Risk Officer, Christian Mumenthaler remarked, "Katrina is not a really an extreme event. We set an extreme event at insured loss of $\$ 80$ or 90 billion in industrywide damage. ${ }^{.80}$

As far as the wider impact of Hurricane Katrina is concerned, that too was in most cases overstated. After 90 per cent of the Gulf's oil refinement capacity was shut down by the storm, analysts and consumers panicked, bracing themselves for line-ups at gas stations and soaring heating prices; and while third quarter output did fall slightly, production rebounded by the end of $2005 .{ }^{81}$ Oil companies warned of profit losses due to rising insurance costs, when in fact this also failed to materialize, as profits in this sector have continually risen for several years. It is also worth noting that insurance costs typically average 0.4 per cent of oil companies' revenues, so increased insurance costs have very little impact on the oil industry's profits. ${ }^{82}$ In fact, the Financial Accounting Standards Board called Hurricane Katrina 'ordinary' in terms of its overall impact on the American economy. ${ }^{83}$

\footnotetext{
${ }^{80}$ C. Fleming, "Katrina Claims Could Leave Holders of a 'Cat Bond' With Major Losses," The Wall Street Journal, 6 October 2005.

${ }^{81}$ The Economist, "After the Flood - Hurricane Katrina."

${ }^{82}$ U. Dauer, "In Katrina's Wake."

${ }^{83}$ D. Gullapalli, "For Annual-Report Purposes, Hurricane Katrina is 'Ordinary,"” The Wall Street Journal, 2 September 2005.
} 
Climate models predicted that the 2006 Atlantic hurricane season was going to be 50 per cent more active than the 1950-2005 average, causing many of the premium hikes that were discussed earlier. ${ }^{84}$ As it turned out, 2006 only cost $\$ 15$ billion in insured losses, making it the third least expensive year since 1987. The combination of higher premiums and fewer claims payments meant that industry profits soared even higher, nearing a record $\$ 60$ billion compared to $\$ 43$ billion in $2005 .{ }^{85}$ Europe's two biggest insurers, Axa and Allianz, easily surpassed their forecasts as profits continued to climb; Munich Re and Swiss Re quietly hit their profit targets for a third consecutive year; after a poor 2005, Hannover Re returned to profitability in 2006; American primary insurers Hartford Financial Services Group, the Chubb Group and St. Paul Travelers all saw tremendous growth in net income; and despite a nearly 20 per cent drop in newly issued homeowners insurance policies, Allstate returned to profitability in $2006{ }^{86}$

It would seem then that the insurance industry did not suffer much during two years of record natural hazards losses. The fact that 2006 saw few losses further strengthened the industry's financial position. Yet the public discourse coming out of the insurance industry has been anything but uniform as the industry seems unsure as to what to make of the odd combination of record claims payments and profits. Allstate, State Farm and others have deemed the situation in the Gulf states untenable, pulling out of what were traditionally lucrative markets and calling for a national insurance plan. But

\footnotetext{
${ }^{84}$ A. Felsted, "Natural Catastrophes: Nature's Toll Increases."

${ }^{85}$ The Wall Street Journal, "Moving the Market;" J. Treaster, "Earnings for Insurers are Soaring," The New York Times, 14 October 2006.

${ }^{86}$ A. Jones and I. Simensen, "Fall in Natural Disasters Helps Results at Axa and Allianz Insurance," The Financial Times, 23 February 2007; FT.com, "Reinsurance/Munich Re," FT.com, 7 November 2005; The Wall Street Journal, "Hannover Re AG: Reinsurer Returns to Profit, Aided by Low Disaster claims," The Wall Street Journal, 15 March 2007; L. Pleven and I. McDonald, "Insurers' Profits Rise on Sales, Fewer Hurricanes," The Wall Street Journal, 27 October 2006; L Kuykendall, "Allstate Posts 5\% Earnings Gain," The Wall Street Journal, 20 July 2006.
} 
the industry largely opposed such a move, arguing that it had the capacity and the institutional flexibility to pay for large-scale events and adjust to a future of more catastrophic losses.

In addition to padding investors' portfolios, the changes wrought by the 2004 and 2005 hurricane seasons saw a shift in the way that risks are distributed in high-risk living. In fact, the industry has increased individual responsibility by pulling out of markets and raising premiums. Recent data suggest that, although premiums have fallen marginally around the world so far in 2007, they continue to remain high in areas with significant hurricane and earthquake exposure.$^{87}$ The aversion to creating a state-sponsored reinsurance scheme also bears this out as insurers and reinsurers would prefer to allow market forces, rather than public sentiment, to determine who should bear the most risk.

\section{LEADING THE WAY ON CLIMATE CHANGE}

While raising premiums, reducing risk and establishing ARTs have helped insurers and reinsurers to improve (or at least maintain) profitability, flexibility and capacity, major firms have recognized that the nature of their core business has changed. In conventional insurance markets - for instance, in automobile or life insurance insurers face a large number of independent risks that tend to follow fairly predictable patterns across time and space; rarely do they ever require a large amount of capital on hand for massive payouts. Under these conditions, insurers can generate profits by investing collected premiums to earn a return. Catastrophic events, however, present an entirely different set of problems that insurers must deal with and threaten the way in

\footnotetext{
${ }^{87}$ I. McDonald and L. Pleven, "Skies May Darken for Insurers: Investors Face Risks as Rising Competition Erodes Premiums," The Wall Street Journal, 9 January 2007.
} 
which these companies make money. Unlike conventional loss events, catastrophic losses tend to be clustered in time, space and cost. Events such as hurricanes, earthquakes, landslides and so forth are problematic for insurers in that these events produce losses that are unpredictable and require massive financial resources. ${ }^{88}$

Before Hurricane Andrew in 1992, the industry assumed that a worse-case loss event would cost $\$ 8$ billion; in 2004 , that figure rose to $\$ 80$ billion. However, since Hurricane Katrina, insurers have raised their estimate to over $\$ 100$ billion. ${ }^{89}$ The increasing estimates are due to two reasons. First, as mentioned earlier, home and property owners ,particularly in the United States, have continued their decades-long "lemming-like march to the sea." $"$ With increasing concentrations of both people and wealth along US coastlines, the insurance industry is grappling with a new reality where catastrophic, rather than conventional losses, will become frighteningly more common. Secondly, while current research is still inconclusive as to whether or not global warming is linked to an increase in the severity and frequency of Atlantic hurricanes, many insurers and reinsurers have chosen not to take a wait and see approach; companies like Munich Re and Swiss Re have moved forward under the assumption that Atlantic hurricanes will become more common and destructive. In discussing his company's move to reduce exposure on the Gulf coast, Brit Insurance CEO Dane Douetil states, "we do not believe that the last 12 months is an anomaly."

\footnotetext{
${ }^{88}$ P. Born and W. Viscusi, "The Catastrophic Effects of Natural Disasters on Insurance Markets."

${ }^{89}$ A. Tugend, "The Peace of Mind of Home Insurance, Unless You Use It." The New York Times. 1 October 2005; A. Felsted et al., "Reinsurers Confront Question of Catastrophe."

${ }^{90}$ A. Revkin, "Climate Experts Warn of More Coastal Building," The New York Times, 25 July 2006. 28 October 2004.

${ }^{91}$ A. Felsted et al., "Reinsurers Confront Question of Catastrophe."
} 
What is of central concern to the insurance industry is that these events may become more unpredictable. The unpredictability of weather events threatens to undermine insurers' actuarial and pricing processes, the foundation of their business; unpredictable climate events would require a massive capital base from which claims payments would have to be made. Thus, it is not surprising that insurers have attempted to mitigate such events, as unpredictable weather affects both their short and long-term profitability. While insurers have been active on the first concern by raising premiums and pulling out of markets, they have also become heavily involved in trying to reverse, or at least mitigate, the effects of climate change.

While political will continues to be a problem for developing an action plan that will address global warming, the insurance industry has emerged as a leading figure in both climate research and mitigation and adaptation strategies. The world's largest firms, including Lloyd's of London, Swiss Re and Munich Re, have publicly made climate change the primary concern for the industry and have invested millions of dollars into research. ${ }^{92}$ Munich Re, for example, heavily funds climate modelling research through public institutional grants and through its own GeoRisks Research group. ${ }^{93}$ The company's official position is as follows: "In view of continued global warming, we anticipate a long-term increase in severe, weather-related natural catastrophes... Climate change is a fact. All we can do now is to limit global warming; it can no longer be stopped or reversed in the present century." ${ }^{94}$ Similarly, Swiss Re employs a staff of 30 seismologists, climatologists, engineers and mathematicians whose task is to help

\footnotetext{
${ }^{92}$ R. Knight and G. Tett, "Insurers Add Voices to Climate Debate," The Financial Times, 3 February 2007. ${ }^{93}$ A. Smolka, "Natural Disasters and the Challenge of Extreme Events."

${ }^{94}$ Munich Re Group, Topics Geo Natural Catastrophes 2006: Analyses, assessments, positions, (Druckerei Vogl: Munich, 2007): 43.
} 
develop more accurate climate models. ${ }^{95}$ The reasons for such heavy involvement are many, but ultimately insurers and reinsurers alike need to try to minimize some of the unpredictability of future weather changes as they will have serious consequences on the industry's profitability and reputation.

The research thus far has revealed some troubling trends, particularly for those living on coastlines. Of the 20 most costly insured natural catastrophes from 1970 to 2005 , only two of them were not climate-related - the September 11 attacks and the Northridge Earthquake in $1994 .{ }^{96}$ Hurricanes thus remain the primary concern for both insurers and homeowners as they continue to be the most costly natural hazard in North America. For instance, a $2.2^{\circ} \mathrm{C}$ increase in mean temperature would lead to a 5 to 10 per cent increase in storm wind speeds; a doubling of wind speed would quadruple hurricane damages. ${ }^{97}$ Peter Hoppe, former head of Munich Re's GeoRisks Research group, suggests that 20 to 30 years from now, it is possible that hurricanes may even hit the more affluent, and densely populated, European coast. Munich Re estimates that climate change could cost the global insurance industry up to $\$ 300$ billion per year by $20500^{98}$ The spectre of such changes has obvious repercussions for an industry that will have to help pay for such weather-related events.

It is in the context of such projections that the insurance industry has begun to reassess its public role and its ability to affect societal change. In the past, insurance companies flew under the public radar, choosing to operate quietly in the background. In

\footnotetext{
${ }^{95}$ A. Felsted et al., "Reinsurers Confront Question of Catastrophe."

${ }^{96}$ P. Born and W. Viscusi, "The Catastrophic Effects of Natural Disasters on Insurance Markets," 56.

${ }^{97}$ M. Hawker, "Climate Change and the Global Insurance Industry," The Geneva Papers, 32, (2007): 23.

${ }^{98}$ A. Felsted et al., "Reinsurers Confront Question of Catastrophe;" S. Dunn, "Down to Business on Climate Change: An Overview of Corporate Strategies," Greener Management International, 39, (Autumn 2002): 31 .
} 
assessing the industry's relationship with the media, Eccles and Vollbracht write, "as long as everything was going reasonably well in the insurance industry, it was a comfortable place to be from a communications standpoint: to communicate or not to communicate, either was fine. ${ }^{.99}$ However, the spectre of an unpredictable future has pushed the industry to the forefront of these discussions. In addition, it is not without reason to suggest that the industry has seen an opportunity to improve its public reputation, which had suffered in the wake of Hurricane Katrina. In recent years, the industry (especially the bigger players within it) has embraced this newfound voice and become deeply involved on several fronts.

Recognizing that it is difficult to force homeowners out of certain areas, several insurers and their trade organizations have tried to modify existing living arrangements. In the United States, Canada and elsewhere, insurers continue to lobby the government for tougher building codes and zoning regulations and demand that their customers take certain precautions with their homes before offering coverage - for instance, upgrading roofs and windows. One proposal from the Institute for Business and Home Safety (IBHS) in the United States calls for a 'seal of approval' program for all new homes. The designation, Fortified... for safer living, would be given to buildings that raise a home's overall disaster resistance above the minimum requirement of building codes. Such a program would be particularly useful for insurers who may choose to provide coverage only to homes that meet the requirements of the Fortified designation. ${ }^{100}$ The Fireman's Fund Insurance Company presently provides discounts to owners who purchase solar

\footnotetext{
${ }^{99}$ R. Eccles and M. Vollbracht, "Media Reputation of the Insurance Industry: An Urgent Call for Strategic Communication Management," The Geneva Papers. Vol. 31, (2006): 395.

${ }^{100} \mathrm{H}$. Kunreuther, "Disaster Mitigation and Insurance: Learning from Katrina" Annals of the American Academy of Political and Social Science. Vol. 604, (March 2006): 222.
} 
panels, green roofs and recycled water systems both as a means to help mitigate GHG emissions and to reduce the time it takes to get these systems running again following a large storm; similarly, Travelers insurance offers a 20 per cent discount on auto insurance to hybrid car owners. ${ }^{101}$ Insurance companies have also teamed up with companies like DuPont to help develop stronger glass, 'safe rooms' and impervious roofs to use on homes; consumers who choose to install such upgrades are usually granted significant discounts. ${ }^{102}$ The Institute for Catastrophic Loss and the Co-operators Group recently built an experimental house in Prince Edward Island that is built with tougher shingles, steel reinforcements and windows that can withstand 200 kilometre winds. ${ }^{103}$

Insurance companies have become more involved in political circles as well.

Swiss Re has publicly called for a "concerted effort by all economic and social stakeholders," suggesting that, "climate protection efforts need to be accelerated, and politicians and the public are increasingly aware of the significant role they can play." 104 In Australia, the Insurance Australia Group (IAG) teamed up with the Australian Conservation Foundation (a leading environmental NGO) and major businesses to form the Australian Business Roundtable, which has put some pressure on a government that has refused to ratify the Kyoto Protocol. ${ }^{105}$ Various insurers have also developed partnerships with leading intergovernmental organizations including the OECD, the

\footnotetext{
${ }^{101}$ H. Kunreuther and E. Michel-Kerjan, National Bureau of Economic Research, Climate Change, Insurability of Large-Scale Disasters and the Emerging Liability Challenge, January 2007. A vailable from http://www.nber.org/papers/w12821.

${ }^{102}$ Q. Kim, "Industry Aims to Make Homes Disaster-Proof: Companies Roll Out 'Safe Rooms,' Impervious Roofs, 2x4-Proof Glass; Discounts on Home Insurance," The Wall Street Journal, 20 September 2004.

${ }^{103}$ T. Grant, "Insurers Seek Shelter from Climate Change: Weather-Related Claims Continue to Mount," The Globe and Mail, 5 February 2007: B1, B10.

${ }^{104} \mathrm{P}$. Heck et al., The Effects of Climate Change: Storm Damage in Europe on the Rise, (Swiss Reinsurance Company: Zurich, 2006): 2 and 4 respectively.

${ }^{105}$ M. Hawker, "Climate Change and the Global Insurance Industry."
} 
United Nations, the World Bank and so forth. At the 2005 G8 meeting, the insurance industry took a prominent role when the discussions turned to the issue of climate change. The Association of British Insurers published The Financial Risks of Climate Change in advance of the meetings in Gleneagles. Munich Re has also publicly called for governments to support and uphold Kyoto Protocol targets, arguing that, "a follow-up

agreement to the Kyoto Protocol, with consistent reduction targets, is indispensable."106

Although the insurance industry should certainly be commended for taking a leadership role in climate change research and mitigation and adaptation strategies, it is clear that these companies also recognize that such involvement will help to ensure the long-term viability of their industry. Munich Re and Swiss Re, for instance, have crafted a corporate image that is allied with environmental interests, proudly publicizing its prominent role in the climate change meetings. But it is only under certain conditions that both business and environmental needs have the potential to be mutually beneficial. By better understanding the consequences of a warmer planet, insurers can better predict weather-related risks in a particular area. Similarly, rewarding certain behaviours and urging governments to meet emissions targets and enforce building codes has the added benefit of improving insurers' bottom lines as these measures may serve to reduce climate-related risks. The more insurers and reinsurers can diminish the unknown, the better-positioned they are to generate grater profits.

\section{CONCLUSIONS}

By all accounts, the 2004 and 2005 Atlantic hurricane seasons were devastating. Thousands of people lost their homes, lives, livelihoods and possessions as a series of

${ }^{106}$ Munich Re Group, Topics Geo Natural Catastrophes 2006, 43. 
severe storms battered the Gulf coast. It was during these two years that rumblings were heard from insurers and reinsurers both in the areas that were directly hit by the storms and elsewhere as the financial effects of the hurricanes were felt in North America, Europe and Asia. Amidst dire profit warnings, companies were forced to raise premiums and pull out of markets that were becoming too risky to be financially viable. Companies like Allstate and State Farm cried poor, raising rates, pulling out of markets and calling for federal government bail-outs.

At the same time, the 2004 to 2006 period demonstrated that the industry is wellequipped to deal with catastrophic events like Hurricane Katrina. Recognizing that the risks in the Gulf states were too high, many companies raised rates for home and property owners in the region or pulled out of these markets completely. These moves transferred a greater proportion of risk to homeowners. As discussed in the previous chapter, such actions may serve to make individuals more responsible for their behaviours, forcing people to be more aware of their environs and take ownership for their high-risk decisions. Also, the fact that most insurers were only responsible for damages caused by high winds - flood damages were covered through the NFIP - meant that the industry was only responsible for a portion of the region's losses. ${ }^{107}$ At the same time, the adjustments made by insurers and reinsurers proved beneficial for the industry as a whole. The steady profits earned in the last several years prove that the industry's riskspreading arrangement works well; the geographical and financial flexibility along with the ability to frequently reassess risks have allowed insurers and reinsurers to maintain their profitability. The fact that hurricanes repeatedly struck one area in the world did not

\footnotetext{
${ }^{107}$ The Economist, "How to Stiff Both Louisianans and the Federal Government," The Economist, 21 July 2007.
} 
seem to hurt the industry to a great extent. The protection offered through a network of policyholders, reinsurers, investment portfolios and, more recently, ARTs, meant that two years of costly hurricanes did little to disrupt insurers' bottom lines.

In considering the implications of climate change, Mills et al. argue that insurers have two options: "[they] may rise to the occasion and become more proactive players in improving the science and crafting responses. Or, they may retreat from oncoming risks, thereby shifting a greater burden to governments and individuals." ${ }^{108}$ The insurance industry, it would appear, has taken both avenues, with primary insurers deciding to pull out of risky markets and leading reinsurers taking on a leadership role on climate change. With the inaction of many of the world's governments, the industry has moved into what is essentially a power vacuum, challenging the authority of traditional political players on climate change. In addition to pushing political leaders on their Kyoto targets and tougher building codes and zoning regulations, the industry has forged its own action plan in combating climate change by encouraging policyholders to make changes in the way in which they live both as a means to mitigate and adapt to natural hazards. While the public discourse is one of social responsibility, it is clear that insurers also recognize the financial benefits of reducing their clients' damages in storm events.

${ }^{108}$ E. Mills et al., "Insurance in a Climate of Change," Science, 309, (12 August 2005): 1043. 


\section{Chapter 6: Conclusions}

The incredible magnitude and scale of hazards places a great deal of pressure on the institutions that are charged with the task of providing security against such events. Preparing for and responding to natural hazards and disasters now requires massive coordinated efforts between research centres, NGOs, federal and local governments, private businesses and emergency services. Beck writes, "precisely because of their explosiveness in the social and political space, hazards remain distorted objects, ambiguous, interpretable, resembling modern mythological creatures, which now appear to be an earthworm, now again a dragon, depending on the perspective and the state of interests." It seems that we are presently in an era where hazards appear 'dragon-like' as accelerated urbanization and wealth accumulation along coasts and a future of more frequent and severe extreme weather-related events becomes a reality. It is in this context that various institutions have grappled with the formidable task of providing security against natural hazards. That one body, business, institution or technique can guarantee absolute security is wishful thinking, and so it is important to look at two institutions that have taken up the challenge to protect communities against natural hazards and see what can be learned by these different approaches.

In its current formulation, the state alone is not prepared to secure human societies from the threat posed by natural hazards and disasters. While states remain successful in some regards, their weaknesses prevent them from being the securing agent against extreme weather-related events. States are useful in that they can be very adept at building massive infrastructure projects such as sturdy buildings, dykes, dams, pumping

\footnotetext{
1 U. Beck, "From Industrial Society to the Risk Society: Questions of Survival, Social Structure and Ecological Enlightenment," Theory, Culture \& Society, Vol. 9, (1992): 105.
} 
stations and floodways. They have access to vast resources of capital, labour and expertise that other institutions can only dream of acquiring. Also, as it currently stands, states are the only players that are allowed to negotiate and sign international environmental agreements that may address climate concerns - whose link to hazards is still unknown. However, states continue to rely on Cold War era thinking when it comes to formulating approaches in preparing for, mitigating and responding to natural hazards and other global dangers. Hazards and disasters security strategies are predicated on an ontology that views security in militaristic and institutional terms and nature as an ontologically separate and subservient realm. Hazards threats are understood to be 'evil' forces that threaten the 'good' citizens of a given country; and according to the state, the best way to combat these threats is to revert to technological and militaristic solutions. In addition, hazards' variable geography - from local inputs and impacts to transnational effects - puts into question the idea that states remain the default guarantors of security when in fact their geographical scope is limited. New Orleans' experience in 2005 demonstrated that, despite the government's best intentions, communities cannot always engineer their way around natural hazards. The aftermath of Hurricane Katrina also pointed to the important role that states have in reducing society's vulnerability to natural hazards. By improving socioeconomic conditions, providing hazards information and education, exercising sound urban planning and strengthening building codes, states have the ability to prevent natural hazards from becoming disasters. But again, Hurricane Katrina demonstrated that, while the capacity is certainly present, the interest in reducing vulnerability and moving beyond traditional responses to hazards is lacking. 
One of the main difficulties facing states is that hazards and disasters operate on frustratingly vague scales. On one hand, disasters are made possible by urban expansion and wealth accumulation along coastlines and mountainsides. On the other hand, extreme weather-related events originate in the Earth's atmosphere and are affected by global temperatures, cloud cover and wind and ocean currents among other factors. While these systems are incredibly complex and massive in scale, they tend to affect fairly limited areas, such as coastal communities along the Gulf of Mexico; regions like Southern Ontario generally do not experience the same level and/or intensity of hazards.

In an age of fluid state boundaries and the rise of capital in global politics, insurance, it seems, has the ability to overcome such problems of scale that render states both cumbersome on the local level and powerless on the international level. Recent literature suggests that viewing the world only in terms of autonomous states that have exclusive access to the international community ignores the power that lies in the daily flows of commerce and knowledge. Agnew and others have suggested that corporations and economic alliances are more 'international' than states, as they operate on many scales simultaneously. ${ }^{2}$ Similarly, insurance and reinsurance companies have the ability to link the global with the local through risk-sharing agreements that connect bilateral agreements between policyholders and providers to a vast array of corporations, investors and clients.

State responses also have a tendency to be administered in a technocratic, topdown fashion which perpetuates existing beliefs that hazards and disasters are somebody else's problem. Perhaps hazards can be better addressed when responsibility is born by

\footnotetext{
${ }^{2}$ See J. Agnew, Geopolitics: Re-Visioning World Politics, 2nd Ed., (New York: Routledge, 2003) and S. Dalby, "Globalisation or Global Apartheid? Boundaries and Knowledge in Postmodern Times,"

Geopolitics. Vol. 3, No. 1, (Summer 1998): 132-150.
} 
individuals, as they can better understand the risks that are involved with certain practices such as living on floodplains or beaches. Insurance providers can use premiums, conditional agreements, coverage options and education programs to 'responsibilize' their customers and make them more aware of the true risks that are inherent to an area. Also, loss-prevention initiatives, such as installing better roofs and windows, address hazards issues from the bottom-up as they force homeowners to be become their own 'agents of prevention.' By transferring greater responsibility for risk onto policyholders, insurance companies can force individuals to be more responsible for their own security.

The analysis of the insurance industry's movements, transactions, position statements and financial performance from 2004 to 2006 suggests that insurers and reinsurers are in fact quite adept at spreading and managing risks. The robustness of the industry is largely due to trends towards increasing firm size, greater diversification, greater integration of insurance with other financial services and improved tools to transfer risk. ${ }^{3}$ These factors meant that the industry was well-positioned to pay for Hurricane Katrina's $\$ 40$ billion bill. Furthermore, insurers responded to the unusually costly 2004 and 2005 Atlantic hurricane seasons by appropriately raising premiums and pulling out of risky markets, moves that served to better reflect the degree of risk in these regions. Combined with an unusually inactive 2006 hurricane season, insurers and reinsurers maintained profitability over the three-year period feeling few ill-effects of two record-breaking hurricane seasons. It is interesting that the discourse coming out of the industry, particularly in 2004 and 2005, seemed to signal massive changes in the way in which insurers and reinsurers conducted their respective businesses when in actual fact,

\footnotetext{
${ }^{3}$ Intergovernmental Panel on Climate Change, Climate Change 2001: Impacts, Adaptation and Vulnerability, (Cambridge: Cambridge University Press, 2001). Available from http://www.grida.no/climate/ipcc_tar/wg2/index.htm.
} 
climbing profits suggested that the industry's built-in risk-spreading and reduction measures worked as planned.

Nevertheless, recent years have seen insurers, and reinsurers in particular, take a more vocal stand on climate change. Fearing a significant change in the way in which they calculate and predict hazards risks, insurers have attempted to better understand what a warmer planet will mean for natural hazards, especially hurricanes. Prominent reinsurers, including Munich Re and Swiss Re, have taken a lead role in climate change discussions and developing action plans, perhaps recognizing the inability of states to move beyond stifling international power dynamics. At the local level, primary insurers have pressured municipalities on better enforcement of and improvements to building codes and land-use regulations, while on the national and international levels, larger firms have become involved with various NGOs and intergovernmental organizations (IGOs) in pushing national governments on meeting emissions targets and developing better disaster response plans. Also, research into better building techniques and premium incentives has been used in an attempt to circumvent government inaction and reduce losses at the individual level. Such behaviours benefit the industry on two fronts: first, more frequent and severe natural hazards are bad for business, since they require greater access to capital, and thus pushing for climate change mitigation and adaptation strategies helps to reduce such pay-outs; second, leading the charge on climate change has enabled the industry to improve its public image, which is good for a business that sells 'peace of mind.'

While insurance certainly possesses some potential to help secure individuals from natural hazards and disasters, there are a few issues that are causes for concern, 
many of which suggest a revised role for state institutions in hazards and disasters mitigation strategies. For instance, insurance can only offer protection against losses that can be assigned a monetary value, such as roofs and furniture. Insurance cannot provide recompense for intangible losses, including culture and community, which are not any less valuable than possessions with economic value. In addition, insurance companies are in the business of making profits; their actions are not primarily altruistic nor do they always operate with the best interests of society in mind. For example, insurers operating along the Gulf Coast have not exactly been forthcoming with claims payments as they have used fine-print and various policy loopholes to short-change homeowners in the region an estimated $\$ 1.5$ billion. ${ }^{4}$ Also, if people who are not profitable (i.e. the poor) require insurance, there is little guarantee that some company will provide the needed coverage and make it affordable.

If we assume that hazards and disasters security is about maintaining some measure of control in an uncertain future and ensuring that all individuals basic needs are satisfied, then it seems that neither the state nor the insurance industry are, in their current iterations, able to offer the promise of security. Insurance helps to reduce the unknown by encouraging a culture a responsibility, better building techniques and addressing climate change issues ex ante; in addition, the promise of financial recompense following a disaster, in theory, allows individuals to meet their basic needs. But the flaws in this security approach, as mentioned earlier, are difficult to ignore. Similarly, the state's best efforts to establish certainty in an unpredictable future continue to rely on strategies and mindsets that worked for an entirely different type of threat. That poverty still exists on

\footnotetext{
${ }^{4}$ The Economist, "How to Stiff Both Louisianans and the Federal Government," The Economist, 21 July 2007.
} 
massive scales in the world suggests that human security is still a long way off. But in matters such as these, failures also represent opportunities for improvement, and so it is important to continue to examine alternative modes of hazards and disasters security.

Foucault's analytics of power were invoked in the opening chapter to provide both the theoretical and methodological underpinnings for this work. His writings remain relevant because they challenge the normalizing behaviours and discourses that claim to provide 'the answer,' thereby foreclosing all other possibilities. What has been challenged here is the belief that certain institutions have exclusive rights to provide and dictate hazards and disasters security. We must remember that knowledges emerge from a historical set of discursive practices. For instance, the militaristic and technological approaches to hurricanes in the United States are based on a fifty-year history of Cold War politics. In addition, hazards and disasters security is presently influenced by a dichotomous ontology that pits 'nature' and 'humans' against one another. If we take Dalby's assertion that "the environment as a simple category of concern has also been transcended" seriously, then hazards and disasters security would mean something entirely different from the status quo. ${ }^{5}$

That states can unproblematically claim exclusive rights to power has also been questioned here. Global dangers denormalize the belief that states remain the default guarantors of security because they expose weaknesses in states' claims to power. Thus, crucial 'certainties' from as recently as fifteen years ago - such as the existence of fixed and unquestioned political boundaries between states - are seriously in question. Issues such as natural hazards, international trade and transnational terrorism have put the

\footnotetext{
${ }^{5}$ S. Dalby, "Ecology, Security, and Change in the Anthropocene," Brown Journal of World Affairs, Vol. 8, No. 2, (Spring/Summer 2007): 159.
} 
validity of such 'truths' into serious doubt and have raised important questions as to where power now resides. Agnew writes that "understanding power as if it is attached singularly to state territories makes no sense."6

Foucault also implores his students to examine the "extremities" of power and to view power as a process rather than an object. ${ }^{7}$ This thesis has sought to understand the role of insurers in the context of hazards and disasters security. It has been argued here that the insurance industry wields power at many levels. First, its tremendous size and financial activity grants it serious leverage in international financial markets. In terms of economic power alone, the industry has demonstrated its robustness in the face of significant hazards losses. Second, insurers continue to lobby governments at various levels: at the local level various companies have pushed for tougher building codes while at the federal level, insurers and reinsurers have pressed governments on creating a national insurance scheme and meeting GHG emission targets. Finally, insurers possess a governing ability over homeowners in their ability to dictate how much risk and responsibility each individual must bear. Turning policyholders into 'agents of prevention' shifts power away from institutions and faces individuals with the consequences and costs of their own choices - whether these are constrained choices is a separate issue.

The crucial point here is that insurance provides reason for pause when considering how communities secure themselves from hazards. Insurers possess tremendous power insofar as natural hazards are concerned since they can wield their influence in various geographical and temporal scales. Insurance thus holds a great deal

\footnotetext{
${ }^{6} \mathrm{~J}$. Agnew, Geopolitics, 65.

${ }^{7}$ M. Foucault, Society Must Be Defended: Lectures at the Collège de France, 1975-1976, eds. M. Bertani and A. Fontana, (New York: Picador, 2003): 25.
} 
of potential in offering improvements to current hazards and disasters security regimes. Its institutional flexibility, global political power and ability to transfer risk and responsibility should not be overlooked. Hazards and disasters security does not always necessitate legislative measures, massive infrastructure projects and mobilized action; instead, it can be achieved through daily, mundane decisions and through the actions of non-state institutions and organizations.

This thesis is admittedly a work of criticism, as it follows the postmodern tradition of deconstructing the words, phrases, techniques and/or processes that inform 'knowledge.' But as Simon Dalby reminds his readers in the introduction to Environmental Security, it is important to remember Foucault's thoughts on the importance and function of critique:

Criticism is a matter of flushing out thought and trying to change it: to show that things are not as self-evident as one believed, to see that what is accepted as self-evident will no longer be accepted as such. Practicing criticism is a matter of making facile gestures difficult. ${ }^{8}$

Similarly, Derrida argues that scholars must rigorously challenge the possibility of achieving closure of meaning, "since there is no center or core from which meaning radiates." ${ }^{.9}$ Critique is thus refusing to accept that which has been invented as 'truth.' As Gordon and Miller write,

Government is not just a power needing to be tamed or an authority needing to be legitimized. It is an activity and an art which concerns all and which touches each. And it is an art which presupposes thought. The sense and object of government acts do not fall from the sky or emerge ready formed from social practice. They are things which have had to be and which have been - invented. Foucault observed that there is a parcel

\footnotetext{
${ }^{8}$ M. Foucault, "Practicing Criticism," Politics Philosophy, Culture: Interviews and Other Writings, 19771984, (New York: Routledge, 1988): 154-155 in S. Dalby, Environmental Security, (Minneapolis: University of Minnesota Press, 2002): xxx.

${ }^{9}$ B. Braun and J. Wainwright, "Nature, Poststructuralism, and Politics," 48.
} 
of thought in even the crassest and most obtuse parts of social reality, which is why criticism can be a real power for social change. ${ }^{10}$

The crucial point of this study is to open new possibilities for how Western societies relate to and understand natural hazards, particularly to evaluate the role that insurance plays in governing these relationships and understandings. This thesis is less about producing certainties than it is about introducing alternative modes of thought and raising new questions.

\section{A ROLE FOR THE STATE?}

Much of what has been discussed in this thesis has admittedly represented an idealized view of how the insurance industry manages risk and responsibility in the developed world. There is still a much-needed role for the state when one considers the political economy of insurance. Wealthy people often choose to live in hazards-prone areas "for the view," whereas poor people are constrained by social, economic, cultural and political factors that limit the types of homes that they can afford and where they can live. ${ }^{11}$ States are therefore needed on two fronts: first, they must try to remove, or at least diminish, the structural constraints that limit choices; and second, by revealing choices, states also have a responsibility to ensure that the ensuing decisions are made in a manner that reflects the true nature of environmental risks.

As discussed in Chapter 3, state mechanisms tend to be reactive in nature. Cities like New Orleans, Los Angeles and Miami - not to mention the cash-strapped cities in

\footnotetext{
${ }^{10}$ G. Burchell et al. eds., The Foucault Effect: Studies in Governmentality, (Chicago: University of Chicago Press, 1991) in T. Baker and J. Simon, "Toward a Sociology of Risk," in Embracing Risk: The Changing Culture of Insurance and Responsibility, eds. T. Baker and J. Simon, (Chicago: University of Chicago Press, 2002): 32.

"' B. Wisner et al., At Risk: Natural Hazards, People's Vulnerability and Disasters, 2nd ed., (New York: Routledge, 2004): 11.
} 
the developing world - have adopted a disaster management style that appears to take a 'wait-and-see' approach to hazards. Condoning development along coastlines and relying on decades-old technologies appears to be the norm in many North American cities. But some governments have demonstrated a capacity to be proactive when it comes to disasters, refusing to take a passive approach to hazards. Again, the experiences of Hokkaido and Manitoba are appropriate examples. At the present moment, strict earthquake building codes in Japan and the construction of the Red River Floodway and increased public awareness campaigns have prevented disasters ex ante; the foresight of such measures is especially apparent if one juxtaposes these disaster experiences against those in Kocaeli-Gölcük and New Orleans respectively. Certainly, such measures may reach the limit of what they can secure against, but the fact that these governments have made a concerted effort to use existing strategies judiciously is reason for some optimism. Whether or not such measures can sustain stronger and/or more frequent natural hazards in the long-term remains unknown

As mentioned earlier, perhaps the greatest flaw with insurance as a securing agent is that it is not in the business of building risk pools through collective sentiments; rather, admittance to these groups is achieved through financial means. Since not everyone can afford to buy this type of security, the unavailability and/or high cost of insurance reflects and reinforces the social hierarchies in a given community. ${ }^{12}$ By discussing insurance and its potential to 'responsibilize' individuals, this thesis therefore focuses on a limited segment of the population, mainly those that can afford to purchase insurance. It is important not to take insurance propaganda too much for granted and recognize that there is a distinct role for the state in providing economic security from natural hazards. Poor

\footnotetext{
12 T. Baker and J. Simon. "Toward a Sociology of Risk."
} 
people are simply not profitable for insurance companies as they do not possess much collateral value, nor can they afford to pay high premiums. Lack of access to funds and insurance constrains choices for a large segment of the population. New Orleans' most affordable housing, for example, is in the city's lower-lying areas; more expensive homes are generally found in the higher and therefore drier parts of the city. Even if New Orleans' poorest residents were aware of flood risks, they had little choice but to live in those areas or move elsewhere since their incomes dictated where they could and could not reside. Also, rich people, with their sturdy brick and mortar houses, are not as affected by hazards as their less financially-able counterparts, since weaker structures, like mobile homes, are often all that they can afford. Karen Bakker writes, "wealthier, largely white individuals have secured relatively cleaner, safer environments in American urban centres, leaving poor, largely black communities to locations with higher pollution and higher hazard probabilities and impacts." $" 13$

States therefore play a necessary role where insurance is not available and/or unaffordable. The NFIP was instituted by the US government in recognition of the fact that many citizens cannot afford flood insurance, but due to structural constraints, are often forced to live in flood-prone regions. But the NFIP does not discriminate its aid packages based on whether or not people knowingly placed themselves in harm's way, nor is it particularly proactive in preventing loss or properly assessing risks. States therefore need to re-evaluate how such disaster relief is distributed and applied and find a way to incorporate risk-mitigation strategies into public insurance schemes - for instance, NFIP policies should be tied to affordable, but mandatory, building improvements for

\footnotetext{
${ }^{13}$ K. Bakker, "Katrina: the Public Transcript of 'Disaster," Environment and Planning D: Society and Space, 23, (2005), 797.
} 
landlords. Even enforcing existing building codes and revisiting land-use regulations would assist in reducing hazards vulnerability tremendously. While offering premiums at artificially low levels maintains affordability, these subsidies must also force individuals to take ownership of their risks.

It is clear that government-sponsored programs are necessary as are improvements to social infrastructure projects that seek to address the root causes of why people are limited to certain choices. Rather than focus almost exclusively on the science and technology aspects of hazards mitigation, states should also direct their energies towards programs that seek to reveal more choices to those with limited means and to raise environmental awareness so that decisions are made with the hopes of decreasing one's vulnerability to hazards. This can perhaps be achieved by increasing funding for welfare programs, education and skills development programs, daycare and public health initiatives. Many of the root causes of disaster seem to relate to poverty, which Wisner et al. argue is intrinsically linked to vulnerability, a term they define as "the characteristics of a person or group and their situation that influence their capacity to anticipate, cope with, resist and recover from the impact of a natural hazard." ${ }^{14}$ States can play a muchneeded role in helping to alleviate the conditions that make certain people more vulnerable to natural hazards

Insurance certainly has the potential to change the terms of security for a significant portion of the global population, but access issues undermine its ability to provide widespread promises of future security. Insurers are very adept at spreading risk and have influence at both the international and individual levels, through their financial capacity and availability respectively. Also, by encouraging and subsidizing building

\footnotetext{
${ }^{14}$ B. Wisner et al., At Risk, 11.
} 
improvements, insurers have helped to reduce homeowners' vulnerability to various hazards. Since disasters are in many ways products of the social, economic and political environments, then states have the power and obligation to address these issues before hazards occur. States need to think seriously about building codes and zoning legislation as they unnecessarily place people in harm's way. Perhaps states could borrow some insurance principles and techniques, such as fostering a culture of prevention and reevaluating the administration of state-funded insurance plans, in order to move away from current top-down approaches and placing greater responsibility for hazards mitigation and prevention on citizens.

Understanding security from natural hazards requires a multi-faceted and institutional approach that is not afraid to consider atypical methods and techniques. The crucial point is that we must continue to search for ways to improve the current hazards and disasters security regime. States, in particular, need to break out of traditional security moulds and modify their strategies so that they can better understand and address the amorphous nature of global dangers. For example, poverty alleviation and better environmental awareness would be useful projects in improving disaster preparedness in many parts of the world. Until all hazards losses are completely eliminated - an insurmountable task indeed - research into new ways of looking at these problems should continue to spark debate and facilitate improvements to the status quo.

\section{DIRECTIONS FOR FUTURE RESEARCH}

Although this thesis is not presented as a policy-driven discussion, it is worth noting how such a transition from theory to practice could be facilitated through various 
empirical studies. Further studies by those with detailed knowledge of government-run hazards institutions and the insurance industry would provide an opening into policy research by providing a more complete picture of how these bodies operate in practice. This would include focussing the present analysis on specific localities and individual insurance providers since it is clear that, "the insurance 'industry' is non-monolithic, with considerable regional variations in coverages, hazard exposure, and regulation within and among countries." 15

This thesis also assumes that taking greater responsibility for hazards risks will encourage individuals to be more reflexive about how they relate to their natural surroundings, perhaps causing a gradual shift in the dominant human-nature ontology. But people are not always rational and do not always conflate things like natural hazards and global warming. This is a logical jump that has not been proven here as it hinges on temporal considerations and numerous individual decision-making factors. Thus, the earlier discussion on insurance as the 'sleeping giant of power' begs further research into measuring the degree of influence that insurers and their policies actually have on homeowners and their decision-making processes. For instance, a longitudinal study of homeowners and their responses to decreasing coverage or increasing restrictions on their policies would give some indication as to the extent to which insurance forces homeowners to take responsibility for their own hazards and disasters security. A better understanding of homeowners' decision-making processes in relation to responding to hazards risks would also be useful - for example, one could ask a local group of homeowners to rank the influence of insurance affordability, cost of building improvements, climate change projections, the absence/presence of federal insurance

${ }^{15}$ E. Mills et al., "Insurance in a Climate of Change," Science. 309, (12 August 2005): 1040. 
schemes and so forth on whether or not they will relocate or undertake risk reduction measures. As far as the ontological underpinnings of this thesis and the normalization of 'nature' are concerned, a survey on the societal perceptions of hazards (e.g. whether or not they are 'acts of God' or 'acts of humans') and local environments would help to link some of the social nature discussions with the hazards literature.

Further analysis of other 'extremities of power' would also prove useful as it would expand the terms of the hazards and disasters security debate. A similar investigation into the role of religion, NGOs, IGOs and other institutions' influence over hazards and disasters security would be appropriate. Indigenous approaches and responses to hazards are particularly interesting. For instance, in building 'Western-style' houses, many Malaysians have increased their susceptibility to flooding by abandoning traditional 'kampung' house design, which uses stilts to elevate homes. ${ }^{16}$ In another case, on the Andaman and Nicobar Islands in the Indian Ocean, the islands' five indigenous tribes amazingly suffered no human losses in the 2004 Boxing Day Tsunami. Through an oral history that spanned several centuries, the islands' inhabitants understood that when the ground shook, everyone was to immediately head into the dense forests and seek higher ground. ${ }^{17}$ In general, traditional or 'folk' knowledge is geographically specific and is thus able to nurture locally appropriate hazards-response strategies. But such types of knowledge and practice are no longer treated as acceptable modes of disaster mitigation due to their lack of scientific backing. ${ }^{18}$ If security remains one of the goals of Western

\footnotetext{
${ }^{16}$ N. Chan and D. Parker, "Response to Dynamic Flood Hazard Factors in Peninsular Malaysia," The Geographical Journal, Vol. 162, No. 3, (November 1996): 320.

${ }^{17}$ S. Bhaumik, "Tsunami Folklore 'Saved Islanders," BBC News, 20 January 2005. Available from http://news.bbc.co.uk/2/hi/south asia/4181855.stm.

${ }^{18}$ D. Parker and J. Handmer, "The Role of Unofficial Flood Warning Systems," Journal of Contingencies and Crisis Management, Vol. 6, No. 1, (March 1998): 60.
} 
society, then we must not preclude alternative visions of how we can best achieve these desired futures.

As stated in the opening chapter, this thesis has admittedly focussed on one particular view of security, one that has directed the discussion in a particular manner. The present study is mainly concerned with securing lives, homes and possessions against damages and losses due to natural hazards, a definition that is influenced in part by Barnett's human security approach. But what happens if we consider a broader definition of what is to be secured? For example, a discussion of ecological security and hazards - an approach that takes the Earth, rather than humans, as the referent object of security - shifts the terms of debate such that the health of the human species is equal to that of the millions of other beings that live on the planet and the Earth itself. Similarly, expanding the definition of security so that it encompasses intangibles such as culture and community would dramatically change which institutions are charged with the task of ensuring security and their methods. Exploration into these and other approaches to security would raise important questions concerning how present society understands and values hazards and disasters security.

Given that events that seem age-old (e.g. floods, storms and landslides) still occur in places where it had been thought that these problems were 'solved,' it is premature to think that disasters research will soon reach its endpoint. As Hewitt writes, "a critical and searching approach, rather than a merely prescriptive one, seems warranted by present conditions." 19 This thesis takes Hewitt's call seriously and attempts to critically search

\footnotetext{
${ }^{19}$ K. Hewitt, Regions of Risk: A Geographical Introduction to Disasters, (Essex: Addison Wesley Longman Limited, 1997): 16.
} 
for a different approach to natural hazards and disasters mitigation and adaptation. While Hewitt and Wisner et al., focus primarily on vulnerability and how poverty and development affect certain group's capacity to adapt to and respond to hazards, this thesis critiques the dominant approach to hazards and examines how insurance overcomes problems of scale and encourages responsibility on an individual level. Whether or not what is proposed here is feasible is not the focus of the current work; instead, this research simply seeks to take the current research in a different direction.

It seems that many of Western society's current environmental problems stem from an inability to move beyond an ontology that views the human and natural worlds as irrevocably separate entities. Moreover, it is this ontology that informs the belief that hazards pose a security threat to human societies. While natural hazards are certainly powerful and are often very destructive, the crucial point is that they are not maliciously motivated. Hazards and disasters security needs to move beyond the notion that human societies are victims, when it is in fact people who enable disasters. There also needs to be some thought put into whether or not we can artificially separate the environment from the human, especially in light of discussions concerning the Anthropocene era. As Wisner et al. write, "the 'natural' and the 'human' are, therefore, so inextricably bound together in almost all disaster situations, especially when viewed in an enlarged time and space framework, that disasters cannot be understood to be "natural in any straightforward way." 20

\footnotetext{
${ }^{20}$ B. Wisner et al., 9 .
} 


\section{Bibliography}

Adam, David. "Leaders Say Warning System is Priority.” The Guardian. 7 January 2005.

Adetunji, Lydia. "Munich Re Promises 55\% Dividend Rise - Insurance." The Financial Times. 30 December 2005.

Alexander, David. "The Study of Natural Disasters, 1977-1997: Some Reflections on a Changing Field of Knowledge." Disasters. 21, 4, (1997): 284-384.

AllState, "Insurance Products at Allstate Insurance," 2005. Accessed 4 February 2005. Available from http://www.allstate.com/Products/pagerender.asp?page=main.htm.

Agnew, John, Geopolitics: Re-Visioning World Politics. $2^{\text {nd }}$ Ed. New York: Routledge, 2003.

Baker, Tom. "Risk, Insurance, and the Social Construction of Responsibility." In Embracing Risk: The Changing Culture of Insurance and Responsibility, eds. Tom Baker and Jonathan Simon, 33-51. Chicago: University of Chicago Press, 2002.

Baker, Tom and Jonathan Simon. "Embracing Risk." In Embracing Risk: The Changing Culture of Insurance and Responsibility, eds. Tom Baker and Jonathan Simon, 126. Chicago: University of Chicago Press, 2002.

Baker, Tom and Jonathan Simon. "Toward a Sociology of Risk." In Embracing Risk: The Changing Culture of Insurance and Responsibility, eds. Tom Baker and Jonathan Simon, 27-32. Chicago: University of Chicago Press, 2002.

Bakker, Karen. "Katrina: the Public Transcript of 'Disaster." Environment and Planning D: Society and Space. 23, (2005), 795-802.

Bankoff, Greg. "Rendering the World Unsafe: 'Vulnerability' as Western Discourse." Disasters. 25,1, (2001): 19-35.

Bankoff, Greg. "Constructing Vulnerability: The Historical, Natural and Social Generation of Flooding in Metropolitan Manila." Disasters. 27, 3, (2003): 224238.

Barnet, Richard J. and Cavanagh, John. Global Dreams: Imperial Corporations and the New World Order. New York: Simon \& Schuster, 1994.

Barnett, Jon. The Meaning of Environmental Security. New York: Zed Books, 2001.

Bayot, Jennifer. "Cost Estimates by Reinsurers are Climbing." The New York Times Abstracts. 13 September 2005. 
Beck, Ulrich. "From Industrial Society to the Risk Society: Questions of Survival, Social Structure and Ecological Enlightenment." Theory, Culture \& Society. Vol. 9, (1992): 97-123.

Beier, Marshall. "Beyond Hegemonic State(ments) of Nature." In Power, Postcolonialism and International Relations, eds. G. Chowdhry and S. Nair, 82114. London: Routledge Ltd., 2002.

Berz, Gerhard A. "Catastrophes and Climate Change: Concerns and Possible Countermeasures of the Insurance Industry." Mitigation and Adaptation Strategies for Global Change. Vol. 4, (1999): 283-293.

Bhaumik, Subir. "Tsunami Folklore 'Saved Islanders.” BBC News. 20 January 2005. Available from http://news.bbc.co.uk/2/hi/south_asia/4181855.stm.

Blackwater USA. "About Us.” 2005. Accessed 12 August 2006. Available from http://www.blackwaterusa.com/about/.

Bourdeau, Ph. "The Man-Nature Relationship and Environmental Ethics." Journal of Environmental Radioactivity. 72, (2004): 9-15.

Born, Patricia and W. Kip Viscusi. "The Catastrophic Effects of Natural Disasters on Insurance Markets." Journal of Risk and Uncertainty. 33, (2006): 55-72.

Braun, Bruce and Joel Wainwright. "Nature, Poststructuralism, and Politics." In Social Nature: Theory, Practice, and Politics, eds. Noel Castree and Bruce Braun. 4163. Oxford: Blackwell Publishers, 2001.

Braun, Bruce. "Hurricane Katrina and Abandoned Being." Environment and Planning D: Society and Space. 23, (2005), 802-809.

Brouwer, Greg. "The Creeping Storm." Civil Engineering. Vol. 73, No. 6, (June 2003): 46-88.

Brown, Lori. "State of the World: A Year in Review." In State of the World 2005: A Worldwatch Institute Report on Progress Toward a Sustainable Society, ed. Linda Starke. xxiii-xxvii. New York: W.W. Norton and Company, 2005

Burchell, Graham, Colin Gordon and Peter Miller, eds. The Foucault Effect: Studies in Governmentality. Chicago: University of Chicago Press, 1991.

Burton, Ian and Robert Kates. "The Perception of Natural Hazards in Resource Management." Natural Resources Journal, Vol. 3, (1964): 412-441.

Burton, Ian, Robert Kates and Gilbert White. The Environment as Hazard. New York: Oxford University Press, 1978. 
Campbell, David. Writing Security: United Sates Foreign Policy and the Politics of Identity. $2^{\text {nd }}$ Ed. Minneapolis: University of Minnesota Press, 1998.

Carson, Rachel. Silent Spring. New York: Haughton Mifflin Company, 1962.

Castree, Noel. "Socializing Nature: Theory, Practice, and Politics." In Social Nature: Theory, Practice, and Politics, eds. Noel Castree and Bruce Braun, 1-21. Oxford: Blackwell Publishers, 2001.

Castree, Noel. Nature. New York: Routledge, 2005.

CBC News. "Canada Sending DART to Help in Sri Lanka." cbc.ca. 4 January 2005. Available from http://www.cbc.ca/story/canada/national/2005/01/03/dart050103.html.

Chan, Ngai Weng and Dennis J. Parker. "Response to Dynamic Flood Hazard Factors in Peninsular Malaysia." The Geographical Journal. Vol. 162, No. 3, (November 1996): 313-325.

Changnon, Stanley A. and David Changnon. "Record-High Losses for Weather Disasters in the United States During the 1990s: How Excessive and Why?" Natural Hazards. 18, (1999): 287-300.

CNN. "You are Either With Us or Against Us." CNN.com. 6 November 2001. Available from http://archives.cnn.com/2001/US/11/06/gen.attack.on.terror/.

Colter, Allison Bisbey. "Catastrophe-Bond Supply Builds Up." The Wall Street Journal. 27 September 2006.

Cooper, David E. “Heidegger on Nature.” Environmental Values. 14 (2005): 339-351.

Crossley, David. "10 'Worst' Natural Disasters." Department of Earth and Atmospheric Sciences, St. Louis University. 18 October 2005. Available from http://www.eas.slu.edu/hazards.html.

Dalby, Simon. "Security, Modernity, Ecology: The Dilemmas of Post-Cold War Security Discourse." Alternatives. 17, (1992): 95-134.

Dalby, Simon. "Ecological Metaphors of Security: World Politics in the Biosphere." Alternatives. 23, (1998): 291-319

Dalby, Simon. "Globalisation or Global Apartheid? Boundaries and Knowledge in Postmodern Times." Geopolitics. Vol. 3, No. 1, (Summer 1998): 132-150.

Dalby, Simon. Environmental Security. Minneapolis: University of Minnesota Press, 2002. 
Dalby, Simon. "Anthropocene Ethics: Rethinking 'the Political' after Environment." Conference Paper, Montreal: International Studies Association, March 2004.

Dalby, Simon. "Ecological Politics, Violence, and the Theme of Empire." Global Environmental Politics. 4, 2, (May 2004): 1-11.

Dalby, Simon. "Environmental Security: Ecology or International Relations?" In International Ecopolitical Theory: Critical Approaches, eds. Peter Stoett and Eric Laferrière. 17-33. Vancouver: University of British Columbia Press, 2006.

Dalby, Simon. "Introduction to Part Four: The Geopolitics of Global Dangers." In The Geopolitics Reader, eds. Gearóid Ó Tuathail, Simon Dalby and Paul Routledge. 2nd ed., 177-187. New York: Routledge, 2006.

Dalby, Simon. "Ecology, Security, and Change in the Anthropocene." Brown Journal of World Affairs. Vol. 8, No. 2, (Spring/Summer 2007): 155-164.

Dauer, Ulrike. "In Katrina's Wake: Oil-Rig Insurers Expect Price Jumps - Premiums Could Rise 50\% Following Damages in Gulf to at Least 58 Installations." The Wall Street Journal. 8 September 2005.

Davies, Paul J. "Brit Insurance Makes Record Profits." The Financial Times. 1 March 2005.

Davis, Mike. Ecology of Fear. Toronto: Random House Inc., 1998.

Demeritt, David. "Being Constructive About Nature." In Social Nature: Theory, Practice, and Politics, eds. Noel Castree and Bruce Braun, 22-40. Oxford: Blackwell Publishers, 2001.

Demeritt, David. "Science, Social Constructivism and Nature." In Remaking Reality, eds. Bruce Braun and Noel Castree, 173-192. London: Routledge, 1998.

De Mey, Jozef. "Insurance and Capital Markets." The Geneva Papers. Vol. 32, (2007): 35-41.

Der Derian, James. "The Boundaries of Knowledge and Power in International Relations." In International/Intertextual Relations: Postmodern Readings of World Politics, eds. James Der Derian and Michael J. Shapiro. 3-10. Cambridge: Cambridge University Press, 1989.

Detwiler, Fritz. “'All My Relatives:' Persons in Oglala Religion." Religion. Vol. 22, no. 3, (July 1992): 235-246. 
Dion, Stephane. "Minister Dion's Statement for the Japanese Webcast on the Entry into Force of the Kyoto Protocol." 18 February 2005. Available from http://www.climatechange.gc.ca/english/newsroom/2005/kyoto_feb16statement.a sp.

Dreyfus, Hubert L. and Paul Rabinow. Michel Foucault: Beyond Structuralism and Hermeneutics. $2^{\text {nd }}$ ed. Chicago: University of Chicago Press, 1983.

Dunn, Seth. "Down to Business on Climate Change: An Overview of Corporate Strategies." Greener Management International. 39, (Autumn 2002): 27-41.

Eccles, Robert G. and Matthias Vollbracht. "Media Reputation of the Insurance Industry: An Urgent Call for Strategic Communication Management." The Geneva Papers. Vol. 31, (2006): 395-408.

The Economist. "After the Flood - Hurricane Katrina." The Economist. 3 September 2005.

The Economist. "Assessing the Damage - Insurers and Hurricane Katrina." The Economist. 17 September 2005.

The Economist. "Time for a Makeover - Insurance in America." The Economist. 12 August 2006.

The Economist. "Balmy in Bermuda - Catastrophe insurance." The Economist. 14 October 2006.

The Economist. "How to Stiff Both Louisianans and the Federal Government." The Economist. 21 July 2007.

Eilpern, Juliet. "Shrinking Louisiana Coastline Contributes to Flooding." The Washington Post. 30 August 2005. A07.

Ericson, Richard V., Aaron Doyle and Dean Barry. Insurance as Governance. Toronto: University of Toronto Press, 2003.

Felsted, Andrea. "A Rapidly Shifting Landscape of Risk: The Process of Protecting Businesses Against Hazards is Subject to Unprecedented Change." The Financial Times. 18 April 2005.

Felsted, Andrea, Patrick Jenkins and Haig Simonian. "An Ill Wind: Why the Rising Cost of Cover for Natural Disasters Will Alter an Industry." Financial Times. 20 December 2005: 13.

Felsted, Andrea. "Insurers Face Record \$80 Billion Bill for 2005." The Financial Times. 20 December 2005. 
Felsted, Andrea. "Hurricanes Give Lloyd's a Lashing." The Financial Times. 4 April 2006.

Felsted, Andrea. "Premiums Soar in Disaster Areas." The Financial Times. 13 April 2006.

Felsted, Andrea. "Natural Catastrophes: Nature's Toll Increases." The Financial Times. 24 April 2006.

Feldsted, Andrea. "Hurricane Losses Start to Bite: Insurance Rates." The Financial Times. 25 April 2006.

Felsted, Andrea. "Allstate Tries to Bring a Breath of Sanity." The Financial Times. 16 October 2006.

Felsted, Andrea, Patrick Jenkins and Haig Simonian. "Reinsurers Confront Question of Catastrophe." FT.com. 19 December 2006.

Fleming, Charles. "Katrina Claims Could Leave Holders of a 'Cat Bond' With Major Losses." The Wall Street Journal. 6 October 2005.

Foucault, Michel. Language, Counter-Memory, Practice: Selected Essays and Interviews, ed. Donald F. Bouchard, trans. Donald F. Bouchard and Sherry Simon. Ithaca: Cornell University Press, 1977.

Foucault, Michel. "Practicing Criticism." Politics Philosophy, Culture: Interviews and Other Writings, 1977-1984. New York: Routledge, 1988.

Foucault, Michel, Society Must Be Defended: Lectures at the Collège de France, 1975 1976, eds. Mauro Bertani and Alessandro Fontana. New York: Picador, 2003.

Francis, Theo. "Boss Talk: CEO Says Allstate Adjusts Storm Plan." The Wall Street Journal. 6 September 2005.

Francis, Theo and Michael Schroeder. "Hurricanes Push Insurers to Seek Government Aid." The Wall Street Journal. 26 September 2005.

Freeman, Paul K. and Howard Kunreuther. "Managing Environmental Risk Through Insurance." In International Yearbook of Environmental and Resource Economics, eds. Henk Folmer and Tom Tietenberg. London: Edward Elgar Publishing Ltd., 2003. Available from http://grace.wharton.upenn.edu/risk/downloads/02-15-HK.pdf.

FT.com. "Lex: Insurance." FT.com. 10 August 2005.

FT.com. "Reinsurance/Munich Re." FT.com. 7 November 2005. 
Gapper, John. "Earthquake Insurance Should Cost a Lot." The Financial Times. 3 April 2006.

Gregory, Derek. "(Post)Colonialism and the Production of Nature." In Social Nature: Theory, Practice, and Politics, eds. Noel Castree and Bruce Braun, 84-111. Oxford: Blackwell Publishers, 2001.

Gullapalli, Diya. "For Annual-Report Purposes, Hurricane Katrina is 'Ordinary." The Wall Street Journal. 2 September 2005.

Grant, Tavia. "Insurers Seek Shelter From Climate Change: Weather-Related Claims Continue to Mount." The Globe and Mail. 5 February 2007: B1, B10.

Hawker, Michael. "Climate Change and the Global Insurance Industry." The Geneva Papers. 32, (2007): 22-28.

Heck, Pamela, David Bresch and Serge Tröber. The Effects of Climate Change: Storm Damage in Europe on the Rise. Swiss Reinsurance Company: Zurich, 2006.

Hewitt, Kenneth. Regions of Risk: A Geographical Introduction to Disasters. Essex: Addison Wesley Longman Limited, 1997.

Hofman, David and Patricia Brukoff. "Insuring Public Finances Against Natural Disasters: A Survey of Options and Recent Initiatives." International Monetary Fund Working Paper. August 2006. Available from http://www.imf.org/external/pubs/ft/wp/2006/wp06199.pdf.

Insurance Bureau of Canada. A National Mitigation Strategy: Protecting Canadians from Severe Weather and Earthquakes. Toronto: Insurance Bureau of Canada, April 1999.

Insurance Bureau of Canada. Facts of the General Insurance Industry in Canada. $31^{\text {st }} \mathrm{ed}$. Toronto: Insurance Bureau of Canada, 2005.

Insurance Information Institute. International Insurance Fact Book, 2006-2007. 2006. Available from http:/www.internationalinsurance.org/international/toc/.

Insurance Information Institute. "Reinsurance." Insurance Information Institute. July 2006. Available from http://www.iii.org/media/hottopics/insurance/reinsurance/.

Intergovernmental Panel on Climate Change. Climate Change 2001: Impacts, Adaptation and Vulnerability. Cambridge: Cambridge University Press, 2001. Available from http://www.grida.no/climate/ipcc_tar/wg2/index.htm.

International Geosphere Biosphere Program. "Global Change and the Earth System: A Planet Under Pressure.” IGBP Science. No. 4 (2001). 
Jaffee, Dwight M. and Thomas Russell. "Should Governments Provide Catastrophe Insurance?" The Economists' Voice. Vol. 3, No. 5, (April 2005). Available from http://www.bepress.com/ev/vol3/iss5/art6.

Jones, Adam and Ivar Simensen. "Fall in Natural Disasters Helps Results at Axa and Allianz Insurance." The Financial Times. 23 February 2007.

Kaplan, Robert. "The Coming Anarchy." Atlantic Monthly. 273, 2, (1994): 44-76.

Kelman, Ari. "City of Nature: New Orleans' Blessing; New Orleans' Curse." Slate Magazine. 31 August 2006. Available from http://www.slate.com/id/2125346/.

Kim, Queena Sook. "Industry Aims to Make Homes Disaster-Proof: Companies Roll Out 'Safe Rooms,' Impervious Roofs, 2x4-Proof Glass; Discounts on Home Insurance.” The Wall Street Journal. 20 September 2004.

King, Peter. "The Latest 100-Year Disaster." The Los Angeles Times. 15 March 1995.

Klare, Michael T. Resource Wars: The New Landscape of Global Conflict. Metropolitan Books: New York, 2001.

Knight, Rebecca and Gillian Tett. "Insurers Add Voices to Climate Debate." The Financial Times. 3 February 2007.

Kremmer, Janaki. "A Natural Low-Tech Solution to Tsunamis: Mangroves." The Christian Science Monitor. 10 January 2005. Available from http://www.csmonitor.com/2005/0110/p07s01-wosc.html

Kunreuther, Howard. "Disaster Mitigation and Insurance: Learning from Katrina." Annals of the American Academy of Political and Social Science. Vol. 604, (March 2006): 208-227.

Kunreuther, Howard and Mark Pauly. "Rules Rather than Discretion: Lessons From Hurricane Katrina." Journal of Risk and Uncertainty. Vol. 33, (2006): 101-116.

Kunreuther, Howard C. and Erwann O. Michel-Kerjan. "Climate Change, Insurability of Large-Scale Disasters and the Emerging Liability Challenge." National Bureau of Economic Research Working Paper Series. January 2007. Available from http://www.nber.org/papers/w12821.

Kuykendall, Lavonne. “Allstate Posts 5\% Earnings Gain.” The Wall Street Journal. 20 July 2006.

Lambourne, Helen. "Tsunami: Anatomy of a Disaster." BBC News. 27 March 2005. Available from http://news.bbc.co.uk/1/hi/sci/tech/4381395.stm. 
Lipschutz, Ronnie D. Global Environmental Politics: Power, Perspectives, and Practice. Washington: CQ Press, 2004.

Livingstone, David N. The Geographical Tradition: Episodes in the History of a Contested Enterprise. Oxford: Blackwell Publishing Ltd., 1992.

MacDonald, Gordon. "Environment: Evolution of a Concept." Journal of Environment and Development. Vol. 12, No. 2, (June 2003): 151-176.

MacDonald, Heather. "Send a Message to God: He has Gone Too Far this Time." Slate Magazine. 10 January 2005. Available from http://www.slate.com.

Matthews, Jessica Tuchman. "The Environment and International Security." In World Security: Challenges for a New Century, eds. M.T. Klare and D.C. Thomas, 274289. New York: St. Martin's Press, 1994.

McDonald, Ian and Liam Pleven. "Skies May Darken for Insurers: Investors Face Risks as Rising Competition Erodes Premiums." The Wall Street Journal. 9 January 2007.

McGeown, Kate. "Tsunami-Hit Thais Live in Fear." BBC News. 29 March 2005. Available from http://news.bbc.co.uk/2/hi/asia-pacific/4389721.stm.

McQueen, M.P. "Homeowners Face Rising Insurance Rates: Reeling After Katrina, Insurers Drop Policies And Increase Premiums Far From Disaster Zones." The Wall Street Journal. 23 March 2006.

McQueen, M.P. "Who Needs A Flood Policy? There's a Good Chance You Do: Feds Urge More Inlanders to Buy Insurance Before the Next Katrina." The Wall Street Journal. 6 May 2006.

McWilliams, Wayne C. and Harry Piotrowski. The World Since 1945: A History of International Relations. Boulder: Lynne Rienner Publishers, 1997.

Mead, Julia C. “Will Other Insurers Follow Allstate's Move?” The New York Times. 5 February 2006.

Mills, Evan et al. "Insurance in a Climate of Change." Science. 309, (12 August 2005): 1040-1044.

Munich Re Group. Topics Geo Natural Catastrophes 2006: Analyses, assessments, positions. Druckerei Vogl: Munich, 2007.

Northcott, Michael S. Environment and Christian ethics. Cambridge: Cambridge University Press, 1996. 
Office of the Assistant Secretary of Defense (Public Affairs). "Fiscal 2006 Department of Defense Budget is Released." U.S. Department of Defense. 7 February 2005. Available from http://www.defenselink.mil/releases/2005/nr20050207-2066.html.

Ó Tuathail, Gearóid. "De-Territorialised Threats and Global Dangers: Geopolitics and Risk Society." Geopolitics. Vol. 3, No. 1, (Summer 1998): 17-31.

Parker, Dennis J. and John W. Handmer. "The Role of Unofficial Flood Warning Systems." Journal of Contingencies and Crisis Management. Vol. 6, No. 1, (March 1998): 60.

Pelling, Mark. "Natural Disasters?" in Social Nature: Theory, Practice, and Politics, eds. N. Castree and B. Braun, (Oxford: Blackwell Publishers, 2001): 170-188.

Pleven, Liam and Ian McDonald. "Insurers' Profits Rise on Sales, Fewer Hurricanes." The Wall Street Journal. 27 October 2006.

Pleven, Liam. "Risk and Reward: Hurricane Losses Prompt Allstate to Pursue New Path - Cutting Coverage on Coasts, It Eyes Big Opportunity to Insure Boomers' Lives - Challenges of a Personal Pitch." The Wall Street Journal. 24 November 2006.

Porter, Gareth. "Environmental Security as a National Security Issue." Current History. 94, no. 592, (May 1995).

Revkin, Andrew C. "Climate Experts Warn of More Coastal Building." The New York Times. 25 July 2006.

Rothschild, Matthew. "Katrina Compounded." The Progressive. 2 September 2005. Available from http://www.commondreams.org/cgibin/print.cgi?file=/views05/0902-26.htm.

Santmire, H. Paul. The Travail of Nature: the Ambiguous Ecological Promise of Christian Theology. Philadelphia: Fortress Press, 1985.

Sengezer, Betül and Ercan Koç. "A Critical Analysis of Earthquakes and Urban Planning in Turkey." Disasters. 2005, 29(2): 171-194.

Smith, Neil. Uneven Development. Oxford: Blackwell, 1984.

Smith, V. Kerry et al. "Adjusting to Natural Disasters." Journal of Risk and Uncertainty. $33,(2006): 37-54$.

Smolka, Anselm. "Natural Disasters and the Challenge of Extreme Events: Risk Management from an Insurance Perspective." Philosophical Transactions of The Royal Society A. 364, (2006): 2147-2165. 
Treaster, Joseph B. "Storm and Crisis: The Coverage." The New York Times. 24 September 2005.

Treaster, Joseph B. and Claudia H. Deutsch. "G.E. to Sell Insurance Business to Swiss Re." The New York Times. 19 November 2005.

Treaster, Joseph B. "Earnings for Insurers are Soaring." The New York Times. 14 October 2006.

Treaster, Joseph B. "A Proposal for Federal Protection from Catastrophe Divides Insurers." The New York Times. 31 October 2006.

Tugend, Alina. "The Peace of Mind of Home Insurance, Unless You Use It." The New York Times. 1 October 2005.

The Wall Street Journal. "Munich Re AG: Profit Soared in Fourth Period on Cost Cuts, Lower Tax Rates." The Wall Street Journal. 16 March 2005.

The Wall Street Journal. "Munich Re: Reinsurers Say Their Exposure To Hurricane Will Hurt Profits." The Wall Street Journal. 6 September 2005.

The Wall Street Journal. "Moving the Market: Catastrophe Losses Drop Sharply from 2005." The Wall Street Journal. 21 December 2006.

The Wall Street Journal. "Hannover Re AG: Reinsurer Returns to Profit, Aided by Low Disaster claims." The Wall Street Journal. 15 March 2007.

Waugh Jr., William L. "The Political Costs of Failure in the Katrina and Rita Disasters." The Annals of the American Academy of Political and Social Science. 604, (March 2006): 10-25.

White, Rodney and David Etkin. "Climate Change, Extreme Events and the Canadian Insurance Industry." Natural Hazards. 16, (1997): 135-163.

Wisner, Ben. "Disaster: What the United Nations Can Do." UN Chronicle. Vol. 39, No. 4, (December 2000/February 2001). Available from http://www.un.org/Pubs/chronicle/2000/issue4/0400p6p.htm.

Wisner, Ben, Piers Blaikie, Terry Cannon and Ian Davis. At Risk: Natural Hazards, People's Vulnerability and Disasters. $2^{\text {nd }}$ ed. New York: Routledge, 2004.

World Resources Institute, International Energy Agency, United Nations Framework Convention on Climate Change. Climate and Atmosphere 2005. Available from http://earthtrends.wri.org/pdf_library/data_tables/cli1_2005.pdf. 